\title{
Universiteit
}

Leiden

The Netherlands

\section{Psychiatric Comorbidity in Epilepsy}

Swinkels, Wilhelmina Adriana Maria

\section{Citation}

Swinkels, W. A. M. (2006, June 20). Psychiatric Comorbidity in Epilepsy.

Retrieved from https://hdl.handle.net/1887/4444

Version: $\quad$ Corrected Publisher's Version

Licence agreement concerning inclusion of doctoral

License: $\quad$ thesis in the Institutional Repository of the University of Leiden

Downloaded from: $\quad$ https://hdl.handle.net/1887/4444

Note: To cite this publication please use the final published version (if applicable). 


\title{
Psychiatric Comorbidity in Epilepsy
}

\author{
Miranda Swinkels
}


The studies described in this thesis were performed at the Epilepsy Institute of the Netherlands (SEIN), Heemstede, in cooperation with the Division of Clinical and Health Psychology of Leiden University, and the Department of Psychiatry of the Vrije Universiteit Amsterdam.

This study was made possible by a fellowship from the 'Christelijke Vereniging voor de Verpleging van Lijders aan Epilepsie', Heemstede, and a grant from the'Nationaal Epilepsie Fonds/De Macht van het Kleine' (project no 97-02).

ISBN 90-8559-177-5

Cover: Painting by Inge Vreeswijk

Printed by: [Optima] Grafische Communicatie, Rotterdam

Publication of this thesis was financially supported by: Christelijke Vereniging voor de Verpleging van Lijders aan Epilepsie, Nationaal Epilepsie Fonds/De Macht van het Kleine, UCB Pharma B.V. 


\title{
Psychiatric Comorbidity in Epilepsy
}

\section{PROEFSCHRIFT}

\author{
ter verkrijging van \\ de graad van Doctor aan de Universiteit Leiden, \\ op gezag van de Rector Magnificus Dr. D.D. Breimer, \\ hoogleraar in de faculteit der Wiskunde en \\ Natuurwetenschappen en die der Geneeskunde, \\ volgens besluit van het College voor Promoties \\ te verdedigen op dinsdag 20 juni 2006 \\ klokke 14.15 uur
}

door

\section{Wilhelmina Adriana Maria Swinkels}

geboren te Geldrop

in 1969 


\section{Promotiecommissie}

Promotores: Prof. dr. Ph. Spinhoven

Prof. dr. R. van Dyck

Copromotor: Dr. J. Kuyk

Referent: $\quad$ Prof. dr. B. Schmitz

Overige leden: Dr. W. van Emde Boas

Prof. dr. E. Hoencamp

Prof. dr. H.A.M. Middelkoop

Prof. dr. F.G. Zitman 
"The important thing is not to stop questioning. Curiosity has its own reason for existing" Albert Einstein 



\section{CONTENTS}

Chapter 1 General introduction 9

1.1 Definition epilepsy and classification 11

1.2 Classification of psychiatric disorders in epilepsy 13

1.3 Research objectives and outline of the thesis 13

$\begin{array}{lll}\text { Chapter } 2 & \text { Psychiatric comorbidity in epilepsy: review } & 17\end{array}$

Chapter 3 Prevalence of psychopathology in Dutch epilepsy inpatients: 43 a comparative study

Chapter 4 Personality disorder traits in patients with epilepsy

Chapter 5 Interictal depression, anxiety, personality traits and psychological dissociation in patients with Temporal Lobe Epilepsy (TLE) and extra-TLE

Chapter 6 Psychometric properties of the Dutch version of the Washington Psychosocial Seizure Inventory

Chapter 7 Psychosocial impact of epileptic seizures in a Dutch epilepsy 107 population: a comparative Washington Psychosocial Seizure Inventory study

Chapter 8 Psychopathology in patients with nonepileptic seizures with and without comorbid epilepsy: how different are they?

Chapter 9 Summary and general discussion 133

9.1 Summary 135

9.2 Methodological considerations 138

9.3 Strengths and limitations of the present studies 141

9.4 Clinical implications 142

9.5 Suggestions for future studies $\quad 142$

$\begin{array}{ll}\text { Samenvatting } & 145\end{array}$

Dankwoord 151

Curriculum Vitae 153 



\section{General introduction}

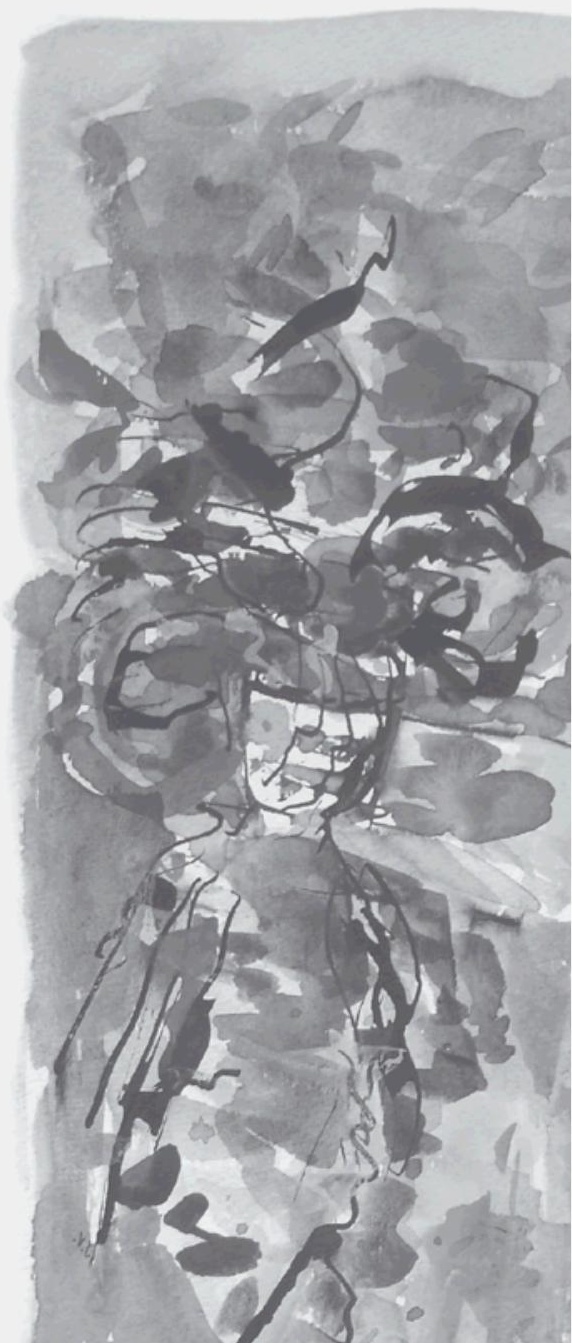



Many people with epilepsy lead normal lives. However, this does not apply to all patients with epilepsy. Emotional problems, cognitive deficits and psychosocial difficulties are frequently found among these patients. The relationship between epilepsy and psychiatric disorders has been recognised since antiquity and is still a topic of many investigations that may lead to expanding our understanding of the brain-behaviour relations. However, much remains still unclarified about this relationship. Studies performed so far allow no clear cut conclusions about the (relative) contribution of different (epilepsy-related) factors. For example, it is indeterminate if patients with temporal lobe epilepsy experience more psychiatric disorders compared to patients with extra-temporal lobe epilepsy and also the influence of psychosocial risk factors in the relationship between epilepsy and psychopathology remains unclear. Partly this is due to weaknesses in the study designs, inaccurate epilepsy classification and/or unreliable psychiatric classification. Frequently small patient groups are investigated and a control group to compare the findings is often lacking. This study sets out to investigate the relation between epilepsy and psychopathology while trying to avoid the pitfalls of earlier studies.

\subsection{DEFINITION EPILEPSY AND CLASSIFICATION}

According to recent definitions of epilepsy and epileptic seizures by the International League Against Epilepsy (ILAE) and the International Bureau for Epilepsy (IBE) ${ }^{1}$, epilepsy should not be seen as one condition, but rather as a diverse family of disorders that have in common that there is an abnormally increased predisposition to seizures. The underlying brain dysfunction that is responsible for the epilepsy may follow from different causes. Epilepsy is defined as a brain disorder characterised predominantly by recurrent and unpredictable interruptions of normal brain function, called epileptic seizures. An epileptic seizure is a transient occurrence of signs and/or symptoms due to abnormal excessive or synchronous neuronal activity in the brain. The seizure presentation depends on the location of onset in the brain, patterns of propagation, and a variety of other factors. Seizures can affect sensory, motor, and autonomic function.

The ILAE proposed an international classification of epilepsy, both for seizure types and epilepsy syndromes, to achieve uniformity of terminology ${ }^{2,3}$. Seizures are classified as partial (or focal) seizures and generalised seizures. A seizure is classified as partial when there is evidence of a clinical partial onset, regardless of whether the seizure secondarily generalises. The first clinical signs of the seizure have a highly localising value and result from the functional neuronal activation of part 
of one hemisphere. Partial seizures are subdivided on the basis of whether or not consciousness is impaired during the seizure:

1. Simple partial seizures, when consciousness is not impaired and the ability to interact appropriately with the environment is maintained.

2. Complex partial seizures, when consciousness is impaired, amnesia, or confusion during or after a seizure is reported.

3. Partial seizures with secondarily generalisation, when a seizure becomes secondarily generalised.

A seizure is considered generalised when clinical symptomatology provides no indication of an anatomic localisation and no clinical evidence of focal onset. The ictal EEG patterns are bilateral and reflect neuronal discharge that is widespread in both hemispheres. Three main seizure subtypes may be categorised:

1. Generalised convulsive seizures (with predominantly atonic, tonic, clonic, or tonic-clonic features).

2. Generalised nonconvulsive seizures (absence seizures).

3. Myoclonic seizures.

Patients can have several types of partial seizures or even both generalised and partial seizures. When it is impossible to classify seizures (due to lack of adequate information) seizures should be defined as unclassified seizures.

Epilepsy syndromes can be classified into idiopathic, symptomatic and cryptogenic. Idiopathic (or primary) epilepsy is virtually synonymous with genetic epilepsy, that means that no underlying cause is apparent other than a hereditary predisposition to seizures. When the epilepsy is the consequence of a known or suspected cerebral disease (e.g. metabolic disturbances, cerebral malformations, head injury, infections, brain tumours) the epilepsy syndrome is called symptomatic (or secondary epilepsy). Cryptogenic epilepsy is considered as a secondary epilepsy, but the underlying cause has not been identified.

It is recommended that the classification of epileptic seizures, which is based on clinical semiology exclusively, be complemented by an epileptic syndrome classification, which is based on all available clinical information (such as clinical history, neurological examination, ictal semiology, EEG, and anatomical and functional neuroimaging). This is necessary because there does not necessarily exist a one-to-one relationship between epileptic seizures and epilepsy syndromes. This approach would be more consistent with the clinical neurology of today and for research purposes leads to a more reliable epilepsy classification. 


\subsection{CLASSIFICATION OF PSYCHIATRIC DISORDERS IN EPILEPSY}

Besides an accurate classification of epilepsy also a reliable and valid classification of psychiatric disorders is of importance. Psychiatric disorders in epilepsy can be divided according to the temporal relationship between the presentation of the psychiatric symptoms and the seizure occurrence:

- Ictal symptoms (i.e. psychiatric symptoms are a clinical manifestation of the seizure).

- Periictal symptoms (i.e. symptoms precede and/or follow the seizure occurrence and are considered as associated with the epileptic seizure).

- Interictal symptoms (when the symptoms occur independently of the seizure occurrence).

For example, a patient can experience ictal depression as the expression of a simple partial seizure (aura). Likewise, a patient can also experience post-ictal depressive symptoms and have a comorbid depression interictally. The studies described in this dissertation all concern interictal psychiatric disorders.

When studying psychiatric comorbidity in epilepsy different kinds of diagnostic methods and instruments can be used. Currently there are more instruments available than for example forty years ago. Early studies on psychiatric disturbances in epilepsy patients often looked at the presence or absence of a history of psychiatric treatment or hospitalisation, because of the lack of alternative methods. Later on, studies relied more on self-report measures (e.g. the Beck Depression Inventory, Minnesota Multiphasic Personality Inventory) and rating scales specifically developed for patients with epilepsy (e.g. Bear-Fedio Inventory, Washington Psychosocial Seizure Inventory). Nowadays, studies use more reliable and valid (semi-) structured psychiatric interviews based on objective diagnostic criteria, such as the Diagnostic and Statistical Manual of Mental Disorders, now in its fourth edition (DSM-IV ${ }^{4}$ ) (e.g. Structured Clinical Interview for DSM).

\subsection{RESEARCH OBJECTIVES AND OUTLINE OF THE THESIS}

On the basis of the preceding observations, a classification of both epilepsy and psychiatric disorders which is up-to-date and based on objective criteria is needed to improve and expand our understanding of the relationship between epilepsy and psychopathology. An accurate epilepsy syndrome classification based on all clinical information is needed, as well as a solid and detailed psychiatric classification is needed by using reliable and valid diagnostic instruments. 
Therefore, the main objective of this thesis is to study the relationship between epilepsy and psychiatric symptoms by investigating the following key objectives:

- The prevalence of psychiatric disorders, both DSM axis I clinical disorders and axis II personality disorders, in patients with epilepsy.

- The relationship between psychiatric disorders and specific epilepsy syndromes.

- The contribution of epilepsy-related variables to psychiatric disorders.

- Psychosocial functioning of patients with epilepsy.

All patients that participate in these studies are recruited in the specialised epilepsy centre Stichting Epilepsie Instellingen Nederland (SEIN, Epilepsy Institute of the Netherlands). SEIN comprises hospitals and clinics that are dedicated to the diagnosis, care, counselling and support of patients with epilepsy and related disorders. SEIN provides specialised care for inpatients at the three locations Heemstede, Cruquius and Zwolle. Besides the inpatient clinics, SEIN also comprises nine outpatient clinics. The referral of patients often entails complex questions concerning the diagnosis, therapy, and psychosocial issues that demand a multidisciplinary approach.

This dissertation contains nine chapters. Chapter $\mathbf{1}$ is the general introduction to the subject of this dissertation. Chapter $\mathbf{2}$ concerns a review of the literature on psychiatric comorbidity in epilepsy from the perspective of DSM classification. In this chapter the empirical findings of axis I clinical disorders and axis II personality disorders are separately described. In chapter $\mathbf{3}$ and $\mathbf{4}$ the prevalence of psychiatric disorders and personality disorders in Dutch patients with epilepsy is investigated. In both studies, the results are compared with a control group from the general population. In chapter 5 the relationship between the localisation and lateralisation of the epileptogenic zone and symptoms of interictal depression, anxiety, personality traits and psychological dissociation is investigated in more detail.

Patients with temporal lobe epilepsy (TLE) are compared with patients with extraTLE, and patients with lateralisation of the epileptogenic zone in the left hemisphere are compared with patients with lateralisation in the right hemisphere. Also, the role of tempero-mesial limbic structures in psychopathology is assessed by comparing patients with antero-mesial-TLE to patients in whom more latero-basal temporal areas are involved. Additionally, other epilepsy related variables are evaluated as potential risk factors for psychiatric symptoms. Chapter $\mathbf{6}$ presents the psychometric properties of the Dutch translation of the Washington Psychosocial Seizure Inventory (WPSI). The dimensional structure, reliability and validity of the WPSI scales are assessed and compared to the original English version of Dodrill. In chapter 7 the WPSI is used to investigate psychosocial functioning in Dutch epilepsy patients 
and to compare these results with those from other countries. The impact of epilepsy was studied in Dutch inpatients and outpatients. The outpatient group was subdivided into seizure-free outpatients and not seizure-free outpatients. In chapter 8 patients with psychogenic non-epileptic seizures (PNES) are compared with PNES patients with comorbid epilepsy on psychiatric disorders. The rationale was to assess if patients with co-morbid PNES should be included or excluded in studies on psychiatric disorders in epilepsy. In the final chapter, chapter 9, the results of the studies are summarised and methodological issues and implications for clinical practice and suggestions for future research are discussed. 


\section{REFERENCES}

1. Fisher RS, Van Emde Boas W, Blume W, Elger C, Genton P, Lee P, Engel J. Epileptic seizures and epilepsy: Definitions proposed by the International League Against Epilepsy (ILAE) and the International Bureau for Epilepsy (IBE). Epilepsia 2005;46(4):470-472.

2. Commission on Classification and Terminology of the ILAE: Proposal for revised clinical and electroencephalographic classification of epileptic seizures. Epilepsia 1981;22:489-501.

3. Commission on Classification and Terminology of the ILAE: Proposal for revised classification of epilepsies and epileptic syndromes. Epilepsia 1989;30:389-399.

4. American Psychiatric Association, Committee on nomenclature and Statistics. Diagnostic and Statistical Manual of Mental Disorders, revised 4th edition. Washington, DC, Americal Psychiatric Press, 1994. 


\section{Psychiatric comorbidity in epilepsy: review}

WAM Swinkels, J Kuyk, R van Dyck, Ph Spinhoven

Epilepsy \& Behavior 2005;7:37-50

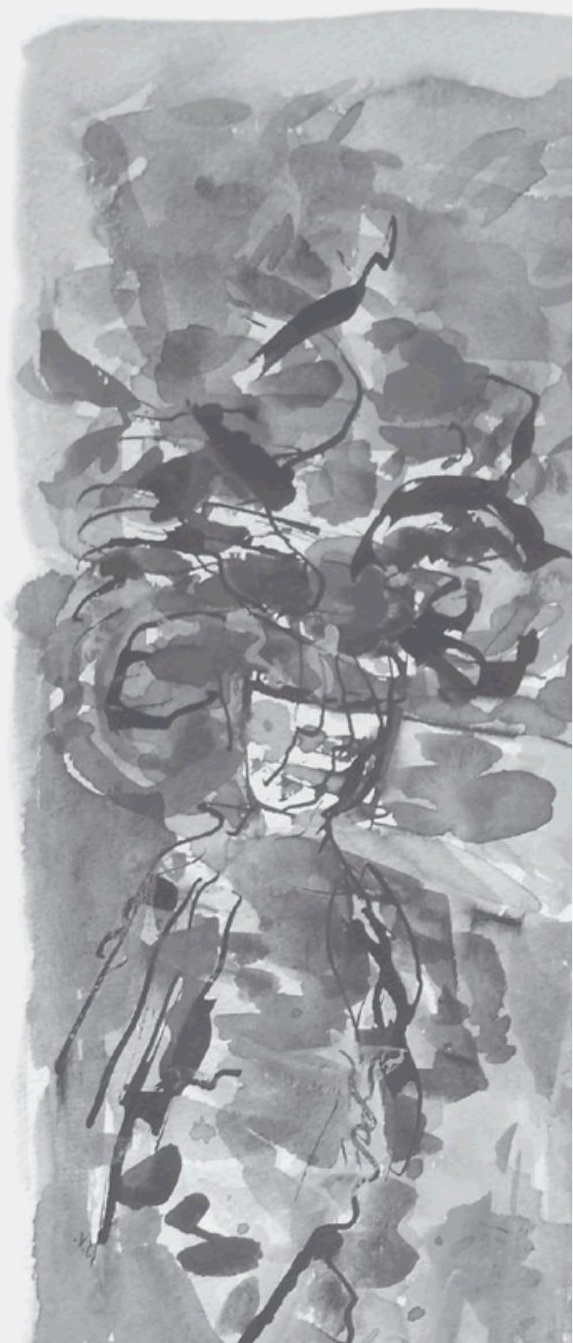




\section{ABSTRACT}

Many studies on psychiatric comorbidity in epilepsy have been performed using many different patient groups and diagnostic instruments. This methodological heterogeneity complicates comparison of the findings. In this article, psychiatric disorders in epilepsy are reviewed from the perspective of the DSM classification system. The empirical findings of axis I clinical disorders and axis II personality disorders are described separately. Furthermore, the existence and specificity of conditions such as interictal dysphoric disorder, interictal behaviour syndrome, and psychosis of epilepsy are discussed. From the many studies that have been performed on this topic it can be learned that there is a need for well-controlled studies using representative patient groups and valid and standardised diagnostic instruments. So far, the majority of the studies have concerned axis I disorders; relatively little research has been performed on axis II personality disorders. More research on personality disorders, as well as on the relative contributions of the different (brainand non-brain-related) factors to the relationship between epilepsy and psychiatric disorders, is recommended. 
Epilepsy is one of the most common chronic neurological disorders. The prevalence of epilepsy varies across studies, but generally ranges from 4 to 10 per 1000 population (1-5). This range is partly related to varying definitions, but also to true differences in prevalence rates across the populations. The impact of epilepsy on quality of life can be considerable. Epilepsy may, but does not inevitably, affect emotional, behavioural, social, and cognitive functioning. Studies investigating these problems frequently use the term 'psychopathology'. Because of the diverse and confusing ways this term has been used, psychopathology can refer to psychiatric problems of various types, maladaptive emotional disorders, psychosocial adjustment difficulties, and behavioural and personality characteristics. To prevent further confusion, in this article a distinction has been made between axis I clinical disorders and axis II personality disorders according to the Diagnostic and Statistical Manual of Mental Disorders (DSM-IV). Currently, DSM-IV is the international standard with respect to classification of mental disorders. The empirical findings regarding the relationship between epilepsy and axis I and II disorders are reviewed by focussing on measures that somehow reproduce the prevalence rates of these problems. For that reason, we do not describe the extensive literature in which the Minnesota Multiphasic Personality Inventory (MMPI) (6) was used as a diagnostic instrument, as the MMPI is a dimensional instrument and does not lead to a psychiatric diagnosis. Apart from the empirical findings, the different concepts and theories about supposed epilepsyspecific disorders are also discussed. But first, we give a short overview of some historical facts about the relationship between epilepsy and psychiatry.

\section{Some historical facts}

The term 'epilepsy' is derived from the Greek word 'epilepsia', which means "falling sickness". The ancient Greeks considered epilepsy as a sacred disease. A person with epilepsy was seen as seized by a God. Only a God could throw a sane normal man to the ground, deprive him of his senses, cause him to convulse, and then restore him to normality. In his book 'The Sacred Disease' written in 400 BC, Hippocrates was the first to suggest that epilepsy, like other diseases, has a natural and not a sacred cause. He argued that epilepsy was by no means divine or sacred and ascribed epilepsy to a disorder of the brain. During the Middle Ages, epileptic phenomena were explained by various mystical, magical, and religious concepts (see e.g., 7). Epilepsy patients were seen as being possessed, which worsened the already existing fears, anxieties, and feelings of shame. Many of the psychological and social problems experienced by epilepsy patients today have their origins in these unfortunate concepts (that still persist in some cultures). Increasing insight into the medical background of epilepsy began in the Renaissance, but particularly developed since the mid-19th century. The neurologist Hughlings Jackson developed the first 
comprehensive understanding of seizure origin. In 1873, he gave the first accurate definition of epilepsy: "Epilepsy is the name given for occasional, sudden, excessive, rapid and local discharges of gray matter" (8). He is often considered as the founder of modern epileptology. His contemporary, Gowers, further detailed the excessive variety of clinical epileptic symptoms, and also was engaged in the separation of epileptic convulsions from nonepileptic (hysterical) convulsions (9). The differentiation between epilepsy and so-called 'hystero-epilepsy' was also the work of the French neurologist Jean Martin Charcot and his group. Through such French workers as Briquet (10) and Morel (11) it became recognised that psychological disturbances may occur as part of the seizure itself (ictal) or as an interictal disturbance involving various behavioural and cognitive functions. Understanding of epilepsy progressed in the 1930s with the introduction of phenobarbital and, more importantly, the use of the electroencephalogram (EEG), developed by Hans Berger, in patients with epilepsy. It was realised that the localisation of epileptic discharges in the brain and their association with lesions was more important than anything else in determining the character of the seizures. Nevertheless, the clinical impression continued to exist that patients with epilepsy suffer from mental problems. Discovery of the temporal lobe focus (and, thus, temporal lobe epilepsy) in 1949, together with the concept of the limbic system as important in the processing of emotions, led to the idea of mental disorders being linked to epileptic disturbances in specific brain areas. People with epilepsy were considered mentally normal, but it was assumed that brain dysfunctions would lead to seizures as well as psychological complaints.

Currently, it is believed that not only biological factors (e.g., aetiology, focus localisation), but also medication (e.g., number and types of medication) and psychological and social factors (e.g., fear of seizures, perceived stigma) are important aspects in the development of psychiatric problems in epilepsy. It is therefore recommended that all these factors be considered when investigating psychopathology in epilepsy.

\section{Comorbid psychiatric disorders in epilepsy}

Psychiatric symptoms can be classified according to their temporal relationship with seizure occurrence. They can be divided into peri-ictal (related to the seizure itself) and interictal (independent of the seizure) symptoms. Peri-ictal symptoms are symptoms that precede the seizure (preictal), clinical manifestations of the seizure itself (ictal), and symptoms that follow the seizure directly (postictal). Because this article concerns psychiatric comorbidity in epilepsy, we focus on the interictal disorders.

Although there are many studies on this topic, accurate estimates of psychiatric comorbidity are hard to find. To a large extent, this is attributable to methodological 
differences among the studies, which make comparison of the results complicated. Most important are the differences in patient groups and diagnostic instruments used. Patient groups are often small, and frequently, no (appropriate) control group is included. Furthermore, the epilepsy group is often not representative of the total epilepsy population because, for example, only inpatients or outpatients, or sometimes a very specific subgroup of epilepsy patients (e.g., surgery patients), are studied. Also important is the use of a variety of diagnostic instruments: only a few studies use standardised diagnostic instruments based on specific criteria such as DSM-IV. Frequently, no distinction is made between axis I clinical disorders and axis II personality disorders. In the next two sections the empirical findings for DSM-IV axis I clinical disorders and axis II personality disorders are reviewed.

\section{Clinical disorders}

It is commonly believed that epilepsy places a patient at increased risk of developing psychiatric problems. Most of the studies on this topic are based on epilepsy patients admitted to hospitals or specialised epilepsy clinics. There are some population-based studies: however, they constitute a minority (12-15). Table 1 is an overview of studies on psychiatric comorbidity in adult epilepsy patients (12-28). The percentage of psychiatric cases varies considerably (range between 19 and 80\%). As can be observed in a substantial number of studies, no control group is included. The majority of studies with a control group report increased psychiatric problems in patients with epilepsy compared with normal controls.

An important question is: Is the epilepsy condition itself predisposing these patients to psychiatric complaints or does the chronicity of epilepsy lead to psychiatric disorders? By "chronicity" of epilepsy, we mean the psychosocial impact of (longterm) epilepsy, not the duration of the condition. With this question in mind, Wells and colleagues (29) compared data on the prevalence of psychiatric disorders in eight chronic medical conditions in a community sample of 2554 persons. Psychiatric disorders were obtained with the Diagnostic Interview Schedule (DIS) for patients with chronic lung disease, diabetes mellitus, heart disease, hypertension, arthritis, physical handicap, cancer and neurological disorders (e.g., stroke). The results were compared with those for a control group of persons with no medical condition. The prevalence of recent and lifetime psychiatric disorders was higher among persons with any chronic medical condition than in persons without any of these conditions. These findings suggest that it is reasonable to assume that chronic illness is generally associated with an increased risk for psychiatric disorders.

Several of the studies listed in Table 1 included, besides epilepsy patients, a control group of patients with another chronic illness $(15,17,18,25,27)$. Most of these studies did not report increased psychiatric comorbidity in patients with epilepsy 


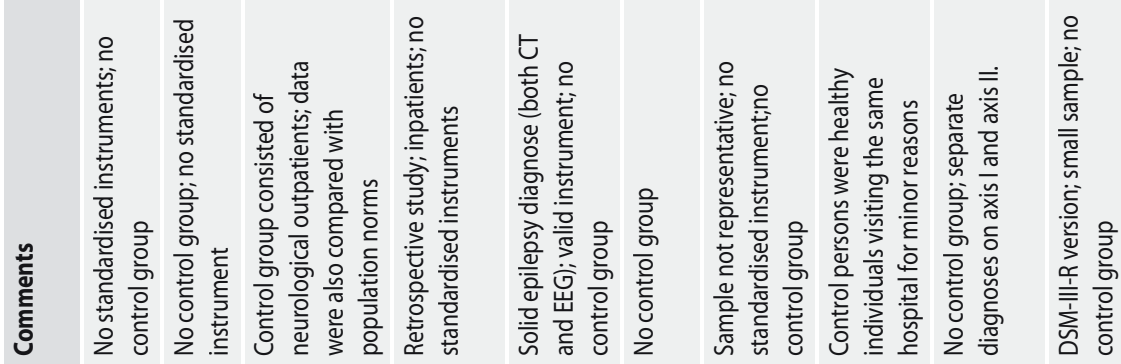
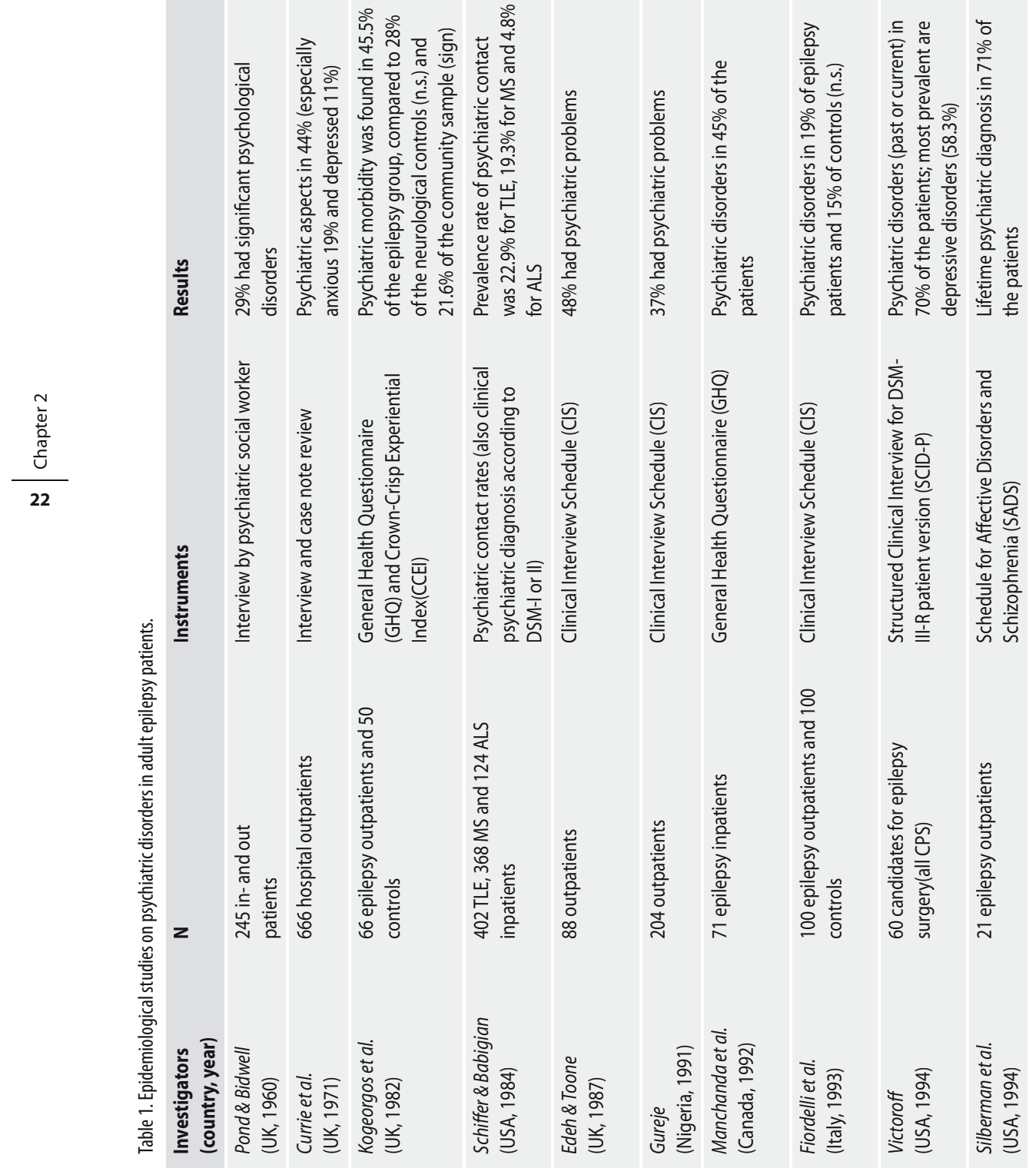


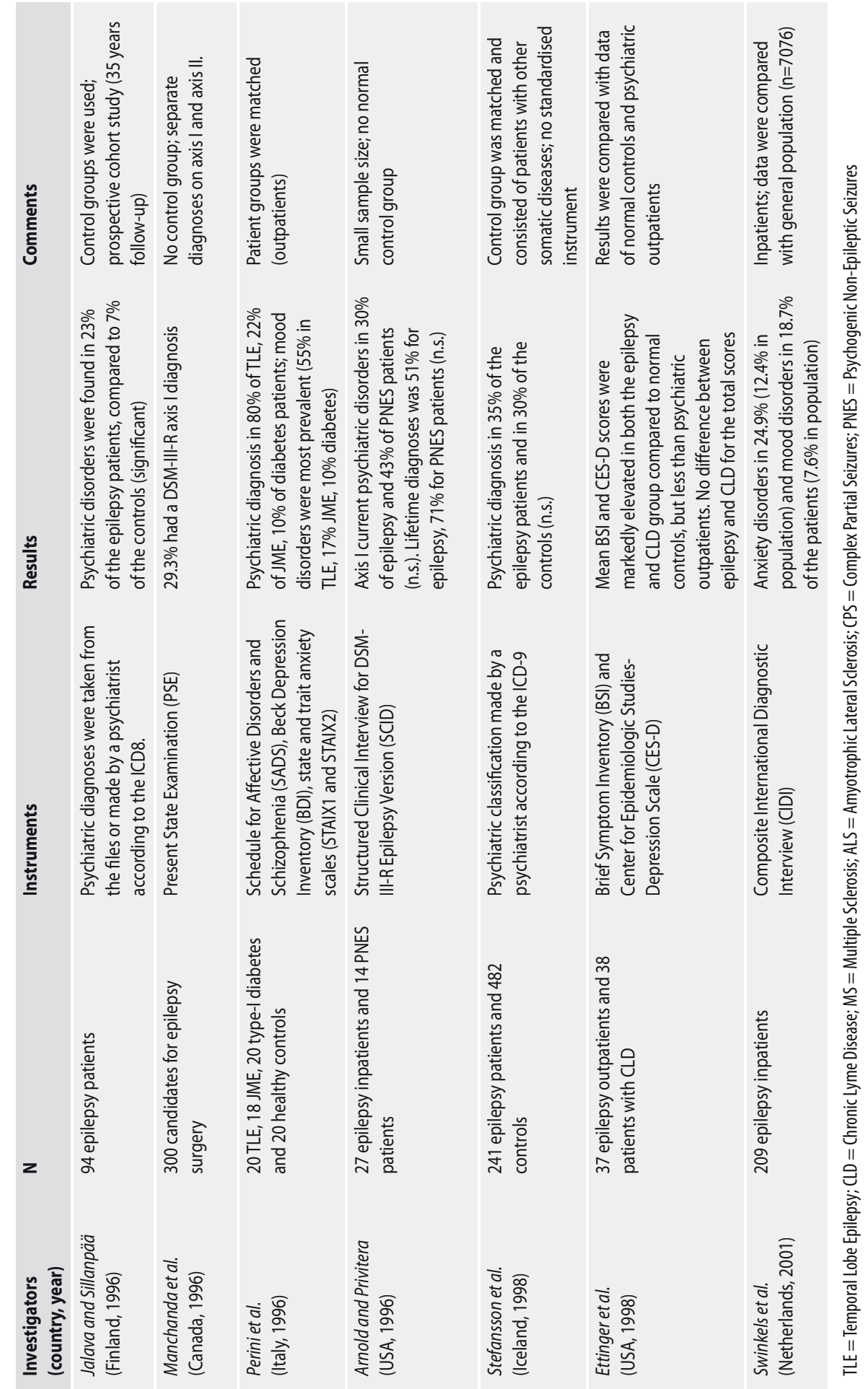


relative to patients with other medical conditions and are in agreement with the assumption that the chronicity of the illness is, in great part, responsible for the increased risk of psychiatric disturbances.

Besides being a chronic disease with its implied psychosocial difficulties, epilepsy is also a neurological disorder, probably adding to the risk for developing psychiatric disorders. Schiffer and Babigian (18) found no difference in psychiatric disorders between TLE patients and patients with multiple sclerosis (MS), except for a significantly increased rate of depressed affect in MS patients. The prevalence rates for both groups were higher than that for amyotrophic lateral sclerosis (ALS) patients. Both epilepsy and MS can be seen as unpredictable and chronic neurological conditions, so this does not explain the higher rate of depression among the MS patients. Several earlier studies also found more depressive symptoms in patients with MS compared with other neurological patients (30-33). Possible explanations for this high rate of depressive diagnoses in MS are the structural involvement of the limbic system (by demyelination), shared genetic vulnerabilities both to depression and to MS, and dysfunction of monoamine metabolism within the central nervous system (18). Currently, it is presumed that MS-associated depression can also be attributed to pathophysiological processes such as cerebral inflammation (see e.g., 34).

The role of brain dysfunction in the aetiology of psychiatric disturbances is also supported by a study of Perini et al. (25). They reported a significantly higher frequency of psychiatric diagnoses in patients with TLE (80\%), than in patients with juvenile myoclonic epilepsy (JME) (22\%) and diabetic patients (10\%). The authors conclude that TLE is a neurological condition that is associated with a high prevalence of interictal psychiatric disturbances, which more likely reflect limbic dysfunction rather than psychological adjustment to a chronic epileptic or medical condition.

It can be concluded that the chronicity of epilepsy is an important factor in the predisposition of these patients to psychiatric disturbances, but that brain dysfunction can pose an additional hazard, probably related to the involvement of the limbic system.

\section{Temporal lobe epilepsy}

Whether patients with TLE are at increased risk of developing psychiatric disorders compared with patients with other types of epilepsy remains one of the most controversial issues in the literature concerning epilepsy and psychiatry. This topic has been repeatedly investigated over the last decades. Several investigators reported more psychiatric disturbances in patients with TLE compared with extra-TLE and/or primary generalised epilepsy patients $(12,19,35-37)$. Others, however, found no such differences $(20,28,38-41)$. Rodin et al. (37) made an important observation, namely, that patients with TLE often have more than one seizure type, and they 
suggest that the number of seizure types is more relevant to emotional and psychiatric problems in epilepsy than the type of seizure per se. These findings were later confirmed by Hermann et al. (42) and Dodrill (43). Apart from the number of seizure types, it is likely that there are more risk factors (e.g., age at onset, laterality of the temporal epileptiform focus) that predispose to or protect patients with TLE from psychopathology $(44,45)$. It might appear that variables other than or in addition to TLE are important determinants of psychiatric disorders in epilepsy. Because the limbic system is involved in the regulation of emotional behaviour, it is likely that the exact localisation and lateralisation of the epileptogenic zone are of importance. The limbic system is situated in the medial parts of the temporal lobes, so more psychiatric disturbances (in particular mood disorders) are expected to be found in patients with an epileptic focus in these parts of the brain. Additionally, concomitant frontal lobe dysfunction may also be of importance.

\section{Model of Hermann and Whitman}

Epilepsy should be considered as a syndrome characterised by different manifestations and aetiologies. It is argued that patients with severe, intractable epilepsy are at a higher risk of developing psychiatric problems than patients with a milder (less active) form of epilepsy. For many patients, epileptic seizures are uncontrollable and unpredictable, which makes living with epilepsy difficult. Also, the patient's fears and concerns regarding his or her seizures, perceived stigma and discrimination (particularly in the area of employment), and lack of social support are considered potential etiological (psychosocial) variables in the development of psychiatric disturbances $(46,47)$. Degree of limbic system dysfunction, brain abnormalities, age at onset of seizures, number of seizure types, aetiology, etc, are also important risk factors. Ideally, when psychiatric disorders in epilepsy are investigated, all these factors should be taken into account. The inconsistency found among the studies on psychiatric comorbidity is, apart from the different diagnostic instruments used, in considerable part attributable to this multitude of variables on which the patient groups are dissimilar.

This brings us to the work of Hermann and Whitman (45). They divided potential risk variables supposed to be associated with psychiatric disorders in epilepsy into three main categories: (1) brain-related factors, (2) non-brain-related factors, and (3) treatment-related factors. They proposed that these risk factors form a conceptual model of psychopathology in epilepsy. However, at the time of its formulation it was premature to attempt to estimate the relative importance (or explanatory power) of the individual risk variables, and this so-called "conceptual model" should rather be seen as a list of variables having some potential relationship to psychopathology in epilepsy (see Table 2). 
Table 2. Factors associated with psychopathology in epilepsy (from: Hermann \& Whitman, 1984).

$\begin{array}{ll}\begin{array}{ll}\text { (1) Brain-related } & \text { Results of history and neurological exam; structural brain abnormalities; } \\ \text { neurological variables } & \begin{array}{l}\text { Topographic distribution of epileptiform activity; laterality of focal spike activity; } \\ \text { degree of limbic system dysfunction; nonepileptiform EEG abnormalities }\end{array} \\ \text { EEG variables } & \begin{array}{l}\text { Aetiology; seizure control; presence of multiple seizure types; age at onset; duration } \\ \text { of disorder; seizure-related experiences/clinical seizure features; seizure type }\end{array} \\ \text { Epilepsy variables } & \text { Overall level of performance; pattern of performance } \\ \text { Neuropsychological variables } & \begin{array}{l}\text { Presence of a chronic disorder; economic stress; limitations of activities and } \\ \text { aspirations; other }\end{array} \\ \hline \text { (2) Non-brain-related } & \begin{array}{l}\text { Nature of epilepsy; medical ignorance and fear of seizures; stigma; social } \\ \text { consequences and discrimination }\end{array} \\ \text { Epilepsy variables } & \text { Familial considerations; effect of epilepsy on the family unit; altered expectations for } \\ \text { a child with epilepsy; age at onset; early experiences }\end{array} \\ \begin{array}{l}\text { Developmental/epilepsy } \\ \text { variables }\end{array} & \text { Socio-economic status; age; sex; premorbid personality/psychological status; other } \\ \text { Demographic/subject variables }\end{array}$

(3) Treatment-related (Reynolds, 1981)

Folate deficiency; altered monoamine metabolism; effects on endocrine function; induction of neuropathological changes in the CNS

An important benefit of such an overview is that it helps to present the many known or suspected etiological variables in a manner that encourages new and more empirical research. It should be kept in mind that these variables may not be independent of one another, but may instead be highly intercorrelated and reflect a more general factor, for example, severity of epilepsy. The severity of epilepsy can be deduced from such variables as the presence of multiple seizure types, early age at onset, poor seizure control, and symptomatic aetiology. The same consideration most likely applies to the non-brain-related and treatment-related factors. The authors furthermore hypothesised that the three factors probably explain different proportions of variance for different disorders: e.g., brain-related factors are supposed to explain most of the variance in psychosis, while non-brain-related factors likely explain most of the variance in affective disorders. This assumption was recently elaborated for depression in an article by Hermann et al. (48). They reviewed 36 studies of depression in epilepsy to obtain more insight into the factors that are reliable predictors of depression. In total, 60 different potential predictor variables were examined. Of all the variables, neurological and epilepsy variables (brain-related) were most frequently studied in case of interictal depression, and psychological/ social variables and medication variables were the least investigated. Nonetheless, these brain-related variables resulted in the fewest positive findings (6\%), whereas the psychological and social variables were associated most frequently with depres- 
sion (79\% positive findings). Surprisingly, variables such as seizure frequency, age at onset, and duration of epilepsy were hardly associated with depression.

Since its introduction in the 1980s, the model of Hermann and Whitman has been empirically evaluated many times, with generally most attention being paid to the biological and psychosocial risk factors. It is demonstrated that certain variables seem to be more closely related to depression than other variables; however, little is understood about the causal relationships involved. Even now, many uncertainties and controversies remain with respect to the precise origin of the various psychiatric disorders in epilepsy. Also, few attempts have been made to integrate the three factors into a comprehensive model of psychopathology in epilepsy.

\section{Personality disorders}

Whereas the majority of the studies concentrate on psychiatric disorders (in particular psychotic disorders, mood disorders, and anxiety disorders), relatively little research is available on the comorbidity of personality disorders in epilepsy. Just as in studies concerning axis I clinical disorders, the MMPI is frequently used when axis II personality disorders in epilepsy are studied $(23,42,49,50)$. For reasons mentioned earlier, we do not report on these MMPI studies. Only a few investigators use psychiatric diagnostic methods. Existing data on personality disorders in patients with epilepsy reveal a prevalence between 4 and 38\% (21, 22, 24, 26, 51-54) (Table 3). In the majority of the studies no control group is included, which makes it difficult to compare these findings with those for nonepileptic (normal) control subjects and control subjects with other chronic medical conditions. Nevertheless, a number of studies have estimated the prevalence of personality disorders in the community and found prevalence rates between 5.9 and $13.4 \%$ (55-58). Compared to these figures, the rate of prevalence of personality disorders in patients with epilepsy seems to be slightly increased. In line with these findings, Swinkels et al. (54) found that patients with epilepsy exhibit more personality disorder traits compared with a control group from the general population. Although these authors used dimensional scores (number of criteria met for each personality disorder) instead of rates of prevalence of personality disorders, they did use an instrument based on the criteria of axis II personality disorders according to DSM-IV. When the results were compared with results for asthma outpatients (59), the epilepsy patients had higher scores. Previously, Schwartz en Cummings (51) also found significantly more personality disorders in patients with epilepsy, compared with a control group of neurological patients.

From these results, we can conclude with some reservation that the higher comorbidity of personality disorders in epilepsy does not seem to be a consequence of the chronic medical condition per se, but is possibly related to the epilepsy condition 


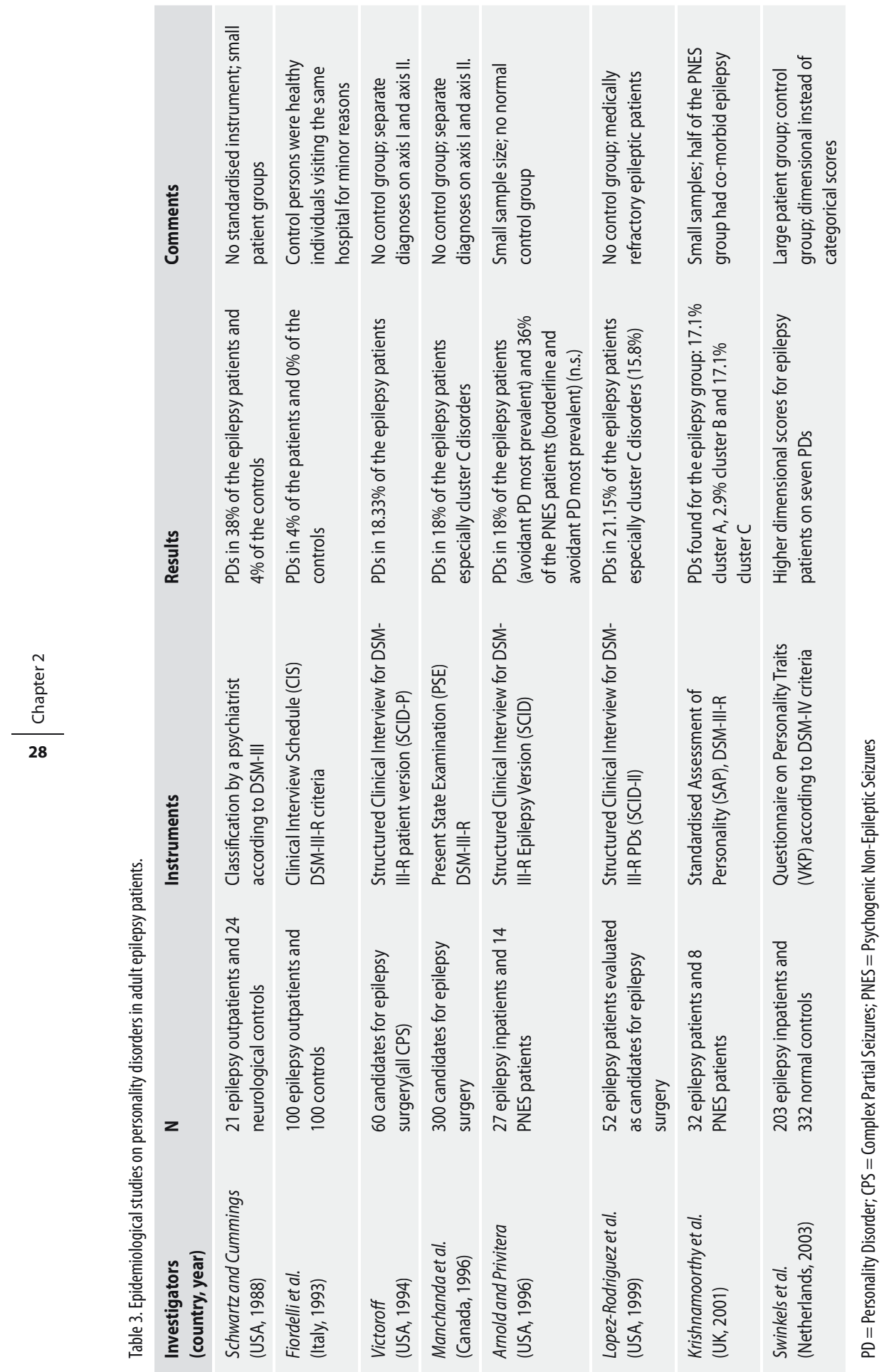


itself. However, these findings are based on a limited number of studies, and further investigation of the (relative) importance of the chronicity factor in the association between epilepsy and personality disorders is needed. Moreover, it is recommended that other chronic patient groups, in addition to the epilepsy group, be included to provide a more direct comparison between different patient groups.

Furthermore, from Table 3 we see that several studies reported a prevalence rate of personality disorders of approximately $18 \%$, which is lower, on average, than what was found for axis I clinical disorders. The same applies, however, to the general population, in whom the prevalence of axis I disorders is also higher than that of axis II disorders. In addition, the range of prevalence rates reported for personality disorders seems to be smaller. This may be explained by the fact that all studies (with one exception) used standardised diagnostic instruments based on DSM criteria. Another consistent finding is the predominance of cluster $C$ personality disorders in patients with epilepsy. However, this is not a unique finding because cluster $\mathrm{C}$ disorders are also most prevalent in the general population.

It has been hypothesised that these personality disorders might be the result of the psychosocial consequences of living with epilepsy, as a maladaptive reaction to a chronic disorder, or the result of disrupted neuronal functioning, or a combination of both. However, Lopez-Rodriquez et al. (52) found that of all epilepsy variables, only the presence of an aura was positively correlated with the likelihood of having a personality disorder. No difference in the rate of personality disorders between patients with TLE and patients with other types of seizures was observed. Also, Swinkels et al. (54) did not find any association between the localisation of the epileptogenic zone and personality disorder traits. Moreover, they found that only a modest part of the variance of particularly cluster $C$ personality disorder traits can be explained by epilepsy-related variables (i.e., severity and duration of the epilepsy). So it can be concluded that, at this time, the relative contribution of these co-called "brain related" and "non-brain related" factors to the association between epilepsy and personality disorders remains uncertain. Only very few studies have investigated these risk factors associated with personality disorders.

\section{Are there psychiatric disorders specific to epilepsy?}

Several neuropsychiatrists with a special interest in epilepsy suggest that the existing systems of classification of psychiatric disorders and personality disorders are inadequate as far as epilepsy is concerned (60-62). They assume that there is an underestimation and underrecognition of psychopathology due mainly to the instruments used. These authors argue that these instruments are developed to detect mental disorders in the general population rather than mental disorders specific to epilepsy. They acknowledge that patients with epilepsy could have comorbid 
psychiatric disorders and personality disorders that fulfil criteria for the DSM-IV classification system, but, in addition, they hypothesise that there are also types of psychopathology that are rather specific to epilepsy and require another classification system. However, it remains to be seen if these supposedly epilepsy-specific disorders exist. In the next sections, three of these syndromes are illustrated, namely, interictal dysphoric disorder, interictal behaviour syndrome, and the psychoses of epilepsy. We discuss whether the syndrome exists and how specific it is to epilepsy.

\section{Interictal dysphoric disorder}

Depressive disorders in epilepsy patients can be identical to those of nonepileptic patients: they meet the diagnostic criteria for major depression or dysthymic disorder. Depression is the most common comorbid psychiatric disorder associated with epilepsy (see, e.g., 63, 64). The lifetime prevalence has been estimated to be between 6 and 30\% in population-based studies and up to $50 \%$ among patients in tertiary centres. However, a certain number of patients have an atypical clinical presentation of depressive symptoms that fails to meet the criteria of any of the DSM affective disorders. Mendez et al. (65) observed that epilepsy patients (although they met the criteria for a major depressive disorder) had atypical peri-ictal features with more paranoia and psychotic symptoms. These patients also had a more chronic dysthymic course between the major depressive episodes, in which they showed more irritability and emotionality. Several investigators believe that the various mood complaints in epilepsy patients are different from those seen in nonepileptic patients. Kraepelin (66) provided a clinical description of such a disorder, and in recent years, Blumer et al. $(67,68)$ introduced the term "interictal dysphoric disorder" (IDD) to refer to these depressive symptoms specifically in patients with epilepsy. The symptoms in IDD have an intermittent course and can be categorised into depressive-somatoform symptoms and affective symptoms. The depressive-somatoform symptoms include depressive mood, anergia, pain, and insomnia. The affective symptoms include irritability, euphoric mood, fear, and anxiety. Blumer et al. $(67,68)$ reported that almost one-third to one-half of patients with epilepsy seeking medical care suffer from IDD of sufficient severity to require pharmacological treatment. Although the overall severity of the symptoms of IDD is milder than that of a major depression, there is a significant impact on the patient's social relations, daily activities, and quality of life. Because of the interrupted course of the symptoms, there is a failure to meet the DSM-IV criteria of dysthymic disorder (69).

Nevertheless, the existence and specificity of a characteristic depressive syndrome such as IDD among patients with epilepsy is controversial. As far as the existence of IDD is concerned, whether it represents a different syndrome unique to patients with epilepsy or is simply a syndrome not fully meeting the DSM-IV criteria for a 
depressive disorder (i.e., sub-threshold) remains uncertain. This issue is part of a more general problem inherent to the use of a categorical classification system such as the DSM. In many cases the number of symptoms experienced is just below the threshold to confirm a psychiatric (DSM) diagnosis. This does not automatically mean that the problems the patient experiences are not severe enough to pay attention to. Unfortunately, studies comparing depression with IDD are notably absent (with the exception of the study by Kanner (64)). It is possible that there exists a spectrum with a chronic dysthymic state characterised by the features of IDD that may intermittently exacerbate and at that time meet the criteria for major depressive disorder. Another question is how specific such a syndrome is to epilepsy. It is unknown whether patients with other chronic medical conditions (with a paroxysmal course) also experience the same combination of symptoms. Clearly, more systematic studies are needed to clarify these issues.

\section{Interictal behaviour (or personality) syndrome}

Specific interictal personality characteristics in epilepsy have been recognised for centuries and described extensively (70-73). Initially, the characteristics were derived largely from case studies and anecdotal observations. Later, personality traits were more systematically investigated. In the course of time, different names were used to describe the cluster of interictal characteristics (viz. "interictal behaviour syndrome", "interictal personality syndrome", "epileptic personality"). All of these names refer to the same subset of features. It should be realised that these interictal personality traits occur in some patients with epilepsy, whereas the majority of patients have a normal personality structure. These traits are difficult to define, quantify, and study. It is frequently not clear which traits are attributable to the epilepsy and which result from other factors. For example, structural brain lesions such as mesial temporal sclerosis and tumours can cause personality changes independent of the epilepsy itself. Likewise, (antiepileptic) medication and psychosocial problems can also have significant behavioural consequences. Furthermore, it is often difficult to distinguish postictal states from interictal periods. Again, the specificity of the personality features for epilepsy is an open question. None of the interictal traits in epilepsy have ever proven to be unique to epilepsy: i.e., they also occur among psychiatric and other neurological patients and normal subjects $(74,75)$.

Many epilepsy patients do not meet the DSM-IV criteria of a specific personality disorder, yet they show some typical personality oddities. Waxman and Geschwind (71) described a subset of personality characteristics, including deepened emotionality, circumstantiality, disrupted religious and sexual concerns, and hypergraphia, among patients with TLE, and attributed these to an "interictal behavioural syndrome". These features are not necessarily maladaptive (or indicative of psychopa- 
thology), and the syndrome should be seen as one of behavioural change rather than of a behavioural disorder. A few years later, Bear and Fedio (72) developed an inventory specifically to assess these and other reported personality traits. This socalled Bear-Fedio Inventory (BFI) consists of 18 traits, which reflect characteristics in behaviour, thought, and affect that previously have been associated in the literature with TLE. These traits are listed in Table 4. Each trait was assessed with five true-false items, so the scores ranged from 0 to 5 .

Frequencies of all 18 traits (self-reports) were increased in patients with TLE, compared with those of normal and neurological controls. The most significant differences were humourlessness, circumstantiality, dependence, and sense of personal destiny. Raters (i.e., family or friends) identified TLE patients as significantly different from controls on 14 traits, most strongly for circumstantiality, obsessionalism, and dependence. Bear (73) and Bear and Fedio (72) suggest that these personality changes result from a sensory-limbic hyperconnection syndrome, in which the epileptic focus leads to enhanced associations between affects and stimuli (e.g., irritability, deepened emotion, hyperreligiosity, hypergraphia). To some extent, this is the opposite of the Klüver-Bucy syndrome (76) in which limbic dysfunction leads to failure to attribute the appropriate emotional significance to stimuli (reflects sen-

Table 4. Interictal personality traits ascribed to temporal lobe epilepsy.

\begin{tabular}{ll} 
Trait & Clinical observation \\
Viscosity & Stickiness, tendency to repetition \\
Humourlessness, sobriety & Overgeneralised ponderous concern, humour lacking \\
Sadness/depression & Discouragement, tearfulness, self-depreciation \\
Anger & Increased temper, irritability \\
Aggression & Overt hostility, rage attacks, violent crimes, murder \\
Altered sexual interest & Loss of libido, hyposexualism \\
Circumstantiality & Loquacious, pedantic, overly detailed \\
Paranoia & Suspicious, overinterpretative of motives and events \\
Guilt & Tendency to self-scrutiny and self-recrimination \\
Hyperreligiosity & Holding deep religious beliefs \\
Feeling of personal destiny & Egocentricity, personal events highly charged \\
Hypergraphia & Keeping extensive diaries, detailed notes \\
Philosophical interest & Nascent metaphysical or moral speculations, cosmological theories \\
Elation, euphoria & Grandiosity, exhilarated mood \\
Heightened emotionality & Deepening of all emotions, sustained intense affect \\
Dependence, passivity & Cosmic helplessness, "at hands of fate" \\
Obsessiveness & Ritualism, orderliness, compulsive attention to detail \\
Hypermoralism & Attention to rules with inability to distinguish significant from minor \\
& infraction \\
& \\
\hline
\end{tabular}


sory-limbic disconnection). It should be kept in mind that the majority of epilepsy patients do not spontaneously offer descriptions of these traits; therefore, these could be easily missed unless specifically asked for.

Since then, many studies have been performed using the BFI with mixed results (for an overview, see, e.g., 75). In their overview, Devinsky and Najjar came to two general conclusions. First, the BFI consistently discriminates epilepsy patients from normals and nonpsychiatric (somatic) control patients, but fails to distinguish epilepsy patients from psychiatric patients. Second, the comparisons of TLE and primary generalised epilepsy patients are inconclusive.

From these findings, it can be concluded that the BFI does not seem to define a personality syndrome specific for TLE. However, some traits seem to occur more often or more intensely in epileptic patients than in the general population. Most of these patients have partial seizures of temporal lobe origin. Several of these traits (e.g., viscosity, hypergraphia, circumstantiality, hyperreligiosity, and dependence) resemble characteristics of cluster $C$ personality disorders, for example, obsessivecompulsive disorder. From studies of axis II personality disorders we know that cluster $C$ personality disorders are frequently observed in patients with epilepsy. Thus, some overlap seems to exist, and it may be suggested that the traits described by the BFI are features associated with axis II personality disorders (particularly cluster C disorders). Nevertheless, it is still uncertain whether a cluster of personality traits exists that is specific to patients with (temporal lobe) epilepsy as the BFI fails to distinguish epilepsy patients from psychiatric patients.

\section{Psychosis of epilepsy}

Psychotic syndromes in epilepsy have traditionally been classified according to their temporal relationship with the seizures (ictal, postictal, interictal). Because this article concerns interictal psychopathology, we focus on the interictal psychosis presumed to be associated with epilepsy. A distinction is made between brief interictal psychosis and more chronic psychotic states.

It may often be difficult to distinguish postictal psychosis from brief interictal psychotic episodes also called "alternating psychoses" (77). In these brief interictal psychotic states, an antagonistic relationship between epilepsy and psychosis is presumed in which periods of increased seizure activity can alternate with seizurefree intervals during which a patient becomes psychotic. This phenomenon, called "forced normalisation" (78), refers to stabilisation of the EEG and not necessarily to seizure control. The episodes are brief (last from several days to weeks), may end in a convulsion, the consciousness is usually clear, and often an association with TLE is found (78-82). The phenomenology is further characterised by paranoid delusions 
and auditory hallucinations, and affective symptoms may also occur $(77,83-85)$. The evidence is, however, limited, so more research on this topic is needed.

Whereas brief interictal psychoses are relatively uncommon (about $10 \%$ of all psychoses in epilepsy), chronic interictal (schizophrenia-like) psychoses are presumed to occur more often (in $20 \%$ of the psychoses in epilepsy) (86). It is suggested that schizophrenia-like psychosis is 6 to 12 times more likely to occur in epileptic patients than in the general population (87). The risk has probably been overestimated because many studies used highly selected patient populations. For example, the landmark study by Slater et al. (88) received considerable criticism principally because of its selection bias (the epilepsy patients with psychosis were specifically sent to these hospitals because they were difficult cases). Nevertheless, this study was of major importance because these investigators were the first to perform a systematic study of psychosis in a sample of 69 hospitalised epilepsy patients and they introduced the term "schizophrenia-like psychosis" to indicate the similarities between these two disorders. According to the present-day classification with the DSM-IV, the diagnosis of schizophrenia requires the presence of at least two of the following five symptom categories with a minimal duration of 1 month: delusions, hallucinations, disorganised speech, grossly disorganised or catatonic behaviour, and negative symptoms. Also, patients must be dysfunctional in social and occupational domains or in self-care for a minimum of 6 months, during which they may present with negative symptoms or with at least two of the symptoms outlined above, but of lesser severity. Slater and co-workers proposed that, if the patients in their study had not had epilepsy, the psychoses probably would have been diagnosed as schizophrenia. Yet, together with several other investigators, they stated that the schizophrenia-like psychosis of epilepsy has some atypical features that are different from what is seen in classic schizophrenia. Notable and frequently mentioned differences are the lack of negative symptoms (i.e., preservation of warm affect) and adequate or even well-preserved personalities and interpersonal relations in schizophrenia-like psychoses (88-96). Slater et al. (88) also mentioned a high frequency of delusions and religious, mystical experiences. A number of investigators described the symptoms as being largely paranoid-hallucinatory $(88-91,95,97)$. Furthermore, the onset of schizophrenia-like psychosis usually occurs after a 10- to 20-year duration of epilepsy, and an association with TLE is repeatedly suggested $(88,91,93-95)$.

It has to be mentioned that several of these investigators are from the same institute and so their findings are based on the same patient material. Also, the lack of a (psychiatric) control group and phenomenological descriptions that are based on impression only make these findings not very convincing. Perez and colleagues (98) tried to overcome these weaknesses by comparing 11 patients with epilepsy 
and psychosis with 9 nonepileptic schizophrenic controls using the Present State Examination (PSE). They concluded that the psychotic episodes in patients with epilepsy are indistinguishable from those of classic schizophrenics. More of these studies are urgently needed to investigate similarities and dissimilarities between schizophrenia and schizophrenia-like psychosis systematically with standardised psychiatric measures.

There is also much controversy about the risk factors. For instance, the relation between temporal lobe seizure foci and psychosis remains to be proven (e.g., 39, $44,99)$. These authors argued that the apparent excess of TLE in patients with both epilepsy and psychosis reflects nothing more than that TLE is the commonest form of epilepsy. There seems to be, however, consensus that psychosis of epilepsy is less severe than schizophrenia and responds better to therapy (100).

The position that a specific interictal psychotic disorder exists in patients with epilepsy has some support. It seems that patients with epilepsy can experience psychotic symptoms rather similar to those of schizophrenia. Several authors noted the relative lack of negative symptoms and a more benign course for epileptic schizophrenia but controlled studies on this topic are lacking. Apparently, some differences, albeit small ones, exist between interictal psychoses in epilepsy and psychosis in classic schizophrenia. Apart from that, the boundary between postictal and brief interictal psychosis is poorly defined, as in the distinction of brief interictal psychosis from more chronic psychotic episodes. Clearly, more investigation is needed.

\section{Summary and conclusions}

It is commonly believed that epilepsy carries with it an increased risk of developing interictal psychiatric disturbances. Research in the field of epilepsy and psychiatry has concentrated on epilepsy mainly as a biological condition. Currently, it is being recognised that the medical and psychosocial dimensions of epilepsy are just as (or even more) important.

A multiplicity of studies on psychiatric comorbidity in epilepsy have been performed, and many different patient groups and diagnostic instruments used. The majority of these studies concern clinical disorders according to the axis I of the DSM. Prevalence rates of axis I psychiatric problems vary between 19 and $80 \%$. This large variation in percentages is probably attributable to the different patient groups investigated and the even greater variety of diagnostic methods (i.e., some studies use no diagnostic instrument at all). A considerable number of studies did not use a control group of "healthy" subjects or other patient groups with which to compare results. From the studies that did include a control group of healthy (nonmedical) subjects, it was found that the prevalence of axis I disorders is higher for patients 
with epilepsy. Studies that (also) included another chronic medical patient group assume that the chronicity of the medical condition is an important factor for an increased risk among epilepsy patients for developing axis I psychiatric disorders, but brain dysfunction seems to be just as important. The precise contribution of the different epilepsy-related variables to the increased risk of psychiatric problems in patients with epilepsy remains unclear. It seems that both brain-related and nonbrain-related factors are important.

Whereas many investigations concentrate on axis I disturbances, relatively little research is performed on the prevalence of axis II personality disorders. The prevalence rate of personality disorders in epilepsy varies between 4 and $38 \%$, which is more consistent than what is found for axis I disorders. Probably this smaller variability is the result of the fact that almost all studies used standardised diagnostic instruments based on the DSM criteria for personality disorders. In a comparison of the results for epilepsy patients with findings from the general population, it seems that the prevalence of personality disorders in patients with epilepsy is slightly increased. From the little research that is available, it also seems that more personality disorders occur in epilepsy patients compared with patients with other chronic medical conditions. In accordance with what is found in the general population is the proneness of cluster $C$ personality disorders in epilepsy. So far, still little is known about the relative contribution of biological and psychosocial factors to personality disorders.

Despite the high prevalence of especially axis I disorders, but also axis II disorders, observed with traditional diagnostic methods, some neuropsychiatrists suggest that the prevalence of psychiatric disorders in epilepsy is underestimated. They assume the existence of psychiatric disorders specific to patients with epilepsy and that are not detected with traditional instruments. Common examples of such syndromes are interictal dysphoric disorder, interictal behaviour or personality syndrome, and the psychoses of epilepsy. Notwithstanding the large number of articles on these syndromes, the existence and specificity of such syndromes solely in patients with epilepsy remains open questions. Possibly, these syndromes can be diagnosed as psychiatric disorders according to DSM or are the manifestations of axis I or axis II disorders on a sub-threshold level. The latter possibility is a problem that might be seen as inherent to the use of classification systems (i.e., categorical, instead of dimensional) and does not imply the existence of real epilepsy-specific disorders. However, this issue is still controversial.

From the many studies that have been performed on psychiatric comorbidity in epilepsy, it can be learned that there is a need for well-controlled studies using representative patient groups and valid and standardised diagnostic instruments. More research on personality disorders in particular is recommended. Finally, future 
studies should focus more on the relative contributions of the different brain- and no-brain-related variables to the relationships between epilepsy and psychiatric disorders. 


\section{REFERENCES}

1. Cowan LD, Leviton A, Bodensteiner JB, Doherty L. Problems in estimating the prevalence of epilepsy in children: the yield different sources of information. Peadiatr Perinat Epidemiol 1989;3:386-401.

2. Hauser WA, Annegers JF, Kurland LT. Prevalence of epilepsy in Rochester, Minnesota: 1940-1980. Epilepsia 1991;32:429-445.

3. Rwiza HT, Kilonzo GP, Haule J, Matuja WB, Mteza I, et al. Prevalence and incidence of epilepsy in Ulanga, a rural Tanzanian district: a community-based study. Epilepsia 1992;33:1051-1056.

4. Placencia M, Sander JW, Roman M, Madera A, Crespo F, et al. The characteristics of epilepsy in a largely untreated population in rural Ecuador. J Neurol Neurosurg Psychiatry 1994;57:320-350.

5. Shackleton DP, Westendorp RGJ, Kasteleijn-Nolst Trenité DGA, De Boer A, Herings RMC. Epilepsy medication: A road to determing the number of individuals with seizures. J Clin Epidemiol 1997;50(9):1061-1068.

6. Hathaway SR, McKinley JC. Minnesota Multiphasic Personality Inventory. Minneapolis, MN, University of Minnesota; 1943.

7. Tempkin O. The falling sickness. 2nd ed. Baltimore: Johns Hopkins University Press; 1971.

8. Jackson JH. Selected writings. In: Taylor J, editor. On epilepsy and epileptiform convulsions, Vol 1. London: Hodder \& Stoughton; 1931.

9. Gowers WR. Epilepsy and other chronic convulsive diseases. London: J\&A Churchill; 1881.

10. Briquet P. Traité clinique et therapeutique de I'hysterie. Paris; 1859.

11. Morel BA. Traité des malades mentales. Paris: Masson et Cie; 1860.

12. Pond DA, Bidwell BH. A survey of epilepsy in fourteen general practices: II Social and psychological aspects. Epilepsia 1959/1960;1:285-299.

13. Edeh J, Toone B. Relationship between interictal psychopathology and the type of epilepsy. Br J Psychiatry 1987;151:95-101.

14. Jalava M, Sillanpaa M. Concurrent illnesses in adults with childhood-onset epilepsy: a populationbased 35-year follow-up study. Epilepsia 1996;37:1155-1163.

15. Stefansson SB, Olafsson E, Hauser WA. Psychiatric morbidity in epilepsy: a case controlled study of adults receiving disability benefits. J Neurol Neurosurg Psychiatry 1998;64:238-241.

16. Currie S, Heathfield KWG, Henson RA, Scott DF. Clinical course and prognosis of temporal lobe epilepsy. Brain 1971;94:173-190.

17. Kogeorgos J, Fonagy P, Scott DF. Psychiatric symptom patterns of chronic epileptics attending a neurological clinic: a controlled investigation. Br J Psychiatry 1982;140:236-243.

18. Schiffer RB, Babigian HM. Behavioral disorders in multiple sclerosis, temporal lobe epilepsy, and amyotrophic lateral sclerosis. An epidemiologic study. Arch Neurol 1984; 41:1067-1069.

19. Gureje O. Interictal psychopathology in epilepsy. Prevalence and pattern in a Nigerian clinic. Br J Psychiatry 1991;158:700-705.

20. Manchanda R, Schaefer B, McLachlan R, Blume WT. Interictal psychiatric morbidity and focus of epilepsy in treatment-refractory patients admitted to an epilepsy unit. Am J Psychiatry 1992;149:1096-1098.

21. Fiordelli E, Beghi E, Bogliun G, Crespi V. Epilepsy and psychiatric disturbance. Br J of Psychiatry 1993;163:446-450.

22. Victoroff J. DSM-III-R psychiatric diagnoses in candidates for epilepsy surgery: lifetime prevalence. Neuropsychiatry, Neuropsychology, and Behavioral Neurology 1994;7(2):87-97.

23. Silberman EK, Sussamn N, Skillings G, Callanan M. Aura phenomena and psychopathology: a pilot investigation. Epilepsia 1994;35(4):778-784.

24. Manchanda R, Schaefer B, McLachlan RS, Blume WT, Wiebe S, Girvin JP, Parrent A, Derry PA. Psychiatric disorders in candidates for surgery for epilepsy. J Neurol, Neurosurg, Psychiatry 1996;61:8289.

25. Perini Gl, Tosin C, Carraro C, Bernasconi G, Canevini MP, Canger R, Pellegrini A, Testa G. Interictal mood and personality disorders in temporal lobe epilepsy and juvenile myoclonic epilepsy. J Neurol Neurosurg Psychiatry 1996;61:601-605.

26. Arnold LM, Privitera MD. Psychopathology and trauma in epileptic and psychogenic seizure patients. Psychosomatics 1996;37:438-443. 
27. Etttinger AB, Weisbrot DM, Krupp LB, Jandorf L, Gaudino E, Cramer J. Symptoms of psychiatric disturbances in epilepsy. J Epilepsy 1998;11(1):10-14.

28. Swinkels WAM, Kuyk J, De Graaf EH, Van Dyck R, Spinhoven Ph. Prevalence of psychopathology in Dutch epilepsy inpatients: A comparative study. Epilepsy \& Behavior 2001;2:441-447.

29. Wells KB, Golding JM, Burnam MA. Psychiatric disorder in a sample of the general population with and without chronic medical conditions. Am J Psychiatry 1988;145:976-981.

30. Baldwin MV. A Clinico-experimental investigation into the psychologic aspects of multiple sclerosis. J Nerv Ment Dis 1952;115:299-342.

31. Surridge D. An investigation into some psychiatric aspects of multiple sclerosis. Br J Psychiatry 1969;115:749-764.

32. Whitlock FA, Siskind MM. Depression as a major symptom of multiple sclerosis. J Neurol Neurosurg Psychiatry 1980;43:861-865.

33. Dalos NP, Rabins PV, Brooks BR. Disease activity and emotional state in multiple sclerosis. Ann Neurol 1983;13:573-577.

34. Pollak Y, Orion E, Goshen I, Ovadia H, Yirmiya R. Experimental autoimmume encephalomyelitisassociated behavioral syndrome as a model of 'depression due to multiple sclerosis'. Brain Behav Immun 2002;16(5):533-43.

35. Gibbs FA, Gibbs EL, Furster B. Psychomotor epilepsy. Arch Neurol Psychiatry 1948;60:331-339.

36. Gudmundsson G. Epilepsy in Iceland. Acta Neurol Scand 1966;43(Suppl.25):1-124.

37. Rodin EA, Katz M, Lennox K. Differences between patients with temporal lobe seizures and those with other forms of epileptic attacks. Epilepsia 1976;17:313-320.

38. Small JG, Small IF, Hayden MP. Further psychiatric investigations of patients with temporal and nontemporal lobe epilepsy. Am J Psychiatry 1966;123:303-310.

39. Stevens JR. Psychiatric implications of psychomotor epilepsy. Arch Gen Psychiatry 1966;14:461471.

40. Mignone RJ, Donnelly EF, Sadowsky D. Psychological and neurological comparisons of psychomotor and non-psychomotor epileptic patients. Epilepsia 1970;11:345-359.

41. Standage KF, Fenton GW. Psychiatric symptom profiles of patients with epilepsy: a controlled investigation. Psychol Med 1975;5(2):152-160.

42. Hermann, BP, Dikmen S, Wilensky AJ. Increased psychopathology associated with multiple seizure types: Fact or artifact? Epilepsia 1982;23:587-596.

43. Dodrill CB. Number of seizure types in relation to emotional and psychosocial adjustment in epilepsy. In: Porter RJ, Ward AA Jr, Mattson RH, Dam M, editors. Advances in epileptology: XVth Epilepsy International Symposium. New York: Raven Press; 1984. p. 541-544.

44. Stevens JR, Herman BP. Temporal lobe epilepsy, psychopathology and violence: the state of evidence. Neurology 1981;31:1127-1132.

45. Hermann BP, Whitman S. Behavioral and personality correlates of epilepsy: A review, methodological critique, and conceptual model. Psychological Bulletin 1984;95(3):451-497.

46. Hauser WA, Hesdorffer DC. Epilepsy: Frequency, causes and consequences. New York: Demos; 1990.

47. Hermann BP, Whitman S. Psychopathology in epilepsy. The role of psychology in altering paradigms of research, treatment, and prevention. Am Psychologist 1992;47(9):1134-1138.

48. Hermann BP, Seidenberg M, Bell B. Psychiatric comorbidity in chronic epilepsy: Identification, consequences, and treatment of major depression. Epilepsia 2000;41(Suppl.2):S31-S41.

49. Hermann BP, Dikmen S, Schwartz MS, Karnes WE. Interictal psychopathology in patients with ictal fear: a quantitative investigation. Neurology 1982;32:7-11.

50. Provinciali L, Franciolini B, Del Pesce M, Signorino M, Ceravolo G. Influence of neurological factors on the personality profile of patients with temporal lobe epilepsy. J of Epilepsy 1989;2:239-244.

51. Schwartz J, Cummings JL. Psychopathology and epilepsy: An outpatient consultation-liaison experience. Psychosomatics 1988;29(3):295-300.

52. Lopez-Rodriguez F, Altshuler L, Kay J, Delarhim S, Mendez M, Engel J. Personaliy disorders among medically refractory epileptic patients. J Neuropsychiatry Clin Neurosci 1999;11:464-469.

53. Krishnamoorthy EA, Brown RJ, Trimble MR. Personality and psychopathology in nonepiletic attack disorder and epilepsy. Epilepsy \& Bahaviour 2001;2:418-422. 
54. Swinkels WAM, Duijsens IJ, Spinhoven Ph. Personality disorder traits in patients with epilepsy. Seizure 2003;12:587-594.

55. Samuels JF, Nestadt G, Romanoski AJ, Folstein MF, McHugh PR. DSM-III personality disorders in the community. Am J Psychiatry 1994;151(7):1055-1062.

56. Samuels JF, Eaton WW, Bienvenu OJ 3rd, Brown CH, Costa PT Jr, Nestadt G. Prevalence and correlates of personality disorders in a community sample. Br J Psychiatry 2002;180:536-542.

57. Jackson HJ, Burgess PM. Personality disorders in the community: a report from the Australian National Survey of Mental Health and Wellbeing. Soc Psychiatry Psychiatr Epidemiol 2000;35(12):531538.

58. Torgerson S, Kringlen E, Cramer V. The prevalence of personality disorders in a community sample. Arch Gen Psychiatry 2001;58(6):590-596.

59. Bauer H, Duijsens IJ. Personality disorders in pulmonary patients. British Journal of Medical Psychology 1998;71:165-173.

60. Krishnamoorthy ES. An approach to classifying neuropsychiatric disorders in epilepsy. Epilepsy \& Behavior 2000;1:373-377.

61. Krishnamoorthy ES. Neuropsychiatric disorders in epilepsy - epidemiology and classification. In: Trimble M, Schmitz B, editors. The Neuropsychiatry of epilepsy. Cambridge: University Press; 2002. p. 5-17.

62. Barry JJ, Lembke A, Huynh N. Affective disorders in epilepsy. In: Ettinger AB, Kanner AM, editors. Psychiatric issues in epilepsy. Philadelphia: Lippincott Williams \& Wilkins; 2001. p. 45-71.

63. Altshuler L. Depression and epilepsy. In: Devinsky O, Theodore WH, editors. Epilepsy and behavior. New York: Wiley-Liss; 1991. p. 47-65.

64. Kanner AM. Depression in epilepsy: Prevalence, clinical semiology, pathogenic mechanisms, and treatment. Biol Psychiatry 2003;54:388-398.

65. Mendez MF, Cummings JL, Benson DF. Depression in epilepsy. Significance and phenomenology. Arch Neurol 1986;43(8):766-770.

66. Kraepelin E. Psychiatrie. Vol 3. Leipzig: Johann Ambrosius Barth; 1923.

67. Blumer D. Epilepsy and disorders of mood. In: Smith D, Treiman D, Trimble M, editors. Neurobehavioral problems in epilepsy. New York: Raven Press; 1991. p. 85-196.

68. Blumer D, Montouris G, Hermann B. Psychiatric morbidity in seizure patients on a neurodiagnostic monitoring unit. J Neuropsychiatry Clin Neurosci 1995;7:445-456.

69. Kanner AM, Kozak AM, Frey M. The use of sertraline in patients with epilepsy: is it safe? Epilepsy \& Behavior 2000;1:100-105.

70. Gastaut H, Morin G, Leserve N. Etude du comportement des épileptiques psycho-moteurs dans l'intervalle de leurs crises. Ann Medico-Psychol 1955;113:1-27.

71. Waxman SG, Geschwind N. The interictal behaviour syndrome of temporal lobe epilepsy. Arch of Gen Psychiatry 1975;32:1580-1586.

72. Bear DM, Fedio P. Quantitative analysis of interictal behaviour in temporal lobe epilepsy. Arch Neurol 1977;34:454-467.

73. Bear D. Temporal lobe epilepsy: a syndrome of sensory-limbic hyperconnection. Cortex 1979;15:357-384.

74. Devinsky O, Vazquez B. Behavioral changes associated with epilepsy. Neurol Clin 1993;11(1):127149.

75. Devinsky O, Najjar S. Evidence against the existence of a temporal lobe personality syndrome. Neurology 1999;53(Suppl 2):S13-25.

76. Klüver H, Bucy P. Preliminary analysis of functions of the temporal lobe in man. Archives of Neurology and Psychiatry 1939;42:979-1000.

77. Tellenbach H. Epilepsie als anfallsleiden und als psychose. Über alternatieve psychosen paranoider prägung bei 'forcierter normalisierung' (Landolt) des electroencephalogramms epileptischer. Nervenartz 1965;36:190-202.

78. Landolt H. Serial electroencephalographic investigations during psychotic episodes in epileptic patients and during schizophrenic attacks. In: Lorentz de Haas AM, editor. Lectures on epilepsy. Amsterdam: Elsevier; 1958.

79. Landolt H. Some clinical electroencephalographic correlations in epileptic psychoses (twilight states). Electroencephologr Clin Neurophysiol 1953;5:121. 
80. Landolt H.Über Verstimmungen, Dämmerzustände und schizophrene Zustandsbilder bei Epilepsie. Schweiz Arch Neurol Psychiatry 1955;76:313-321.

81. Glaser GH, Newman RJ, Schafer R. Interictal psychosis in psychomotor-temporal lobe epilepsy: an EEG psychological study. In: Glaser GH, editor. EEG and behavior. New York: Basic Books; 1963.

82. Dongier S. Statistical study of clinical and electroencephalographic manifestations of 536 psychotic episodes occurring in 516 epileptics between clinical seizures. Epilepsia 1959/60;1:117142.

83. Ramani V, Gumnit RJ. Intensive monitoring of interictal psychosis in epilepsy. Ann Neurol $1982 ; 11: 613-622$.

84. Wolf P. The clinical syndromes of forced normalization. Jpn J Psychiatry Neurol 1984;38:187-192.

85. Pakalnis A, Drake ME, John K, Kellum JB. Forced normalization: acute psychosis after seizure control in 7 patients. Arch Neurol 1987;44:289-292.

86. Schmitz B. Psychiatric issues. In: Schmidt D, Schachter SC, editors. Epilepsy: Problem solving in clinical practice. London: Martin Dunitz Ltd; 2000. p. 169-189.

87. Sachdev P. Schizophrenia-like psychosis and epilepsy: The status of the association. Am J Psychiatry 1998;155(3):325-336.

88. Slater E, Beard AW, Glithero E. The schizophrenia-like psychosis of epilepsy. V. Discussion and conclusions. Br J Psychiatry 1963;109:95-150.

89. Hill D. Psychiatric disorders of epilepsy. Med Press 1953;229:473-475.

90. Pond DA. Psychiatric aspects of epilepsy. J Indian Med Prof 1957;3:142-145.

91. Bruens JH. Psychoses in epilepsy. Psychiatr Neurol Neurochir 1971;74:17-192.

92. Stoudemire A, Nelson A, Houpt JL. Interictal schizophrenia-like psychosis in temporal lobe epilepsy. Psychosomatics 1983;24:331-339.

93. Kristensen O, Sindrup EH. Psychomotor epilepsy and psychosis I. physical aspects. Acta Neurol Scand 1978;57:361-369.

94. Oyebode F, Davison K. Epileptic schizophrenia: clinical features and outcome. Acta Psychiatr Scand 1989;79:327-331.

95. Perez MM, Trimble MR. Epileptic psychosis - diagnostic comparison with process schizophrenia. Br J Psychiatry 1980;137:245-249.

96. Toone BK, Garralda ME, Ron MA. The psychosis of epilepsy and the functional psychosis: a clinical and phenomenological comparison. Br J Psychiatry 1982;141:256-261.

97. Parnas J, Korsgaard S, Krautwald O, Jensen PS. Chronic psychosis in epilepsy: a clinical investigation of 29 patients. Acta Psychiatr Scand 1982;66:282-293.

98. Perez MM, Trimble MR, Murray NMF, Reider I. Epileptic psychosis: an evaluation of PSE profiles. Br J Psychiatry 1985;146:155-163.

99. McKenna PJ, Kane JM, Parrish K. Psychotic syndromes in epilepsy. Am J Psychiatry 1985;142(8):895904.

100. Kanner AM. Psychosis of epilepsy: a neurologist's perspective. Review. Epilepsy \& Behavior 2000;1:219-227. 



\section{Prevalence of psychopathology in Dutch epilepsy inpatients: a comparative study}

WAM Swinkels, J Kuyk, EH de Graaf, R van Dyck, Ph Spinhoven

Epilepsy \& Behavior 2001;2:441-447

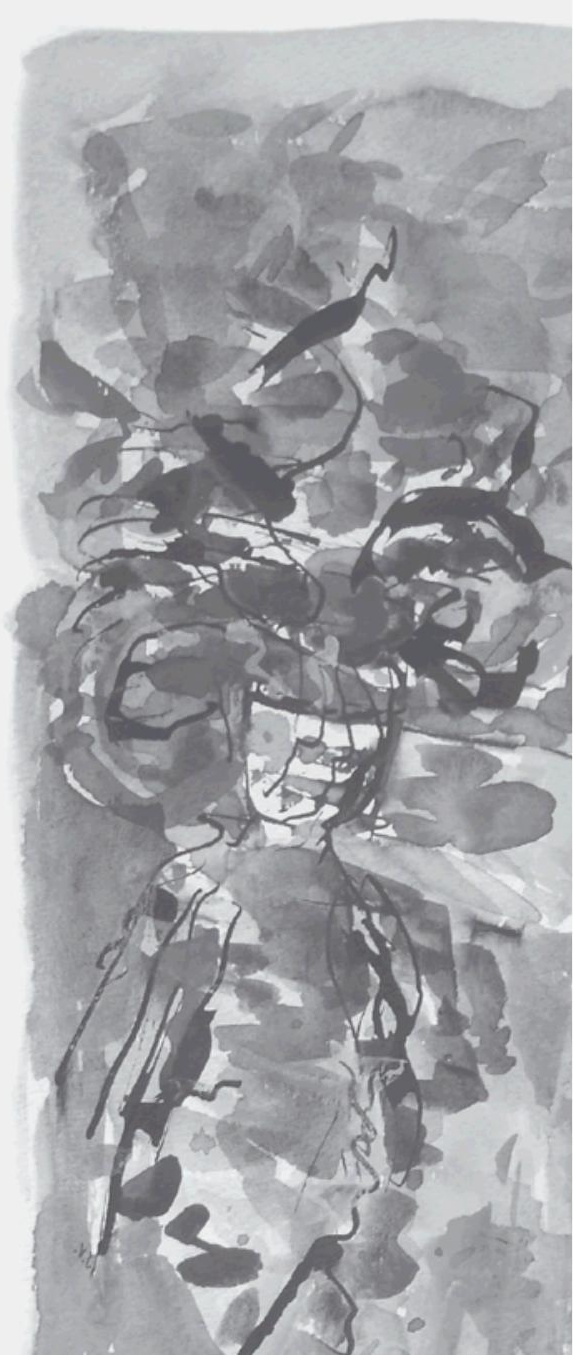




\section{ABSTRACT}

The purpose of this study was to determine the prevalence of psychiatric disorders in Dutch patients with epilepsy in comparison with epidemiological data on a representative sample of the Dutch population. The Composite International Diagnostic Interview (CIDI) was used to determine the prevalence of psychiatric disorders in 209 epilepsy patients and compared with findings in the general Dutch population. The prevalence in temporal lobe epilepsy (TLE) and extra-temporal lobe epilepsy (extra-TLE) was also compared. Psychiatric disorders most frequently found in patients with epilepsy were anxiety and mood disorders. The last-year prevalence of these disorders was $25 \%$ for anxiety disorders and $19 \%$ for mood disorders. Compared with the general Dutch population, the prevalence of these disorders was significantly higher in epilepsy. No differences were found between patients with TLE and extra-TLE. It can be concluded that patients with epilepsy admitted to a tertiary epilepsy center suffer more often from mood and anxiety disorders than the general population. 


\section{INTRODUCTION}

The relationship between psychopathology and epilepsy has been extensively studied in recent decades. In these studies, the psychiatric symptoms can be divided into symptoms directly related to seizure activity (preictal, ictal, and postictal) and symptoms not associated with seizure activity (interictal). This article is concerned with the interictal psychopathology.

Several studies show that there is an increased psychiatric morbidity in patients with epilepsy compared with normal controls (1-7). It is suggested that the presence of a chronic disease may predispose patients to psychiatric complaints. In line with this presupposition, no increased psychopathology was found in epilepsy patients relative to patients with other chronic medical conditions (4, 7-10). Perini et al. (11) compared patients with temporal lobe epilepsy (TLE) and patients with juvenile myoclonic epilepsy to another chronic patient group, namely, type I diabetic patients. They found more psychiatric disorders in TLE patients compared with the other two patient groups, which suggests that these psychiatric disorders are not the consequence of a chronic medical condition per se, but rather represent a limbic dysfunction of the brain. Also, several other studies reported more psychiatric disturbances in patients with TLE compared with extra-TLE patients $(1,12,13)$, while others found no such differences $(6,14-16)$. Consequently, the issue of whether patients with TLE are at increased risk of developing psychiatric disorders remains controversial.

In the search for the determinants of psychiatric disorders in epilepsy, Whitman and Hermann (17) suggested a multietiological model of psychopathology in epilepsy. They hypothesized that the potential etiological variables could be subdivided into three categories: biological, psychosocial, and medication variables. The biological hypothesis presumes that the psychological disturbances found in epilepsy are related to the dysfunction of the central nervous system underlying the patient's epilepsy. Variables relevant to this hypothesis are age at onset, seizure control, seizure type, multiple seizure types, etiology of the epilepsy, and laterality and localization of the brain lesion that causes the epilepsy. The psychosocial hypothesis proposes an influence of variables related to the social and interpersonal stress experienced by people with epilepsy, such as adjustment to the epilepsy, stigma, discrimination, and social support. Finally, the medication hypothesis emphasizes the importance of the influence of medication variables, such as number, type, dosage, and blood level of antiepileptic medication.

There is some evidence that epilepsy-related variables (such as type, duration), but also psychosocial factors and antiepileptic medication, are risk factors in the devel- 
opment of psychopathology, although the exact relation remains unknown. A comparison of study results is hampered by the use of different psychiatric concepts and a variety of diagnostic methods and instruments to determine the prevalence and types of psychopathology. In fact, only a few investigations use standardized diagnostic instruments based on objective criteria. In this study, the prevalence of psychiatric disorders in Dutch patients with epilepsy is determined using a fully structured diagnostic interview, and the results are compared with epidemiological data for a representative sample of 7076 people from the general Dutch population $(18,19)$. Also, the prevalence in TLE and extra-TLE patients was compared to study the hypothesis that involvement of the temporal lobes is an underlying factor in the development of psychiatric problems in patients with epilepsy.

\section{METHODS}

\section{Subjects}

Between January 1997 and June 1999, 254 adult patients suffering from epilepsy were consecutively admitted to the observation department of Stichting Epilepsie Instellingen Nederland (SEIN, a tertiary epilepsy center). To be included in this study, which was approved by the Medical Ethic Committee, a minimum age of 18 years, sufficient knowledge of the Dutch language, and a definite diagnosis of epileptic seizures was required. Patients with concomitant pseudo-epileptic seizures were excluded. Also patients with an acute psychotic episode were excluded, because the results of these patients are not reliable. The treating neurologist recruited all patients. Twenty-three patients did not give their informed consent for this study and 22 patients did not complete the study protocol for different reasons, mainly because of early discharge. Two hundred and nine patients remained for this study. Of them, 113 patients suffered from seizures originating predominantly from locations in the temporal lobes (TLE) and 87 patients had seizures originating from locations outside the temporal lobes (extra-TLE). Epilepsy patients were classified as TLE and extra-TLE primarily on the bases of clinical information obtained during hospital observation. Both the TLE and extra-TLE groups consisted of left, right, and bilateral localizations. For 9 patients it was not clear whether the seizures were of temporal or extra-temporal origin, so they could not be assigned to a subgroup. Nonetheless, these 9 patients were included in the analysis of the total epilepsy group. Patient characteristics of the total epilepsy group and the TLE and extra-TLE groups are reported in Table 1. The information on the epilepsy patients was compared with previously published data for a representative sample of 7076 people from the general Dutch population $(18,19)$. Some differences are observed when 
Table 1. Patient characteristics of the total epilepsy group, TLE and extra-TLE group.

\begin{tabular}{|c|c|c|c|c|}
\hline & $\begin{array}{l}\text { Total } \\
\text { Epilepsy group } \\
(n=209)\end{array}$ & $\begin{array}{l}\text { TLE group } \\
(n=113)\end{array}$ & $\begin{array}{l}\text { Extra-TLE group } \\
(n=87)\end{array}$ & $\begin{array}{l}\text { TLE versus } \\
\text { extra TLE } \\
\text { p-value }\end{array}$ \\
\hline \multicolumn{5}{|l|}{ Sex } \\
\hline$\%$ male & 57.4 & 54 & 60.9 & \\
\hline$\%$ female & 42.6 & 46 & 39.1 & \\
\hline Average age (year) & $\begin{array}{l}39.4 \\
(11.8 \mathrm{SD})\end{array}$ & $\begin{array}{l}41.6 \\
(12.1 \mathrm{SD})\end{array}$ & $\begin{array}{l}36.8 \\
(10.9 \mathrm{SD})\end{array}$ & $p<0.01$ \\
\hline \multicolumn{5}{|l|}{ Marital state (\%) } \\
\hline married/living together & 46.4 & 46 & 47.1 & \\
\hline divorced & 6.7 & 6.2 & 6.9 & \\
\hline single & 44.5 & 44.3 & 44.8 & \\
\hline widow/widower & 2.4 & 3.5 & 1.2 & \\
\hline Labor (\%) & & & & $p<0.05$ \\
\hline housekeeping & 18.4 & 24.1 & 11.5 & \\
\hline employed (paid) & 39.6 & 39.3 & 40.2 & \\
\hline disability pension/welfare & 34.3 & 27.7 & 42.5 & \\
\hline $\begin{array}{l}\text { otherwise (retired/voluntary } \\
\text { work/school) }\end{array}$ & 7.7 & 8.9 & 5.7 & \\
\hline \multicolumn{5}{|l|}{ Education (\%) ${ }^{1}$} \\
\hline primary education & 20.1 & 18.1 & 19.8 & \\
\hline secondary education & 69.8 & 73.3 & 68.6 & \\
\hline higher education & 10.1 & 8.6 & 11.6 & \\
\hline \multicolumn{5}{|l|}{ Number of AEDs * $(\%)$} \\
\hline no AED & 3.4 & 3.6 & 2.3 & \\
\hline one AED & 18.8 & 15.2 & 21.8 & \\
\hline two AED & 35.1 & 41.1 & 31 & \\
\hline three AED & 31.2 & 31.2 & 31 & \\
\hline four or more AED & 11.5 & 8.9 & 13.9 & \\
\hline $\begin{array}{l}\text { Average age at onset epilepsy } \\
\text { (year) }\end{array}$ & $\begin{array}{l}16.8 \\
(13.5 \mathrm{SD})\end{array}$ & $\begin{array}{l}17.8 \\
(13.7 \mathrm{SD})\end{array}$ & $\begin{array}{l}15.8 \\
(13.4 \mathrm{SD})\end{array}$ & \\
\hline
\end{tabular}

the demographic characteristics of the epilepsy group are compared with those of the sample from the general Dutch population. The epilepsy group consists of relatively more single persons and of persons with a lower education and higher degree of unemployment or disability, or both. 


\section{Instruments}

In this study we used the computerized version of the Composite International Diagnostic Interview (CIDI), Dutch version $1.1(20,21)$. The same instrument was used in the study of the general Dutch population. The CIDI is a fully structured diagnostic interview aimed at determining psychiatric syndromes according to the Diagnostic and Statistical Manual of Mental Disorders (DSM-III-R, Axis I)(22). It is a reliable and valid instrument suitable for use in different settings, cultures, and countries (23). The same interviewer examined all patients. For each patient, lifetime and last-year prevalence was determined for the following DSM-III-R psychiatric disorders: mood disorders (major depression, dysthymia, bipolar disorder); anxiety disorders (panic disorder, agoraphobia, simple phobia, social phobia, generalized anxiety disorder, obsessive compulsive disorder); schizophrenia; somatoform disorders (somatization disorder, somatoform pain disorder); psychoactive substance use disorders (alcohol abuse and dependence, drug abuse and dependence); and eating disorders (anorexia nervosa and bulimia nervosa).

\section{Data analysis}

Differences between the epilepsy group and the Dutch population and between the TLE and extra-TLE groups were analyzed by means of the $x^{2}$ test for independent unrelated categorical data. To compensate for multiple testing a significance level of $p<0.01$ was used. A forward logistic regression analysis was performed to investigate the association between demographic variables and psychiatric disorders. For statistical analysis SPSS for windows, Release 9.0, was used.

\section{RESULTS}

Lifetime and last-year prevalence of psychiatric disorders for the epilepsy patients and the general Dutch population is summarized in Table 2. Psychiatric disorders most frequently found among epilepsy patients were anxiety disorders and mood disorders: about $30 \%$ of the epilepsy patients had a lifetime diagnosis for anxiety disorders (25\% last-year prevalence) and $25 \%$ of the patients had a lifetime diagnosis for mood disorders (19\% last-year prevalence). Within the anxiety disorders, social phobia and generalized anxiety disorder prevailed. Concerning mood disorders, major depression and dysthymia were most frequently found in patients with epilepsy.

In a comparison of the lifetime prevalence of psychiatric disorders between the epilepsy group and the general Dutch population, significant differences were found for dysthymia $\left(x^{2}=28.748, d f=1, p<0.001\right)$, social phobia $\left(x^{2}=10.728, d f=1, p<0.001\right)$, 
Table 2. Lifetime and last year prevalence of schizophrenia, mood disorders, anxiety disorders, somatoform disorders, psychoactive substance use disorders and eating disorders for the epilepsy patients compared to the Dutch population.

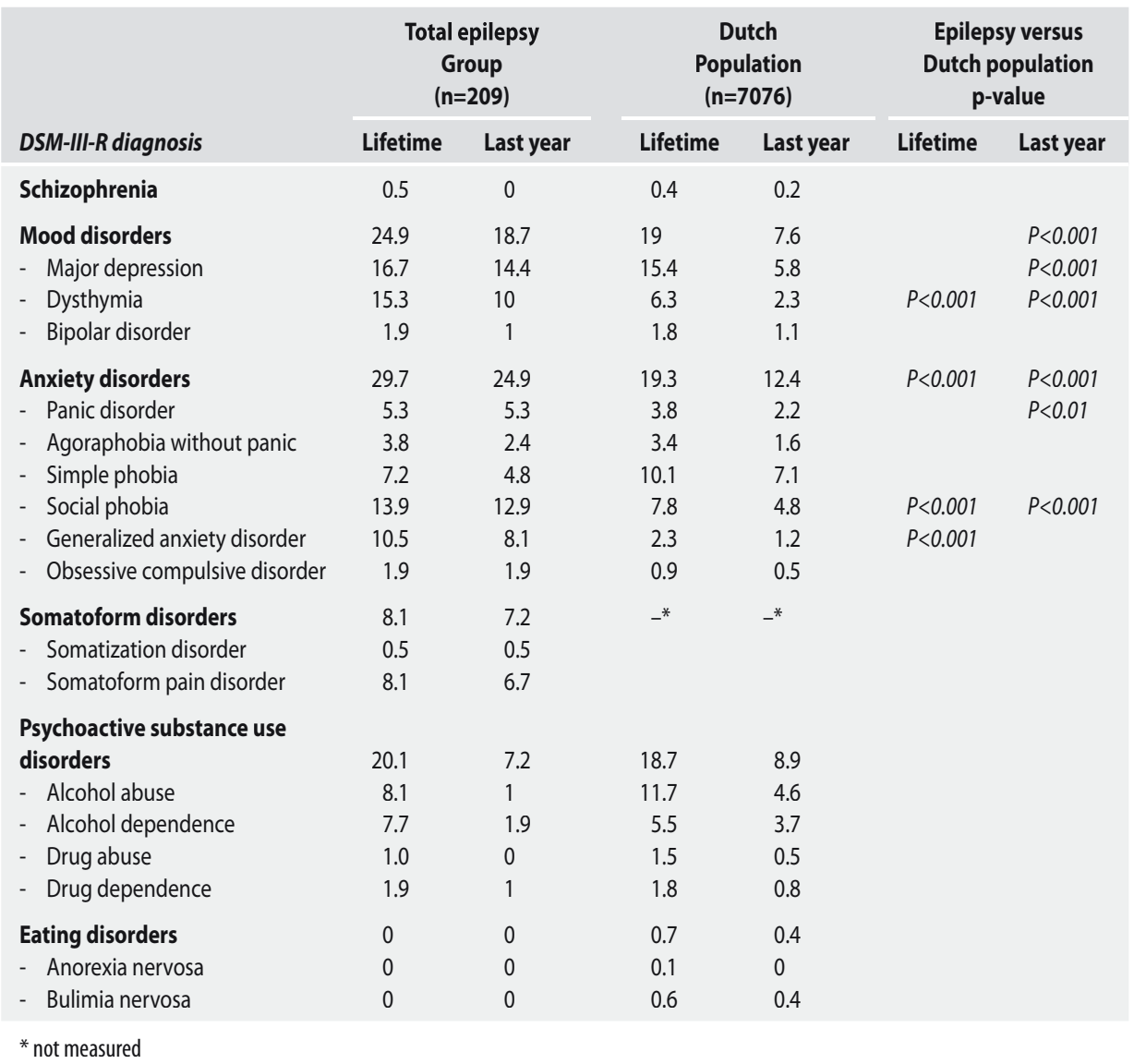

and generalized anxiety disorder $\left(x^{2}=62.941, \mathrm{df}=1, \mathrm{p}<0.001\right)$, with higher rates for the epilepsy patients. If the last-year prevalence is considered, the differences between the groups are even more pronounced. Besides a higher prevalence of dysthymia $\left(x^{2}=55.832, d f=1, p<0.001\right)$ and social phobia $\left(x^{2}=30.146, d f=1, p<0.001\right)$, higher rates for major depression $\left(x^{2}=27.991, d f=1, p<0.001\right)$ and panic disorder $\left(x^{2}=9.114, d f=1, p<0.01\right)$ are found in the epilepsy patients. The difference between the groups for the prevalence of lifetime generalized anxiety disorder disappeared when the last-year prevalence was considered. To investigate the association between the last-year prevalence of mood, anxiety, somatoform, and psychoactive substance use disorders, on the one hand, and the demographic variables sex, age, marital state, labor, and education, on the other hand, a forward logistic regression analysis was performed for the epilepsy group. The results of this logistic regression analysis showed that sex and education are associated with psychoactive substance 
use disorders. The odds ratios were $5.02(p<0.05)$ for males and $5.61(p<0.01)$ for primary education, meaning that male subjects and subjects with a primary education had a five times higher probability of having a psychoactive substance use disorder, compared with females and persons with a higher education.

Comparisons of the patients with TLE and extra-TLE for lifetime and last-year prevalence are shown in Table 3. No significant differences were found between the patients with TLE and extra-TLE for both lifetime and last-year prevalence. Although the differences were not statistically significant, the prevalence of mood disorders in particular tended to be somewhat higher for the TLE patients, especially when looking at last-year prevalence. Twenty-three percent of the TLE patients experienced mood disorders, compared with $15 \%$ of the extra-TLE patients. The last-year prevalence for dysthymia tended to be higher for the TLE patients compared with the extra-TLE patients $\left(x^{2}=3.701, d f=1, p=0.054\right)$.

Table 3. Lifetime and last year prevalence of schizophrenia, mood disorders, anxiety disorders, somatoform disorders, psychoactive substance use disorders and eating disorders for the TLE and extra-TLE patients.

\begin{tabular}{|c|c|c|c|c|}
\hline \multirow[b]{2}{*}{ DSM-III-R diagnosis } & \multicolumn{2}{|c|}{$\begin{array}{c}\text { TLE } \\
(n=113)\end{array}$} & \multicolumn{2}{|c|}{$\begin{array}{l}\text { Extra-TLE } \\
\qquad(\mathrm{n}=87)\end{array}$} \\
\hline & Lifetime & Last year & Lifetime & Last year \\
\hline Schizophrenia & 0.9 & 0 & 0 & 0 \\
\hline Mood disorders & 28.3 & 23 & 23 & 14.9 \\
\hline - Major depression & 20.4 & 18.6 & 13.8 & 10.3 \\
\hline - Dysthymia & 18.6 & 14.2 & 12.6 & 5.7 \\
\hline - Bipolar disorder & 0.9 & 0 & 3.4 & 2.3 \\
\hline Anxiety disorders & 30.1 & 26.5 & 28.7 & 21.8 \\
\hline - Panic disorder & 5.3 & 5.3 & 4.6 & 4.6 \\
\hline - Agoraphobia without panic & 2.7 & 1.8 & 4.6 & 2.3 \\
\hline - Simple phobia & 7.1 & 6.2 & 6.9 & 2.3 \\
\hline - Social phobia & 13.3 & 12.4 & 13.8 & 12.6 \\
\hline - Generalized anxiety disorder & 12.4 & 9.7 & 8 & 6.9 \\
\hline - Obsessive compulsive disorder & 1.8 & 1.8 & 2.3 & 2.3 \\
\hline Somatoform disorders & 5.3 & 5.3 & 11.5 & 9.2 \\
\hline - Somatization disorder & 0.9 & 0.9 & 0 & 0 \\
\hline - Somatoform pain disorder & 5.3 & 5.3 & 11.5 & 8 \\
\hline \multicolumn{5}{|l|}{ Psychoactive substance use } \\
\hline disorders & 18.6 & 6.2 & 19.5 & 6.9 \\
\hline - Alcohol abuse & 4.4 & 0.9 & 10.3 & 1.1 \\
\hline - Alcohol dependence & 8 & 1.8 & 6.9 & 2.3 \\
\hline - Drug abuse & 0.9 & 0 & 1.1 & 0 \\
\hline - Drug dependence & 2.7 & 0.9 & 1.1 & 1.1 \\
\hline Eating disorders & 0 & 0 & 0 & 0 \\
\hline - Anorexia nervosa & 0 & 0 & 0 & 0 \\
\hline - Bulimia nervosa & 0 & 0 & 0 & 0 \\
\hline
\end{tabular}


It should be noted that both groups differed in mean age and social situation: TLE patients were older compared with extra-TLE patients $(t(198)=2.904, p<0.01)$ and more extra-TLE patients were receiving a disability or welfare pension $\left(X^{2}=8.018\right.$, $d f=3, p<0.05$ ). Bijl et al. (19) have reported that older patients suffer to a lesser extent from psychiatric disorders, which is in accordance with our data concerning mood, anxiety, and psychoactive substance use disorders. They also presume that unemployment and incapacity are associated with psychiatric disorders. However, correcting for the influence of age and social situation did not result in a significant difference between TLE and extra-TLE patients on any psychiatric disorder.

\section{DISCUSSION}

The results of this study demonstrate that patients with epilepsy admitted to a tertiary epilepsy center suffer in a higher degree from mood and anxiety disorders than the general Dutch population. The last year prevalence of anxiety and mood disorders was 24.9 and $18.7 \%$, respectively, compared to 12.4 and $7.6 \%$, respectively, for the general Dutch population. This increased psychiatric morbidity in patients with epilepsy is in line with previous studies comparing epilepsy patients with normal controls (1-7). However, it is difficult to compare the results found so far, because of methodological differences among the various studies: often small groups of patients are used, either inpatients or outpatients, generally without appropriate control groups. Moreover, psychiatric problems are assessed by means of different questionnaires and inventories, which are often of questionable reliability and validity. Our study tried to compensate for some of these methodological weaknesses: a substantial number of patients suffering from epilepsy were assessed for psychiatric disorders with a reliable and valid structured diagnostic interview. These results were compared with data from the general Dutch population, who were assessed for psychiatric disorders with the same diagnostic instrument.

It should be noted that there are some demographic differences between the epilepsy group and the sample from the Dutch population that could have affected our results; the epilepsy group consisted of more single persons and persons with a lower education and a higher degree of unemployment.

Furthermore, we cannot generalize these findings to the total population of epilepsy patients, because this study is based on inpatients admitted to a tertiary epilepsy center. In making statements about the general epilepsy population, future research should be directed at investigating psychiatric disorders in a representative sample of epilepsy patients originating from (epilepsy) outpatient clinics, general hospitals, as well as inpatient clinics. 
We used the CIDI to assess psychiatric disorders in patients with epilepsy. It should be recognized that the CIDI is not validated for epilepsy patients. However, no validated instruments exist and, moreover, our study was not aimed at investigating epilepsy-specific psychopathology (e.g., postictal psychosis). We used lifetime and last-year periods to assess the prevalence of psychiatric disorders. For future studies it is advisable to use shorter periods (up to 2 weeks), because the outcome will be more accurate.

In contrast to the high prevalence of anxiety and mood disorders, we found only one patient with a lifetime diagnosis of schizophrenia in our patient group. This may be due to the fact that we excluded all patients with an acute psychotic episode from the study. For this reason the prevalence of schizophrenic disorders in this study could not be accurately determined and is possibly somewhat higher.

Patients with TLE showed a higher prevalence of mood disorders and, to a lesser extent, anxiety disorders than those with extra-TLE, especially with respect to lastyear prevalence. These differences, however, were not statistically significant. This could be due to several reasons. First, the association may be too weak to reach statistical significance. Second, the prevalence of psychiatric disorders in the TLE patients is possibly underestimated because of memory impairments of these patients caused by the very nature of their brain disorder (24). Third, and maybe more important, establishment of the diagnoses TLE and extra-TLE is hard to make accurately. Diagnosing patients as TLE or extra-TLE was done retrospectively by several neurologists on the basis of diagnostic data available and not by means of firm and objective diagnostic criteria established beforehand. Also, a broad definition of extra-TLE was used. All patients with seizures originating from locations other than the temporal lobe were assigned to the extra-TLE group. This heterogeneity of the extra-TLE group may have distorted our results.

In future research a more sophisticated design should be used to make the diagnosis TLE and extra-TLE. It would be advisable to define objective criteria to classify partial epilepsy in TLE and extra-TLE. Also EEG diagnoses and anatomical diagnoses should be used in defining TLE and extra-TLE, preferably made by a clinical expert.

\section{Summary}

The results of this study show a higher prevalence of mood and anxiety disorders in patients with epilepsy, compared with the general population. We found indications that the subgroup of TLE patients, in particular, suffer from these disorders. However, we cannot exclude that some methodological shortcomings in our design may have obscured more pronounced differences between the TLE and extra-TLE subgroups. 


\section{ACKNOWLEDGMENTS}

This study was supported by grants from the "Nationaal Epilepsie Fonds/De Macht van het Kleine" (project no 97-02) and the "Teding van Berkhout Fellowship/Christelijke Vereniging voor de Verpleging van Lijders aan Epilepsie", The Netherlands. We would like to thank the neurologists of the observation department of SEIN for their co-operation. Furthermore, we thank Dorothee G.A. Kasteleijn-Nolst Trenité for critical review of the manuscript and Ann Tierlier-Long for manuscript preparation. 


\section{REFERENCES}

1. Pond DA, Bidwell BH. A survey of epilepsy in fourteen general practices: II Social and psychological aspects. Epilepsia 1959/1960;1:285-299.

2. Bear DM, Fedio P. Quantitative analysis of interictal behaviour in temporal lobe epilepsy. Arch Neurol 1977;34:454-467.

3. Kogeorgos J, Fonagy P, Scott DF. Psychiatric symptom patterns of chronic epileptics attending a neurological clinic: a controlled investigation. Br J Psychiatry 1982;140:236-243.

4. Whitman S, Hermann BP, Gordon AC. Psychopathology in epilepsy: How great is the risk? Biol Psychiatry 1984;19(2):213-236.

5. Mendez MF, Cummings JL, Benson DF. Depression in epilepsy. Significance and phenomenology. Arch Neurol 1986;43(8):766-770.

6. Dodril CB, Batzel LW. Interictal behavioral features of patients with epilepsy. Epilepsia 1986;27(Suppl.2):S64-S76.

7. Ettinger $A B$, Weisbrot $D M$, Krupp LB, Jandorf $L$, Gaudino $E$, Cramer J. Symptoms of psychiatric disturbances in epilepsy. J Epilepsy 1998;11(1):10-14.

8. Standage KF, Fenton GW. Psychiatric symptom profiles of patients with epilepsy: a controlled investigation. Psychol Med 1975;5(2):152-160.

9. Schiffer RB, Babigian HM. Behavioral disorders in multiple sclerosis, temporal lobe epilepsy, and amyotrophic lateral sclerosis. An epidemiologic study. Arch Neurol 1984; 41:1067-1069.

10. Wells KB, Golding JM, Burnam MA. Psychiatric disorder in a sample of the general population with and without chronic medical conditions. Am J Psychiatry 1988;145:976-981.

11. Perini Gl, Tosin C, Carraro C, Bernasconi G, Canevini MP, Canger R, Pellegrini A, Testa G. Interictal mood and personality disorders in temporal lobe epilepsy and juvenile myoclonic epilepsy. J Neurol Neurosurg Psychiatry 1996;61:601-605.

12. Gibbs FA, Gibbs EL, Furster B. Psychomotor epilepsy. Arch Neurol Psychiatry 1948;60:331-339.

13. Rodin EA, Katz M, Lennox K. Differences between patients with temporal lobe seizures and those with other forms of epileptic attacks. Epilepsia 1976;17:313-320.

14. Small JG, Small IF, Hayden MP. Further psychiatric investigations of patients with temporal and nontemporal lobe epilepsy. Am J Psychiatry 1966;123:303-310.

15. Mignone RJ, Donnelly EF, Sadowsky D. Psychological and neurological comparisons of psychomotor and non-psychomotor epileptic patients. Epilepsia 1070;11:345-359.

16. Dikmen S, Hermann BP, Wilensky AJ, Rainwater G. Validity of the Minnesota Multiphasic Personality Inventory (MMPI) to psychopathology in patients with epilepsy. J Nerv Ment Dis 1983;171:114122.

17. Whitman S, Hermann BP. Psychopathology in epilepsy: social dimensions. New York: Oxford University Press, 1986.

18. Bijl RV, Zessen G van, Ravelli A, Rijk C de, Langendoen Y. Psychiatric morbidity among adults in the Netherlands: the NEMESIS study. I. Objectives, design and methods. Ned Tijdschr Geneeskd 1997; 141(50):2448-2451.

19. Bijl RV, Zessen G van, Ravelli A. Psychiatric morbidity among adults in the Netherlands: the NEMESIS study. II. Prevalence of psychiatric disorders. Ned Tijdschr Geneeskd 1997;141(50):2453-2460.

20. Smeets RMW, Dingemans PMAJ. Composite International Diagnostic Interview (CIDI), version 1.1. Amsterdam: World Health Organization, 1993.

21. World Health Organization. Composite International Diagnostic Interview (CIDI). Geneva, 1993.

22. American Psychiatric Association (APA). Diagnostic and statistical manual of mental disorders, 3rd rev ed. Washington, 1987.

23. Wittchen HU. Reliability and validity studies of the WHO-Composite International Diagnostic Interview (CIDI): a critical review. J Psychiatr Res 1994;28(1):57-84.

24. Kapur N, Thompson P, Kartsounis LD, Abbott P. Retrograde amnesia: clinical and methodological caveats. Neuropsychologia 1999;37:27-30. 


\section{Personality disorder traits in patients with epilepsy}

WAM Swinkels, IJ Duijsens, Ph Spinhoven

Seizure 2003;12:587-594

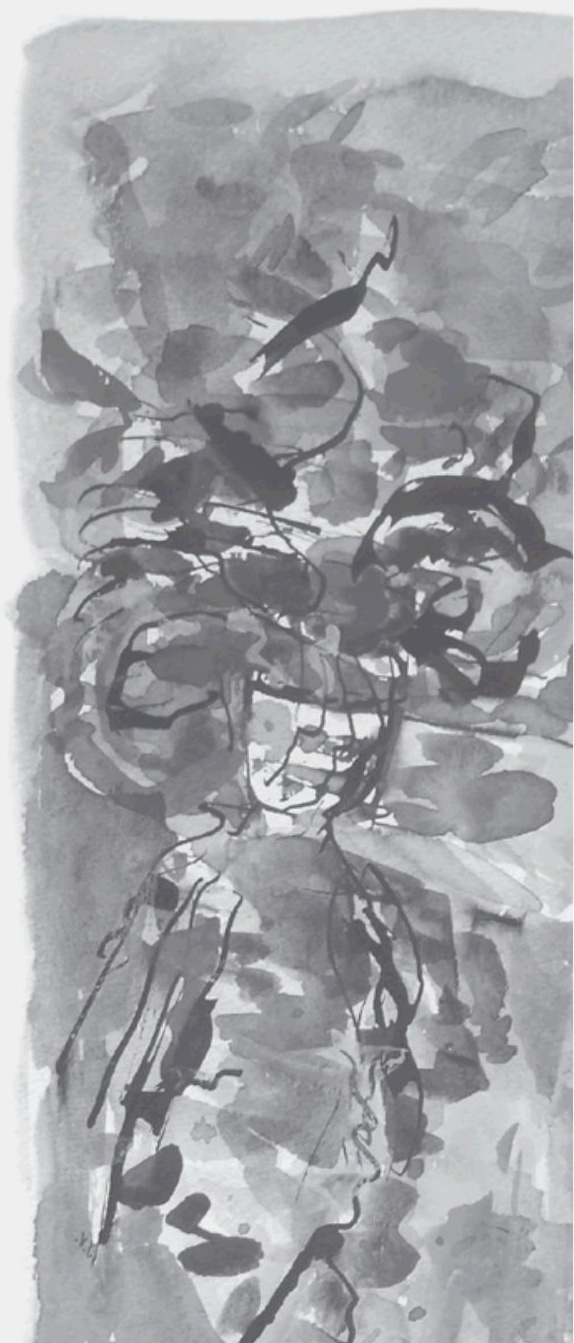




\section{ABSTRACT}

Objective and methods: The Questionnaire on Personality Traits (VKP: Vragenlijst voor Kenmerken van de Persoonlijkheid) was used to investigate personality disorder (PD) traits in 203 patients with epilepsy and a control group of 332 subjects from the general population. Furthermore, the association of PD traits with epilepsy-related variables was studied, as well as the association between PD traits and level of psychopathology.

Results: The results showed that, compared with the control group, patients with epilepsy had higher dimensional VKP scores for several Diagnostic and Statistical Manual of Mental Disorders (DSM-IV) and International Classification of Diseases (ICD-10) PDs. Associations were found between PD traits and age at onset of epilepsy, duration of epilepsy, seizure frequency and number of anti-epileptic drugs. Anxiety and depression were not associated with PD traits.

Conclusion: It is likely that suffering from epileptic seizures negatively influences personality development and can result in the development of maladaptive PD traits. The results also support the idea that PD traits are not (completely) covered by axis I psychopathology and therefore should be separately investigated. 


\section{INTRODUCTION}

The relationship between epilepsy and personality disorders (PDs) is not often the subject of scientific investigation. Much research concentrates on psychiatric disorders, such as psychotic disorders, anxiety disorders and mood disorders, whereas PDs are less frequently studied in epilepsy. Most of the literature concerning psychopathology in epilepsy fails to make the distinction between psychiatric disorders and PDs. According to the Diagnostic and Statistical Manual of Mental Disorders (DSM-IV) ${ }^{1}$ an axis II personality disorder is 'an enduring pattern of inner experience and behaviour that deviates markedly from the expectations of the individual's culture, is pervasive and inflexible, has an onset in adolescence or early adulthood, is stable over time, and leads to distress or impairment'. An axis I psychiatric disorder is an illness appearing any time in life, with its own characteristic features, course and prognosis, which usually can be treated successfully.

When psychopathology and personality in epilepsy is studied, the Minnesota Multiphasic Personality Inventory (MMPI) is frequently used ${ }^{2-5}$. The MMPI has been criticised by several authors as an inappropriate instrument for the detection of interictal behaviour and personality disturbances in epilepsy ${ }^{6,7}$. Bear and Fedio ${ }^{8}$ who noted the shortcomings of the MMPI, developed the Bear-Fedio Inventory (BFI), a rating scale of 18 behavioural traits that previously had been associated in literature with temporal lobe epilepsy (TLE). They found an increased frequency of all 18 traits in patients with TLE, compared with normal and neurological controls, including obsessionality, dependency, emotionality, irritability, religiosity and philosophic interest. Other studies using the BFI showed mixed results, with generally increased behavioural traits in epilepsy patients (both TLE and primarily generalised epilepsy) compared with normal controls ${ }^{9-11}$.

Some investigators use alternative methods like classification by a psychiatrist, to assess psychosis, depressive disorders, anxiety disorders and PDs. In a study by Schwartz and Cummings ${ }^{12}$ the medical records of 21 epilepsy patients and 24 neurological control patients were reviewed. A psychiatrist classified PDs according to DSM-III in eight patients with epilepsy (38\%) and one control patient (4\%). Fiordelli et al. ${ }^{13}$ studied psychiatric disturbances in 100 epilepsy patients and 100 matched control patients. After administration of a psychiatric interview (Clinical Interview Schedule: CIS), 19 epilepsy patients and 15 control patients were identified as having psychiatric disorders. Subsequently, a psychiatrist classified these patients following DSM-III-R criteria. PDs were found in four patients with epilepsy (21\%) and in none of the control patients.

Only few studies exist assessing PDs by means of standardised diagnostic instruments based on objective diagnostic criteria. Lopez-Rodriguez et al. ${ }^{14}$ used the 
Structured Clinical Interview for DSM-III-R personality disorders (SCID-II) for investigating PDs in 52 epilepsy patients. They found PDs in 11 patients (21\%), especially cluster $C$ disorders (15\%). Avoidant and dependent PDs were the most common diagnoses. Also, Victoroff ${ }^{15}$ found axis II PDs in 11 subjects out of 60 epilepsy patients by using the patient version of the SCID. Personality disorder Not Otherwise Specified (NOS) prevailed. Manchanda et al. ${ }^{16}$ investigated both DSM-III-R axis I and II disorders in 300 epilepsy patients who where candidates for epilepsy surgery. They found PDs in $18 \%$ of the patients, especially dependent and avoidant PDs. Also, Arnold and Privitera ${ }^{17}$ found axis II PDs in $18 \%$ of the epilepsy patients using the epilepsy version of the SCID. The most common diagnosis was the avoidant PD, which was present in all patients.

Comparing previous study results of interictal PDs in epilepsy patients is complicated, due to the use of different patient samples. Additionally, patient groups are usually small and frequently no control group is included. Even more important is the use of a variety of diagnostic instruments: many studies use instruments such as the MMPI and BFI which assess personality 'traits' underlying personality psychopathology, and not PDs as defined in widely accepted categorical systems such as the DSM and International Classification of Diseases (ICD).

This study investigates PDs in Dutch patients with epilepsy by means of a selfreport questionnaire assessing PDs according to diagnostic criteria of the DSM-IV and ICD-10. Patients are assessed for each of the PDs but each separate disorder is conceptualised as a continuum. In this way the degree to which a patient exhibits the traits of a particular PD is determined. The results of the epilepsy patients are compared with a control group consisting of people from the general population. Because patients with epilepsy often experience mood and anxiety disturbances ${ }^{18}$, we also investigated their level of general psychopathology. Furthermore, the association of PD traits with epilepsy-related variables was explored. Finally, the relationship between general psychopathology and PD traits was determined in order to investigate whether it is worthwhile to assess PD traits independent of and above assessing the level of psychopathology.

\section{METHODS}

\section{Subjects}

The study population included 203 epilepsy patients and 332 persons from the general population. The epilepsy patients were consecutively admitted to the observation department of the Stichting Epilepsie Instellingen Nederland (SEIN: a tertiary epilepsy centre). A minimum age of 18 years, sufficient knowledge of the 
Dutch language and a definite diagnosis of epileptic seizures (with no concomitant pseudo-epileptic seizures) were the inclusion criteria for this study. Their treating neurologist recruited all patients. The epilepsy patients can be divided into two subgroups: 110 patients suffering from seizures predominantly originating from localisations in the temporal lobes (TLE), and 84 patients with seizures originating from localisations outside the temporal lobes (extra-TLE). The classification of TLE and extra-TLE was made on the bases of all clinical information available (seizure history, clinical observation, EEG, MRI). Nine patients could not be assigned to either subgroup, because it was not clear whether the seizures were of temporal or extratemporal origin. The demographic characteristics of patients with TLE and extra-TLE were not different, except for age. Compared with extra-TLE patients, patients with TLE were significantly older $(t(192)=2,74 ; \mathrm{P}<0.01)$.

The control group consisted of 332 persons. One hundred and forty-three subjects were approached 'door to door' at their home address, and 189 subjects were derived from family members, acquaintances and colleagues of the student researchers ${ }^{19}$.

The characteristics of the epilepsy group and the control group are shown in Table 1. As for general psychopathology, the results of the epilepsy patients were compared with normative data of the general population and a psychiatric outpatient population as described in the Dutch manual of the Symptom Checklist-90 (SCL-90) ${ }^{20}$.

\section{Instruments}

The Questionnaire on Personality Traits (VKP: Vragenlijst voor Kenmerken van de Persoonlijkheid) ${ }^{19}$ was used to investigate PD traits. The VKP is a self-report questionnaire, based on the International Personality Disorder Examination (IPDE) ${ }^{21}$, assessing PDs according to DSM-IV and ICD-10 criteria. It consists of 197 questions scored on a three-point scale (true (2); ? (1); false (0)). There are 12 questions with a fourth answer possibility, namely not applicable (0). The 197 questions can be assigned to seven domains: work, self-image, interpersonal relationship, affects, reality testing, impulse control, and behaviour prior to the age of 15. The VKP assesses 12 PDs according to the DSM-IV and 9 PDs according to the ICD-10 criteria. Intercorrelations between the VKP sub-scales vary from $r=0.03$ to $r=0.57$. The reliability and validity of the VKP proved to be adequate ${ }^{22}$. For each PD a dimensional score and a categorical diagnosis (negative, probable, and positive) are given. The dimensional score is calculated by counting the number of criteria met for each disorder, and thus contains more information than a diagnosis, which is only assigned when a minimum number of criteria have been met. In this study only the dimensional scores for PD traits are used to compare the epilepsy patients with the control group. 
The SCL-90 ${ }^{20,23}$ was used to assess the level of psychopathology. It consists of 90 questions about recent physical and psychological complaints that can be scored on a 5-point scale. The 90 items can be assigned to eight dimensions: anxiety, agoraphobia, depression, somatic complaints, insufficiency, sensitivity, hostility and sleeping problems. On the basis of these eight sub-scale scores, a general psychoneuroticism score is given.

\section{Data analysis}

The t-tests and Chi-square tests were used to investigate differences in demographic characteristics between the epilepsy group and control group.

To investigate differences in PD traits between the epilepsy group and control group, analysis of covariance (ANCOVA) was performed correcting for age, sex and education. ANCOVA is a statistical technique, frequently used in the behavioural sciences and combines regression and ANOVA ${ }^{24}$. A t-test was used to compare the results of the epilepsy patients on the SCL-90 with normative data of the general population and a psychiatric outpatient population as described in the Dutch manual ${ }^{20}$. Also, differences between TLE and extra-TLE patients on the SCL-90 sub-scales were analysed by means of t-tests.

Linear multiple regression analyses (with forced entry) was used to explore the association of VKP PD traits with epilepsy-related variables (age at onset, duration, localisation of the epileptogenic zone, seizure frequency, and number of anti-epileptic drugs).

In order to measure the association between VKP and SCL-90 sub-scales, Pearson's $r$ correlations were calculated. In addition, a linear multiple regression analyses (with stepwise entry) was performed with the SCL-90 sub-scales as independent variables and the VKP PDs as dependent variables.

For statistical analysis SPSS for Windows release 10.0 was used.

\section{RESULTS}

As shown in Table 1, the epilepsy group significantly differed from the control group on the demographic variables age, sex and education: they were significantly older $(P<0.05)$, had a lower level of education $(P<0.001)$ and were predominantly male $(P<0.01)$. Because of these differences in demographic characteristics, a covarianceanalysis was done correcting for age, sex, and education in order to investigate differences on PD traits between both groups. The results of this covariance-analysis are shown in Table 2. Compared with the control group, patients with epilepsy showed significantly higher dimensional scores on seven DSM-IV PDs, namely 
Table 1. Characteristics of the epilepsy group and control group.

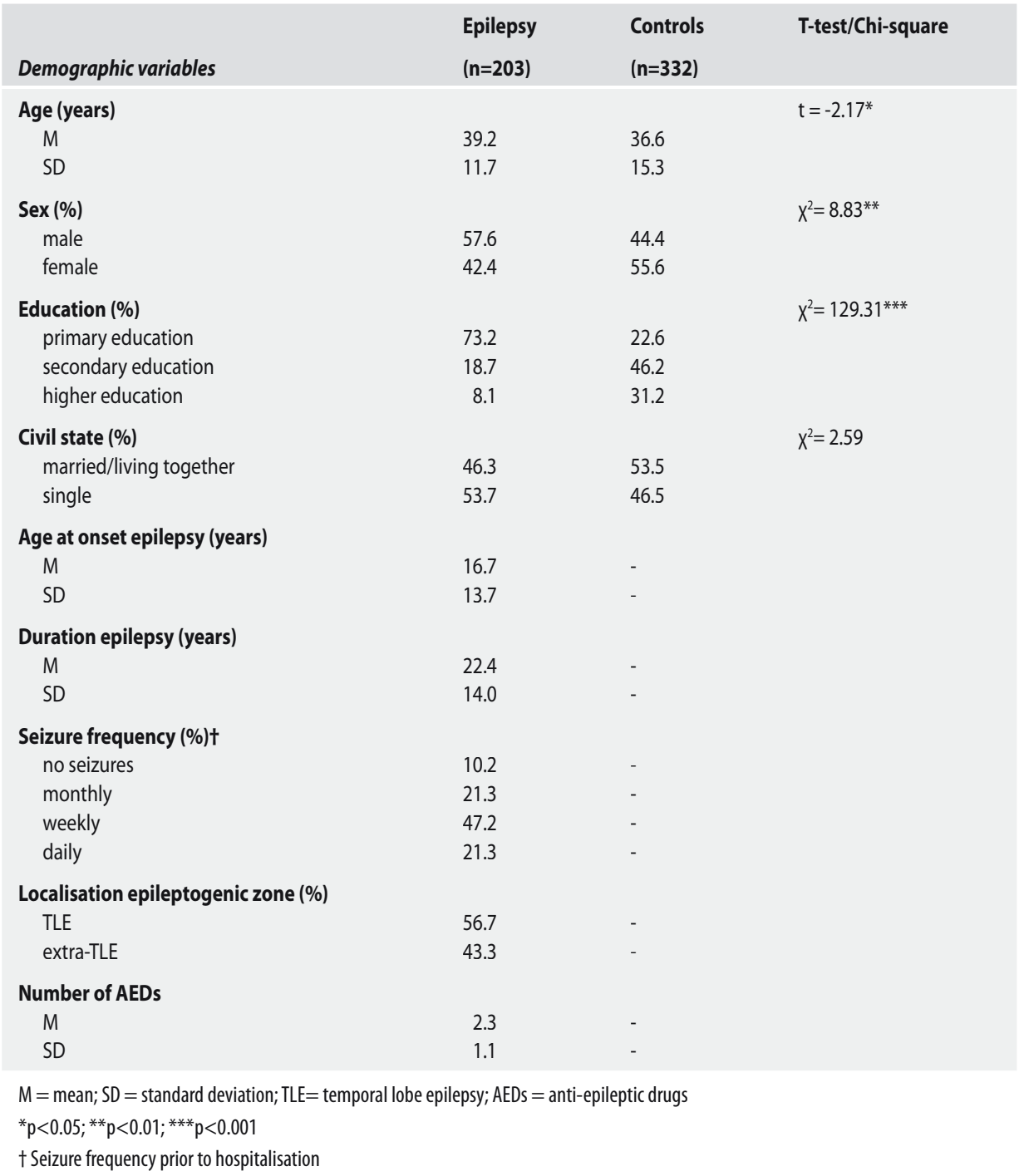

schizoid, antisocial, histrionic, avoidant, dependent, passive aggressive and depressive. Concerning ICD-10 PD traits, they scored significantly higher on the paranoid, schizoid, dyssocial, histrionic, anxious and dependent PD. For both DSM-IV and ICD10 a significantly higher total dimensional score was found in the epilepsy patients. Besides these group-effects, also a certain number of significant age-, sex- and education effects were found.

Compared with normative data of the general population $(n=1009){ }^{20}$, epilepsy patients scored significantly higher on the SCL-90 sub-scales for anxiety $(P<0.001)$, 
Table 2. Covariance analysis (ANCOVA) with group, sex and education as fixed factors, age as covariant and PD traits as dependent variable.

\begin{tabular}{|c|c|c|c|c|c|c|}
\hline \multirow{2}{*}{$\begin{array}{l}\text { PD traits } \\
\text { DSM-IV }\end{array}$} & \multicolumn{2}{|c|}{ corrected means $(\mathbf{s d})^{1}$} & \multicolumn{4}{|c|}{ F-values } \\
\hline & Epilepsy & Controls & group & age & sex & education \\
\hline Paranoid & $1.48(1.70)$ & $1.37(1.49)$ & 0.58 & 1.11 & $7.58^{* *}$ & 1.54 \\
\hline Schizoid & $1.14(1.29)$ & $0.68(1.14)$ & $15.51^{* * *}$ & $30.60^{* * *}$ & $6.60^{*}$ & 2.08 \\
\hline Schizotypical & $1.31(1.60)$ & $1.04(1.40)$ & 3.69 & $8.06^{* *}$ & 0.03 & 1.02 \\
\hline Antisocial & $1.20(2.18)$ & $0.77(1.90)$ & $4.74^{*}$ & $9.38^{* *}$ & $35.73^{* * *}$ & 0.37 \\
\hline Borderline & $1.54(1.77)$ & $1.44(1.54)$ & 0.33 & $7.48^{* *}$ & 1.56 & $3.28^{*}$ \\
\hline Histrionic & $1.29(1.35)$ & $0.76(1.19)$ & $19.13^{* * *}$ & 0.80 & 0.44 & 1.32 \\
\hline Narcissistic & $1.00(1.53)$ & $1.07(1.35)$ & 0.28 & $5.13^{*}$ & $9.54^{* *}$ & 0.65 \\
\hline Avoidant & $1.77(2.08)$ & $1.29(1.81)$ & $6.48^{*}$ & 0.12 & $17.14^{* * *}$ & $4.59^{*}$ \\
\hline Dependent & $1.72(1.74)$ & $0.93(1.53)$ & $25.50^{* * *}$ & 0.59 & $6.39^{*}$ & $5.12^{* *}$ \\
\hline Obsessive-compulsive & $1.84(1.76)$ & $1.71(1.54)$ & 0.65 & $9.35^{* *}$ & 1.22 & 0.82 \\
\hline Passive aggressive & $0.99(1.27)$ & $0.71(1.10)$ & $5.99^{*}$ & 3.51 & 0.02 & 0.65 \\
\hline Depressive & $1.67(1.76)$ & $0.97(1.54)$ & $19.46^{* * *}$ & 0.99 & $13.31^{* * *}$ & 0.28 \\
\hline NOS & $15.76(12.88)$ & $12.73(11.25)$ & $6.88^{* *}$ & 1.61 & 0.50 & 2.90 \\
\hline \multicolumn{7}{|l|}{ ICD-10 } \\
\hline Paranoid & $1.75(1.59)$ & $1.45(1.38)$ & $4.63^{*}$ & $11.35^{* * *}$ & $10.20^{* * *}$ & 2.65 \\
\hline Schizoid & $1.45(1.58)$ & $0.96(1.37)$ & $12.11^{* * *}$ & $19.98^{* * *}$ & $3.97^{*}$ & 0.92 \\
\hline Dyssocial & $0.81(0.98)$ & $0.58(0.85)$ & $6.85^{* *}$ & $6.33^{*}$ & $28.45^{* * *}$ & 0.44 \\
\hline Impulsive type & $1.03(1.31)$ & $1.02(1.15)$ & 0.02 & 3.41 & 3.09 & $6.07^{* *}$ \\
\hline Borderline & $1.90(1.90)$ & $1.72(1.77)$ & 0.99 & $8.44^{* *}$ & $5.50^{*}$ & $5.40^{* *}$ \\
\hline Histrionic & $1.03(1.11)$ & $0.59(0.96)$ & $19.42^{* * *}$ & $7.34^{* *}$ & 3.64 & 0.79 \\
\hline Anankastic & $1.67(1.66)$ & $1.62(1.46)$ & 0.09 & $7.00^{* *}$ & 0.70 & 0.35 \\
\hline Anxious & $1.36(1.58)$ & $0.78(1.37)$ & $17.16^{* * *}$ & 0.03 & $19.52^{* * *}$ & $4.59^{*}$ \\
\hline Dependent & $1.60(1.58)$ & $1.05(1.38)$ & $15.08^{* * *}$ & 0.09 & $18.79^{* * *}$ & $4.91^{* *}$ \\
\hline NOS & $12.73(8.98)$ & $8.75(7.84)$ & $24.36^{* * *}$ & 0.29 & $4.37^{*}$ & $3.87^{*}$ \\
\hline
\end{tabular}

agoraphobia $(P<0.02)$, depression $(P<0.001)$, somatisation $(P<0.02)$, insufficiency $(P<0.001)$ and psychoneuroticism $(P<0.001)$. Within the epilepsy group, patients with TLE scored significantly higher on the SCL-90 sub-scales for insufficiency $(P<0.05)$ and sensitivity $(P<0.05)$, compared with extra-TLE patients.

The results of the linear multiple regression analyses, in which the association of PD traits with epilepsy-related variables was explored, are shown in Table 3. Cluster C PD traits avoidant and obsessive-compulsive were positively associated with 
number of anti-epileptic drugs, duration of epilepsy, seizure frequency (avoidant only) and age at onset (obsessive-compulsive only). Age at onset and duration of epilepsy were also positively associated with the schizoid PD traits. Regarding ICD10 , schizoid and anankastic PD traits were positively associated with age at onset and duration of epilepsy. Impulsive type, borderline and anxious PD traits were positively associated with seizure frequency, whereas anxious was also positively associated with duration of epilepsy and number of anti-epileptic drugs.

Table 3. Multiple Regression (forced entry) with significant regression coefficients (Beta's) and Squared Multiple Correlations ( $R^{2}$ ) with the VKP PD traits as dependent variables and the epilepsy-related variables as independent variables.

\begin{tabular}{|c|c|c|c|c|c|c|}
\hline \multirow[b]{2}{*}{$\begin{array}{l}\text { PD traits } \\
\text { DSM-IV }\end{array}$} & \multicolumn{6}{|c|}{ Epilepsy-related variables } \\
\hline & $\begin{array}{l}\text { Age at onset } \\
\text { epilepsy }\end{array}$ & $\begin{array}{l}\text { Duration } \\
\text { epilepsy }\end{array}$ & $\begin{array}{l}\text { Seizure } \\
\text { frequency }\end{array}$ & $\begin{array}{l}\text { Number } \\
\text { of AEDs }\end{array}$ & $\begin{array}{l}\text { Localisation } \\
\text { epileptogenic } \\
\text { zone }\end{array}$ & $\mathbf{R}^{2}$ \\
\hline \multicolumn{7}{|l|}{ Paranoid } \\
\hline Schizoid & 0.31 & 0.41 & & & & 0.10 \\
\hline \multicolumn{7}{|l|}{ Schizotypical } \\
\hline \multicolumn{7}{|l|}{ Antisocial } \\
\hline \multicolumn{7}{|l|}{ Borderline } \\
\hline \multicolumn{7}{|l|}{ Histrionic } \\
\hline \multicolumn{7}{|l|}{ Narcissistic } \\
\hline Avoidant & & 0.25 & 0.18 & 0.20 & & 0.10 \\
\hline \multicolumn{7}{|l|}{ Dependent } \\
\hline Obsessive-compulsive & 0.21 & 0.24 & & 0.17 & & 0.09 \\
\hline \multicolumn{7}{|l|}{ Passive-aggressive } \\
\hline \multicolumn{7}{|l|}{ Depressive } \\
\hline \multicolumn{7}{|l|}{$I C D-10$} \\
\hline \multicolumn{7}{|l|}{ Paranoid } \\
\hline Schizoid & 0.29 & 0.36 & & & & 0.09 \\
\hline \multicolumn{7}{|l|}{ Dyssocial } \\
\hline Impulsive type & & & 0.18 & & & 0.06 \\
\hline Borderline & & & 0.16 & & & 0.04 \\
\hline \multicolumn{7}{|l|}{ Histrionic } \\
\hline Anankastic & 0.24 & 0.24 & & & & 0.10 \\
\hline Anxious & & 0.24 & 0.20 & 0.19 & & 0.07 \\
\hline Dependent & & & & & & \\
\hline
\end{tabular}


Table 4. Multiple Regression (stepwise) with significant regression coefficients (Beta's) and Squared Multiple Correlations ( $\mathrm{R}^{2}$ ) with the VKP PD traits as dependent variables and the SCL-90 sub-scales as independent variables.

\begin{tabular}{|c|c|c|c|c|c|c|c|c|c|}
\hline & & & & & 90 sub- & les & & & \\
\hline DSM-IV & ANG & AGO & DEP & SOM & IN & SEN & HOS & SLA & $\mathbf{R}^{2}$ \\
\hline Paranoid & & & & & & 0.49 & & & 0.24 \\
\hline Schizoid & & & & & & 0.36 & & & 0.13 \\
\hline Schizotypical & & & & & & 0.57 & & & 0.32 \\
\hline Antisocial & & & & & & & 0.22 & & 0.05 \\
\hline Borderline & & & & & & 0.29 & 0.28 & & 0.25 \\
\hline Histrionic & & & & & & 0.24 & 0.20 & & 0.15 \\
\hline Narcissistic & -0.20 & & & & -0.19 & 0.47 & 0.29 & & 0.24 \\
\hline Avoidant & & 0.14 & 0.25 & & & 0.56 & -0.24 & -0.15 & 0.45 \\
\hline Dependent & & & & & 0.20 & 0.38 & & & 0.28 \\
\hline Obsessive-compulsive & & & & & 0.25 & 0.21 & & & 0.17 \\
\hline Passive-aggressive & & & & & -0.18 & 0.33 & 0.41 & & 0.31 \\
\hline Depressive & & & 0.40 & -0.25 & & 0.32 & & & 0.32 \\
\hline$I C D-10$ & & & & & & & & & \\
\hline Paranoid & & & & & & 0.38 & & & 0.14 \\
\hline Schizoid & & & & & & 0.42 & & & 0.18 \\
\hline Dyssocial & & & & & -0.35 & 0.32 & 0.28 & & 0.15 \\
\hline Impulsive Type & & & 0.30 & & & & 0.37 & & 0.35 \\
\hline Borderline & & & 0.22 & & & 0.26 & 0.22 & & 0.36 \\
\hline Histrionic & & & & & & 0.33 & 0.20 & & 0.22 \\
\hline Anankastic & & & & & 0.32 & 0.23 & & & 0.25 \\
\hline Anxious & & 0.20 & & & & 0.49 & & & 0.38 \\
\hline Dependent & & & & & & 0.45 & & & 0.21 \\
\hline
\end{tabular}

ANG = anxiety; $A G 0=$ agoraphobia; DEP = depression; $S O M=$ somatisation; IN = insufficiency; $S E N=$ sensitivity; HOS = hostility; $S L A=$ sleeping problems; $\mathrm{R}^{2}=$ Squared Multiple Correlation.

For the epilepsy group, we also computed Pearson correlations between the VKP and SCL-90 sub-scales. Significant positive correlations were found between most scales for PD traits and SCL-90 sub-scales. In particular, the SCL-90 sub-scale sensitivity correlated high with most of the VKP sub-scales. Highest correlations were found between avoidant and sensitivity $(r=.62, P<0.001)$, anxious and sensitivity $(r=.59, P<0.001)$ and schizotypical and sensitivity $(r=.57, P<0.001)$. Multiple stepwise regression was carried out with the VKP sub-scales for PD traits as dependent variables and the SCL-90 sub-scales as independent variables (Table 4). Regarding 
DSM-IV PD traits, the avoidant PD is the best represented by the SCL-90 sub-scales $\left(R^{2}=0.45\right)$. For the ICD-10 PD traits, highest $R^{2} s$ were found for the impulsive type $\left(R^{2}=0.35\right)$ borderline $\left(R^{2}=0.36\right)$ and anxious $\left(R^{2}=0.38\right) P D$. Furthermore, the results showed that the SCL-90 sub-scale sensitivity is a strong predictor for all VKP subscales. The sub-scales agoraphobia, anxiety, depression, sleeping problems and somatisation had minimal predictive value.

\section{DISCUSSION}

The relationship between psychopathology and epilepsy has been extensively studied. Patients with epilepsy suffer from a high degree of mood and anxiety disorders ${ }^{18}$. The results of this study show that patients with epilepsy also exhibit more PD traits compared with a control group from the general population. The degree to which a patient exhibits the traits of a PD was determined by conceptualising each PD as a continuum. Most other studies use categorical diagnoses, which are only assigned when a minimum number of criteria have been met. These different approaches limit the comparison of the study results.

In concordance with studies by Lopez-Rodriguez et al. ${ }^{14}$, Manchanda et al. ${ }^{16}$, and Arnold and Privitera ${ }^{17}$, we found higher dimensional scores for the epilepsy patients on the cluster C PDs dependent and avoidant. This corresponds with the clinical impression that patients with epilepsy are frequently seen as unstable, introvert and anxious people, who avoid personal contact for reasons of uncertainty. We also found higher dimensional scores for a number of other PDs that are not previously described in literature. If we compare the results of the epilepsy patients with data of psychiatric patients ${ }^{19}$, the mean dimensional scores for the epilepsy patients are low. On the other hand, when we compare our results with those found in asthma outpatients ${ }^{25}$ (also a chronic medical condition) patients with epilepsy score much higher. These results suggest that the higher scores found in epilepsy patients are not the consequence of a chronic medical condition per se. The significance of this outcome is not quite clear. Probably, a relationship exists between PD traits and epilepsy-related variables.

We studied this hypothesis and we found that a modest part of the variance of several PD traits can be explained by epilepsy-related variables. As was expected, a relationship exists between PD traits and the severity of epilepsy. When patients have more severe epilepsy, they often have a high seizure frequency and they use more anti-epileptic medication. It is likely that in these patients the need for control is usually high (because seizures mean a loss of control). Therefore they are probably more prone to develop a behaviour pattern that corresponds with especially 
cluster C PD traits. Besides, it is well known that epilepsy is a disorder that can have substantial psychological and social consequences for everyday life. Many patients with epilepsy have problems with interpersonal relationships, have low self-esteem, have increased levels of anxiety and depression and are frequently described as persistent and rigid. These characteristics frequently seen in patients with especially severe epilepsy, again correspond with the cluster $C$ traits.

Besides the severity, also a longer duration of epilepsy is supposed to have an influence upon the development of maladaptive personality traits. For some PD traits we found a positive association with both a longer duration and a later age at onset of epilepsy. We expected, however, to find a negative association between the age at onset and the PD traits, because we think that onset of epilepsy in the early phase of personality development will be crucial. The contribution of age at onset of epilepsy in PD traits should be further investigated.

Because previous studies showed a high degree of anxiety and mood disorders in patients with epilepsy, we also investigated the level of general psychopathology. Higher scores were found for patients with epilepsy on several of the SCL-90 sub-scales compared with normative data of the general population, indicating more physical and psychological complaints in patients with epilepsy. This is possibly the result of having epilepsy or the distress of being hospitalised. On the other hand, when we make a comparison with normative data of a group of psychiatric outpatients $(n=2118)^{20}$ the scores for the epilepsy patients were significantly lower on all SCL-90 sub-scales $(P<0.001)$. Within the epilepsy group, we found some differences in the level of general psychopathology depending on the localisation of the epileptogenic zone. Patients with seizures originating from the temporal lobes (TLE) scored higher on the SCL-90 sub-scales for insufficiency and sensitivity than patients with seizures originating from outside the temporal lobes (extra-TLE). We did expect more psychoneurotic complaints in patients with TLE because of the involvement of the temporolimbic system.

Correlations between the SCL-90 sub-scales and VKP PD traits showed high positive correlations between the SCL-90 sub-scale sensitivity and most of the VKP PD traits. Especially the sub-scale sensitivity, and to a lesser extent hostility, appeared to be strong predictors for all VKP PD traits. This can be due to the fact that the sub-scales sensitivity, hostility and insufficiency represent more or less underlying 'traits', whereas the other sub-scales represent more temporary 'states' ${ }^{26}$.

Interestingly, most of the associations of VKP PD traits with the SCL-90 sub-scales for anxiety and depression were not significant. These results suggest that the elevated scores for PD traits in epilepsy patients cannot be attributed to the high prevalence of anxiety and mood disorders as generally found in epilepsy patients. Apparently, scores for PD traits on the VKP were not critically confounded by SCL-90 
scores for anxiety and depression. These results are consistent with the idea that most of the sub-scales of the SCL-90 investigate levels of psychopathology as found in axis I disorders. However, high scores on the sub-scales for sensitivity and hostility may reflect elevated PD traits on axis II and should be further investigated. The constructs of psychopathology and PD traits although interrelated are distinct enough to warrant independent scientific and clinical attention.

\section{Critical remarks and conclusion}

There are some limitations of this study that need to be addressed.

First, all patients were admitted to our epilepsy inpatient clinic at the time of assessment. Presumably, they would have had more severe illness, so we cannot generalise these findings to the total epilepsy population. Therefore, in future studies a more representative sample of epilepsy patients should be used, consisting of patients originating from outpatient clinics, general hospitals, as well as inpatient clinics. Also the control group should be a more representative sample from the general population. The control group in this study consisted of a relatively high proportion of subjects with a higher education.

A second remark concerns the questionnaire we used to screen for PD traits. The VKP is a valid instrument, but does not give accurate diagnoses (it overestimates) of PDs. However, the aim of this study was to compare patients with epilepsy with a control group on the number of traits for each PD and not to determine real PDs. For that, it is recommended to use a questionnaire to screen for the possible presence of PDs. When PDs are present, a standardised interview (such as the IPDE) should be used to further investigate the PDs.

Finally, we did not find any association between the localisation of the epileptogenic zone and PD traits. However, the diagnoses TLE and extra-TLE were made retrospectively by several neurologists on the basis of all diagnostic data available and not by means of firm and objective diagnostic criteria established beforehand. Besides, the extra-TLE group was a mixed group consisting of patients with seizures originating from localisations other than the temporal lobes. Therefore, in future studies the classification of epilepsy should be made more accurately, according to strict criteria, based on EEG and anatomical diagnoses and clinical information. Additionally, only patients with a localisation related epilepsy of temporal or extratemporal origin should be included.

It can be concluded that patients with epilepsy have raised scores for a number of PD traits. It is likely that suffering from epileptic seizures can result in disturbances in the development of personality characteristics. The results of this study also indi- 
cate that a relationship exists between the development of PD traits with the severity and duration of the epilepsy.

From a clinical point of view it is important that we are aware of these personality features, which can occur in addition to Axis I disturbances. However, we must not treat patients with epilepsy as if they are personality disordered. After all, the mean dimensional scores for personality disorder traits range between 0.81 and 1.90 (especially cluster $C$ traits), so we cannot speak of real PDs. Also, compared with psychiatric patients, patients with epilepsy have considerably less PD traits. The personality characteristics in epilepsy patients are generally common manifestations of the chronic epileptic condition, which should be bear in mind when treating these patients.

\section{ACKNOWLEDGEMENTS}

This study was supported by grants from the "Nationaal Epilepsie Fonds/De Macht van het Kleine" (project no 97-02) and the "Teding van Berkhout Fellowship/De Christelijke Vereniging voor de Verpleging van Lijders aan Epilepsie".

We would like to thank the neurologists of the observation department of SEIN for their co-operation. Furthermore, we thank Jarl Kuyk for his critical review of the manuscript and Ann Tierlier-Long for manuscript preparation. 


\section{REFERENCES}

1. American Psychiatric Association, Committee on Nomenclature and Statistics. Diagnostic and Statistical Manual of Mental Disorders, Revised Fourth Edition. Washington, D.C., American Psychiatric Press, 1994.

2. Provinciali, L., Franciolini, B., Del Pesce, M., Signorino, M. and Ceravolo, G. Influence of neurological factors on the personality profile of patients with temporal lobe epilepsy. Journal of Epilepsy 1989; 2: 239-244.

3. Hermann, B.P., Dikmen, S. and Wilensky, A.J. Increased psychopathology associated with multiple seizure types: Fact or artifact? Epilepsia 1982; 23: 587-596.

4. Hermann, H.P., Dikmen, S., Schwartz, M.S. and Karnes, W.E. Interictal psychopathology in patients with ictal fear: A quantitative investigation. Neurology 1982; 32: 7-11.

5. Silberman, E.K., Sussman, N., Skillings, G. and Callanan, M. Aura Phenomena and psychopathology: a pilot investigation. Epilepsia 1994; 35(4): 778-784.

6. Trimble, M.R. Personality disturbances in epilepsy. Neurology 1983; 33: 1332-1334.

7. Perini, G.I., Tosin, C., Carraro, C., et al. Interictal mood and personality disorders in temporal lobe epilepsy and juvenile myoclonic epilepsy. Journal of Neurology, Neurosurgery, and Psychiatry 1996; 61: 601-605.

8. Bear, D.M. and Fedio, P. Quantitative analysis of interictal behavior in temporal lobe epilepsy. Archives of Neurology 1977; 34: 454-467.

9. Brandt, J., Seidman, L.J. and Kohl, D. Personality characteristics of epileptic patients: a controlled study of generalised and temporal lobe cases. Journal of Clinical and Experimental Neuropsychology 1985; 7: 25-38.

10. Rodin, E. and Schmaltz, S. The Bear-Fedio personality inventory and temporal lobe epilepsy. Neurology 1984; 34: 591-596.

11. Sorensen, A.S., Hansen, H., Andersen, R., Hogenhaven, H., Allerup, P. and Bolwig, T.G. Personality characteristics and epilepsy. Acta Psychiatrica Scandinavica 1989; 80: 620-631.

12. Schwartz, J. and Cummings, J.L. Psychopathology and epilepsy: An outpatient consultation-liaison experience. Psychosomatics 1988; 29(3): 295-300.

13. Fiordelli, E., Beghi, E., Bogliun, G. and Crespi, V. Epilepsy and psychiatric disturbance. A Crosssectional study. British Journal of Psychiatry 1993; 173: 446-450.

14. Lopez-Rodriguez, F., Altshuler, L., Kay, J., Delarhim, S., Mendez, M. and Engel, J. Personality disorders among medically refractory epileptic patients. Journal of Neuropsychiatry and Clinical Neuroscience 1999; 11: 464-469.

15. Victoroff, J. DSM-III-R psychiatric diagnoses in candidates for epilepsy surgery: lifetime prevalence. Neuropsychiatry, Neuropsychology, and Behavioral Neurology 1994; 7(2): 87-97.

16. Manchanda, R., Schaefer, B., McLachlan, R.S., et al. Psychiatric disorders in candidates for surgery for epilepsy. Journal of Neurology, Neurosurgery, and Psychiatry 1996; 61: 82-89.

17. Arnold, L.M. and Privitera, M.D. Psychopathology and trauma in epileptic and psychogenic seizure patients. Psychosomatics 1996; 37: 438-443.

18. Swinkels, W.A.M., Kuyk, J., Graaf, E.H. de, Dyck, R. van, and Spinhoven, Ph. Prevalence of psychopathology in Dutch epilepsy inpatients; a comparative study. Epilepsy \& Behavior 2001; 2: 441-447.

19. Duijsens, I.J., Haringsma, R. and Eurelings-Bontekoe, E.H.M. De VKP handleiding, DSM-IV \& ICD-10. Leiderdorp, Datec, 1999.

20. Arrindell, W.A. and Ettema, J.H.M. Handleiding SCL-90. Lisse, Swets \& Zeitlinger, 1986.

21. World Health Organisation. International Personality Disorder Examination (IPDE) DSM-IV module. Dutch adaptation: Duijsens, I.J., Eurelings-Bontekoe, E.H.M. and Diekstra, R.F.W. Leiderdorp, Datec, 1995.

22. Duijsens, I.J. Assessment of personality disorders: construction, reliability and validity of the VKP self-report. Lisse, Swets \& Zeitlinger, 1996.

23. Derogatis, L.R. SCL-90: Administration, scoring and procedures manual-I for the R(evised) version. Baltimore, John Hopkins University School of Medicine, Clinical Psychometrics Research Unit, 1977.

24. Cox, D.R. and McCullagh, P. Some aspects of analysis of covariance. Biometrics 1982; 38: 541-561. 
25. Bauer, H. and Duijsens, I.J. Personality disorders in pulmonary patients. British Journal of Medical Psychology 1998; 71: 165-173.

26. Karterud, S., Friis, S., Irion, R., Mehlum, L., Vaglum, P. and Vaglum, S. A SCL-90-R derived index of the severity of personality disorders. Journal of Personality Disorders 1995; 9(2): 112-123. 
Interictal depression, anxiety, personality traits and psychological dissociation in patients with Temporal Lobe Epilepsy (TLE) and Extra-TLE

WAM Swinkels, W van Emde Boas, J Kuyk, R van Dyck,

Ph Spinhoven

Accepted for publication in Epilepsia

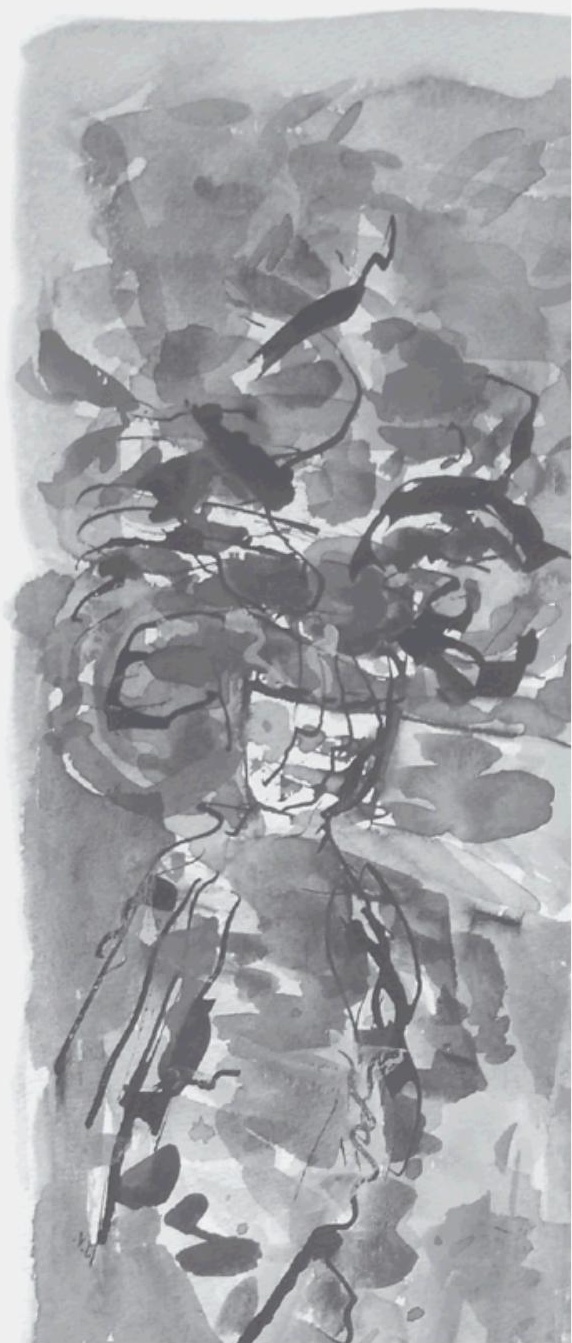




\section{ABSTRACT}

Purpose: This study was performed to investigate the relationship between symptoms of interictal depression, anxiety, personality traits and psychological dissociation with the localization and lateralization of the epileptogenic zone in patients with partial epilepsy.

Methods: All patients were diagnosed according to the localization related concept of the 1989 ILAE Classification of Epilepsies and Epileptic Syndromes, and the localization and lateralization of the epileptogenic zone was established using the clinical criteria for non-invasive presurgical evaluation. This resulted in 67 patients with temporal lobe epilepsy (TLE) and 64 patients with extra-TLE. All patients were assessed on the various aspects of psychopathology using a comprehensive battery of standardized diagnostic instruments.

Results: We found not the hypothesized excess of psychiatric symptoms in patients with (mesial) TLE in comparison with patients with extra-TLE. We also found no differences between patients with the lateralization of epilepsy in the left versus the right hemisphere.

Conclusions: TLE per se cannot be considered as a risk factor in developing more or severer symptoms of psychopathology in patients with partial epilepsy. Concomitant factors, such as the duration of epilepsy, seizure frequency and frontal lobe dysfunction may play an additional role. Our findings support the hypothesis of a multifactorial explanation for the psychiatric symptomatology in patients with epilepsy. 


\section{INTRODUCTION}

Many studies have noted a higher prevalence of psychiatric morbidity in patients with epilepsy compared with normal controls ${ }^{1-9}$. Reviews of the relevant literature suggest that mood and anxiety disorders are the most frequently diagnosed psychiatric disorders in patients with epilepsy ${ }^{10-13}$. Also, an increased prevalence of personality (disorder) traits or disorders is frequently found in these patients ${ }^{14-16}$.

Traditionally, temporal lobe epilepsy (TLE) is considered to present a relatively specific risk factor, notably for affective disorders, because of the major involvement of the limbic system in both seizure generation in TLE and in the regulation of affect and mood. Numerous studies have reported an increased rate of psychiatric disturbances in patients with TLE, compared to patients with other types of epilepsy $1,2,5,14,17-26$. Other studies, however, failed to document such an association between TLE and psychiatric symptoms ${ }^{6,9,27-41}$. The laterality of the seizure focus has also been considered as a potential risk factor for psychiatric illness in epilepsy. Some authors emphasize the role of the right hemisphere ${ }^{42,43}$, which is suggested to have more extensive limbic connections than the left hemisphere, whereas the majority of the studies implicate the left hemisphere ${ }^{5,26,44-48}$, or find no effect of lateralization at all 32,35,37,38,49-54. Although there is support for the association between epilepsy and psychiatric disorders, the empirical evidence for a specific association between the localisation and lateralization of the epileptogenic zone in partial epilepsy and psychiatric morbidity remains equivocal.

Both, methodological and theoretical factors appear to account for these discrepant findings. For psychiatric assessment, a variety of diagnostic instruments is used, ranging from predominantly subjective self-reporting questionnaires to objective and reliable diagnostic tests. Some authors use cut-off scores to classify the subjects, whereas others use mean scores. Psychiatric findings from these studies are thus difficult to compare.

The same can be said for the selection of patients with epilepsy who were investigated, and the control subjects. Several studies fail to define clear diagnostic criteria for epilepsy and/or psychiatric disorders and their selection criteria, and precise definitions of epilepsy subgroups are often unclear or not provided for at all.

Early studies on the prevalence of psychiatric syndromes in epilepsy mostly focussed on patients with 'psychomotor seizures' (e.g. 17,27,29,31,32), then thought to represent exclusively temporal lobe epilepsy. Although these seizures, which now are classified as complex partial seizures ${ }^{55}$, are known to frequently arise from the temporal lobe, they may also originate from extra-temporal areas, notably the frontal lobes. Moreover, seizures which do have their onset in the temporal lobe will often invade extra-temporal structures in the course of the seizure ${ }^{56}$ and several investi- 
gators have suggested that concomitant frontal lobe dysfunction may also play an important role in the association between (left) TLE and psychopathology 45,51,52.

This variability in the pathological anatomy of complex partial seizures seems likely to be in part responsible for the lack of consistent findings across the different studies ${ }^{57}$ and emphasizes the need for more homogeneous patient and control groups. In the studies cited, patient groups were usually limited and control subjects varied. In most studies, subjects with epilepsy were compared to healthy subjects or patients with other varying disorders. Comparison of TLE patients to other subjects with epilepsy was rare. Table 1 and 2 list some of the most commonly cited studies claiming to find an excess of psychiatric comorbidity in TLE patients and those failing to do so. In the Comments column the methodological shortcomings are briefly summarized.

In practice, it is difficult to select truly homogeneous patient groups in partial epilepsy studies because of the multitude of neurobiological, psychosocial and iatrogenic factors involved. Apart from the localization, lateralization and extent of the epileptogenic zone, other variables (e.g. etiology, age at onset/duration of epilepsy, seizure type(s), seizure frequency /severity, anti-epileptic medication) may be of equal importance. Nevertheless, it is usually possible, with the help of careful analysis of the clinical signs and symptoms observed or reported during the seizures, together with state of the art EEG, video and neuroimaging, to classify patients with partial seizures into fairly homogeneous groups, based on the presumed or, in some, documented lobe of seizure onset ${ }^{58}$.

Following the results of previous investigations 9,16,59, this study was designed to assess in more detail the relationship between symptoms of interictal depression, anxiety, personality traits and psychological dissociation with the localization and lateralization of the epileptogenic zone in patients with cryptogenic or symptomatic partial epilepsy. Since earlier studies on the neurobiological factors of depression demonstrated a significant role of tempero-mesial limbic structures in depression 25,60-62, we also wanted to asses whether patients with antero-mesialTLE showed more psychiatric symptoms (especially depression) compared with patients with latero-basal-TLE. To overcome some of the methodological weaknesses of previous investigations, patients were specifically classified into localization-related syndrome subgroups which were then compared with each other. Psychiatric comorbidity was assessed using reliable and valid diagnostic instruments. Finally, other epilepsy-related variables were also evaluated as potential risk factors for psychiatric symptoms and disorders. 


\section{METHODS}

\section{Subjects}

Patients were recruited between October 1999 and May 2002 from the clinical observation wards and from the outpatient departments of the Epilepsy Institute of the Netherlands (SEIN), a specialized epilepsy centre.

In order to participate, adult patients of either sex had to have a firm diagnosis of partial (localization related) epilepsy, unilobar but otherwise independent of etiology, localization or lateralization of the presumed epileptogenic zone. Patients with active Psychogenic Pseudo Epileptic Attacks (PPEA) were excluded. Patients with other types of epilepsy or with equivocal epilepsy classification were also excluded, as were patients with evidence of concomitant progressive or general medical disease.

Patients were recruited by the treating physicians and the study's purpose and content was explained. Patients were also provided with written information and informed consent forms.

Since, hypothetically, patients who were admitted for clinical observation could show different of more severe psychiatric comorbidity than the relatively stable outpatients (many of whom visited the outpatient clinic at 6 or 12 months intervals only), we strove to include equal numbers of inpatients and outpatients. In practice, however, the outpatient group proved to be less motivated for study participation than the inpatients. Only 53 of the 107 (49.5\%) outpatients who received the written information, agreed to participate in the study. Thirty-two patients (29.9\%) refused participation (the most common arguments being: "I am fine now and don't want to be bothered by all this", "I do not want to spend the time necessary for the testing", or "I had all these tests long ago, at the time of my admission, and do not want to have them again") and 22 (20.6\%) failed to respond. In comparison, approximately $80 \%$ of the inpatients agreed to participate.

Over the 32-month period, a total of 153 potential study participants were recruited. Of these, 22 (including 2 outpatients) had to be excluded because of either a change of diagnosis to generalized epilepsy $(n=3)$, observation of PPEAs during admission $(n=4)$, or a final diagnosis of either multilobar or equivocally localized partial epilepsy ( $n=15)$. The final study group thus included 131 subjects; 80 inpatients and 51 outpatients. All patients gave their informed consent and the study was approved by SEIN's Medical Ethics Committee.

An epilepsy diagnosis was formulated for all patients (by WvEB), as if for initial presurgical patient selection, according to the localization related concept of the 1989 ILAE Classification of the Epilepsies and Epilepsy Syndromes ${ }^{58}$. This was based 


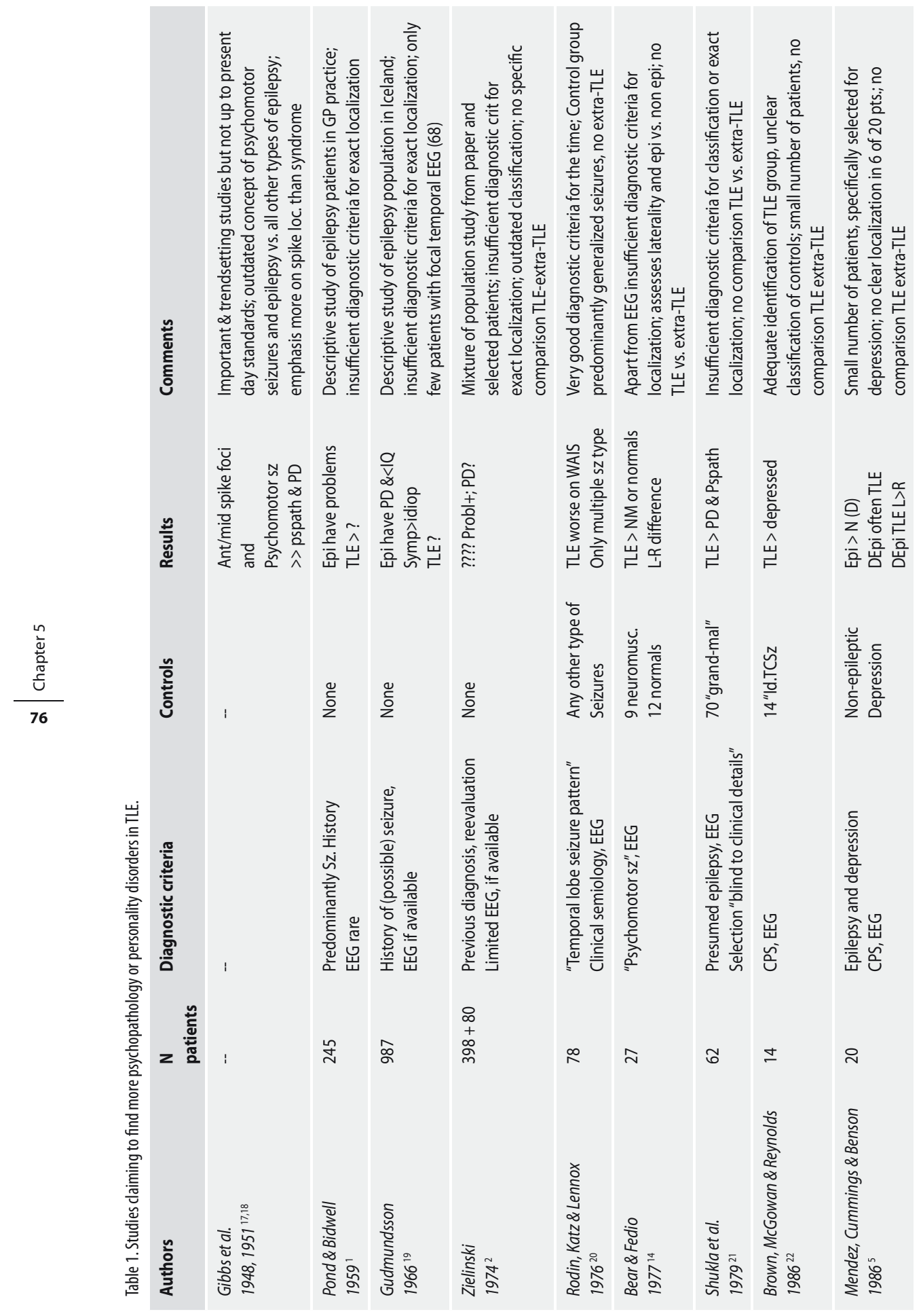




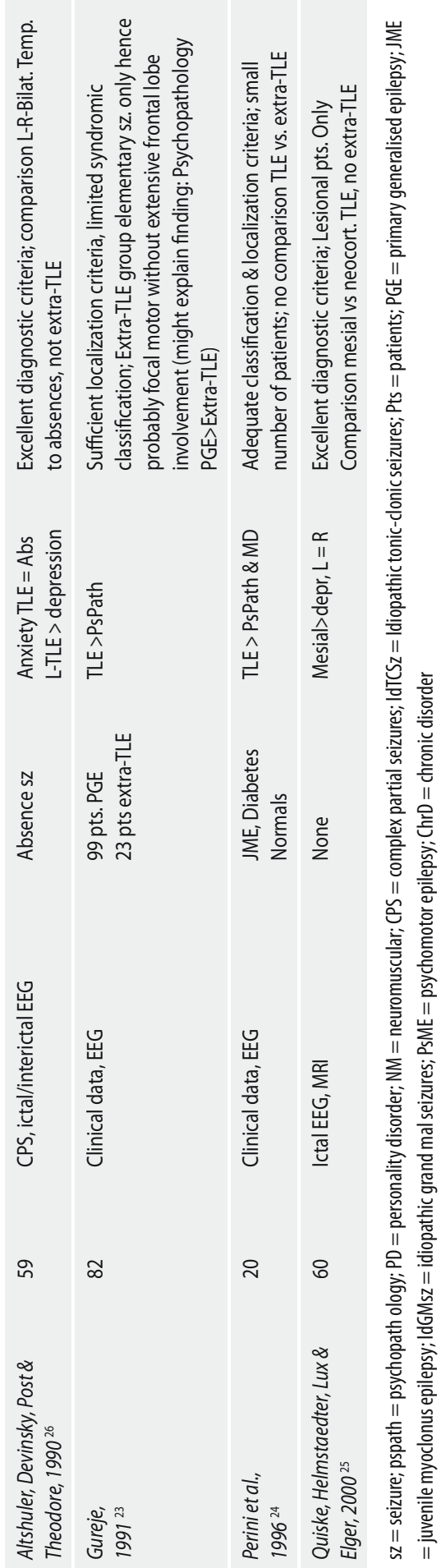




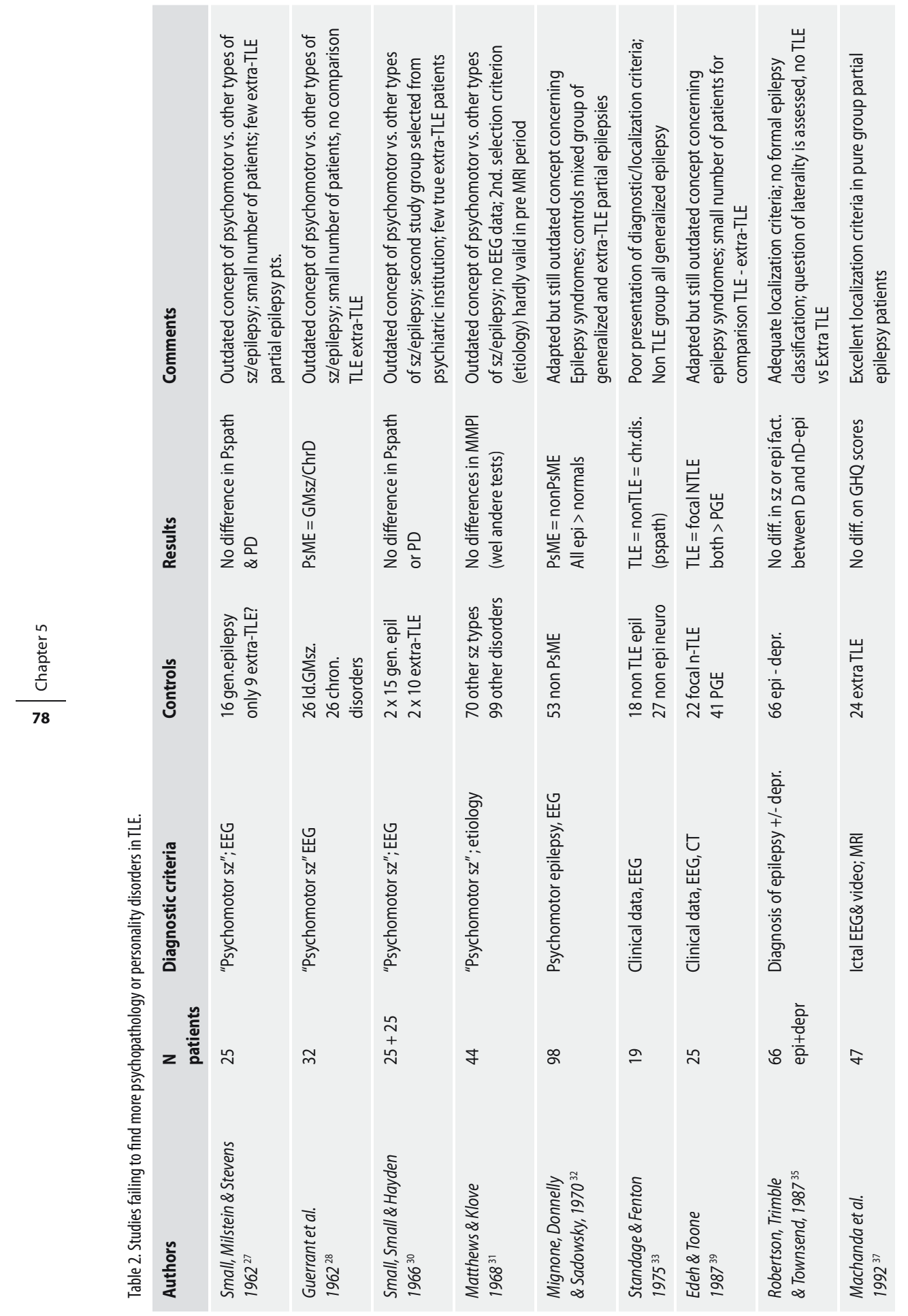




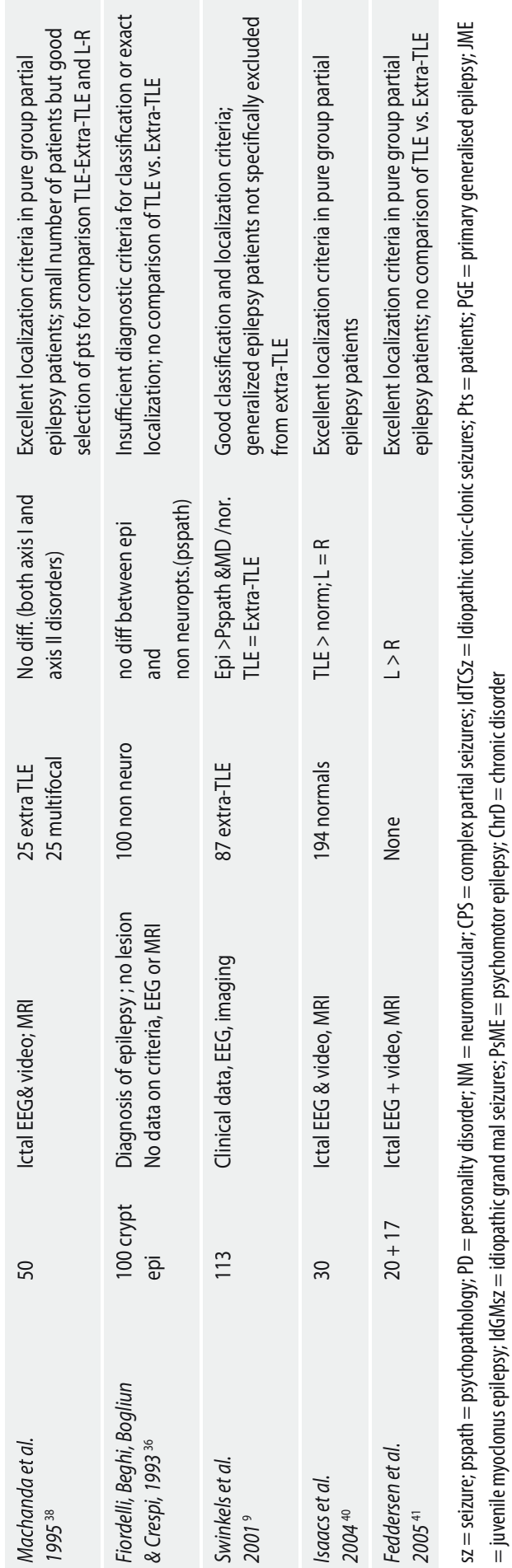


Table 3. Localization and lateralization of the patients.

\begin{tabular}{|c|c|c|c|c|}
\hline Localization & $\begin{array}{ll}\text { Lateralization } & \text { Left } \\
& \text { (n) }\end{array}$ & $\begin{array}{l}\text { Right } \\
\text { (n) }\end{array}$ & $\begin{array}{l}\text { Bilateral } \\
\text { (n) }\end{array}$ & $\begin{array}{l}\text { Total } \\
\text { (n) }\end{array}$ \\
\hline MTLE & 13 & 10 & 3 & 26 \\
\hline LTLE & 17 & 6 & 3 & 26 \\
\hline TLE diffuse & 8 & 4 & 3 & 15 \\
\hline Total & 38 & 20 & 9 & 67 \\
\hline Extra-TLE: Frontal * & 27 & 20 & 9 & 56 \\
\hline Extra-TLE: Parietal & 6 & 1 & 0 & 7 \\
\hline Extra-TLE: Occipital & 1 & 0 & 0 & 1 \\
\hline Total & 34 & 21 & 9 & 64 \\
\hline
\end{tabular}

on all available clinical information (for inpatients reviewed after discharge), neuroimaging (MRI and/or CT available for all patients), and the best available EEG (\& video) data: $E E G / v i d e o$ seizure recordings $(n=67(51.1 \%))$, prolonged $E E G / v i d e o$ records without seizures $(n=10(7.6 \%))$ or multiple awake and sleep recordings $(n=54$ (41.2\%)). Lateralization was categorized as right, left or bilateral when no unequivocal lateralization was possible. For TLE subjects a differentiation was made between antero-mesial TLE and latero-basal TLE, as suggested in the 1989 ILAE Classification ${ }^{58}$. This differentiation was based on clinical, imaging and EEG criteria, as published in the literature ${ }^{63}$, even though more recent studies have shown overlapping electro-clinical features in different TLE seizure types ${ }^{64}$. Localization and lateralization categories of these 131 patients are shown in table 3. The clinical characteristics of the patient groups are listed in table 4.

\section{Instruments}

\section{Depression}

Depressive mood was assessed with the Beck Depression Inventory (BDI), a reliably and widely used self-rating questionnaire. The BDI consists of 21 items, with scores that range from 0 to 3 . A score larger than 12 is considered to indicate a mild form of depressive mood, and a score above 18 is regarded as indicative of clinical depression ${ }^{65,66}$.

DSM-IV Axis I mood disorders were determined by means of the computerised version of the Composite International Diagnostic Interview (CIDI-auto, Dutch version 2.1) ${ }^{67,68}$. It is a valid and reliable structured diagnostic interview for use in 
Table 4. Patient characteristics.

\begin{tabular}{|c|c|c|c|}
\hline Demographic variables & $\begin{array}{l}\text { TLE } \\
(n=67)\end{array}$ & $\begin{array}{l}\text { Extra-TLE } \\
(n=64)\end{array}$ & $\mathbf{P}$ \\
\hline $\begin{array}{c}\text { Sex (\%) } \\
\text { male } \\
\text { female }\end{array}$ & $\begin{array}{l}38.8 \\
61.2\end{array}$ & $\begin{array}{l}64.1 \\
35.9\end{array}$ & $P<0.01$ \\
\hline $\begin{array}{l}\text { Age (yrs) } \\
\text { M } \\
\text { SD }\end{array}$ & $\begin{array}{l}43.5 \\
15.2\end{array}$ & $\begin{array}{l}37.3 \\
11.9\end{array}$ & $P<0.01$ \\
\hline $\begin{array}{l}\text { Education (\%) } \\
\text { primary } \\
\text { secondary } \\
\text { higher }\end{array}$ & $\begin{array}{r}63.6 \\
28.8 \\
7.6\end{array}$ & $\begin{array}{l}45.3 \\
43.8 \\
10.9\end{array}$ & \\
\hline $\begin{array}{l}\text { Civil state (\%) } \\
\text { married/living together } \\
\text { single }\end{array}$ & $\begin{array}{l}50.0 \\
50.0\end{array}$ & $\begin{array}{l}48.4 \\
51.6\end{array}$ & \\
\hline $\begin{array}{l}\text { Age at onset epilepsy (yrs) } \\
\text { M } \\
\text { SD }\end{array}$ & $\begin{array}{l}17.4 \\
12.6\end{array}$ & $\begin{array}{l}18.3 \\
12.8\end{array}$ & \\
\hline $\begin{array}{l}\text { Duration epilepsy (yrs) } \\
\text { M } \\
\text { SD }\end{array}$ & $\begin{array}{l}26.0 \\
17.1\end{array}$ & $\begin{array}{l}19.0 \\
12.2\end{array}$ & $P<0.01$ \\
\hline $\begin{array}{l}\text { Seizure frequency (\%) } \\
\text { no seizures } \\
\text { monthly } \\
\text { weekly } \\
\text { daily }\end{array}$ & $\begin{array}{r}19.6 \\
37.5 \\
39.3 \\
3.6\end{array}$ & $\begin{array}{l}11.3 \\
45.3 \\
11.3 \\
32.1\end{array}$ & $P<0.001$ \\
\hline $\begin{array}{l}\text { Origin patients (\%) } \\
\text { inpatients } \\
\text { outpatient }\end{array}$ & $\begin{array}{l}55.2 \\
44.8\end{array}$ & $\begin{array}{l}67.2 \\
32.8\end{array}$ & \\
\hline $\begin{array}{l}\text { Lesion } \\
\text { yes } \\
\text { no } \\
\text { unclear }\end{array}$ & $\begin{array}{l}59.7 \\
25.4 \\
14.9\end{array}$ & $\begin{array}{l}40.3 \\
46.8 \\
12.9\end{array}$ & $P<0.05$ \\
\hline $\begin{array}{l}\text { AEDs } \\
\qquad \begin{array}{c}\text { M } \\
\text { SD }\end{array}\end{array}$ & $\begin{array}{l}2.27 \\
0.99\end{array}$ & $\begin{array}{l}2.28 \\
1.05\end{array}$ & \\
\hline
\end{tabular}

$M=$ mean; $S D=$ standard deviation $; A E D s=$ anti-epileptic drugs

different settings, cultures and countries. The prevalence of major depression and dysthymia during the last year was determined.

\section{Anxiety}

The Dutch version of the State-Trait Anxiety Inventory (ZBV: Zelf-Beoordelings Vragenlijst) ${ }^{69,70}$ was used to investigate the current anxiety state and anxiety as a personality trait. Both the ZBV state-scale and trait-scale consists of 20 items scored on a 4-point Likert scale from 1 (hardly ever) to 4 (almost always). 
The CIDI was used to determine the prevalence of DSM-IV anxiety disorders during the last year. The following anxiety disorders were assessed: panic disorder, agoraphobia, simple phobia, social phobia, generalised anxiety disorder and obsessive compulsive disorder.

\section{Personality inventories}

DSM-IV axis II personality disorder traits were assessed by the Questionnaire on Personality Traits (VKP: Vragenlijst voor Kenmerken van de Persoonlijkheid) ${ }^{71}$. The VKP is a self-report questionnaire, based on the International Personality Disorder Examination (IPDE) ${ }^{72}$. It consists of 197 questions scored on a 3-point scale (true(2); ?(1); false (0)). There are 12 questions with a fourth answer possibility, namely 'not applicable' (0). For each personality disorder a dimensional score and a categorical diagnosis are given. The dimensional score indicates the number of DSM-IV criteria that are confirmed for each personality disorder, and in this way reflects traits of the personality disorder. The categorical diagnosis contains the negative, probable and positive diagnosis.

The NEO-Five-Factor Inventory ${ }^{73,74}$ was used to assess the five domains of personality, namely, neuroticism, extraversion, openness, agreeableness, and conscientiousness. It contains 60-items on a 5-point scale, ranging from 'strongly agree' to 'strongly disagree'.

\section{General psychopathology}

The Symptom Checklist-90 (SCL-90) ${ }^{75,76}$ was used to assess the general level op psychopathology. It contains 90 questions about recent somatic and psychological complaints that can be scored on a 5-point scale. The 90 items can be assigned to eight dimensions: anxiety, agoraphobia, depression, somatic complaints, insufficiency, sensitivity, hostility and sleeping problems. On the basis of these eight subscale scores, a general psychoneuroticsm score is given.

The Hospital Anxiety and Depression Scale (HADS) ${ }^{77}$ was used to indicate the severity of anxiety and depressive states. The HADS contains two 7-item scales: one for anxiety and one for depression with both a score range of 0-21. A total score is also given. The HADS is considered to be unbiased by coexisting medical condition (because of the exclusion of items referring to symptoms that may have a physical cause).

\section{Psychological dissociation}

The Dissociation Questionnaire (DIS.Q) ${ }^{78}$ is a 63 -item, 5 point, self-reporting questionnaire designed to measure psychological dissociation. Apart from a total score, there are also four sub-scale scores: identity confusion and fragmentation (referring to experiences of derealization and depersonalization), loss of control (overt behav- 
ior, thoughts and emotions), amnesia (referring to memory lacunae), and absorption (referring to experiences of enhanced concentration).

\section{Data analysis}

T-tests and Chi-square tests were used to investigate differences in demographic and epilepsy variables between the different epilepsy subgroups (TLE versus extraTLE, antero-mesial-TLE versus latero-basal-TLE, left versus right, inpatients versus outpatients). Analysis of covariance (ANCOVA) was performed (correcting for age and sex) to investigate differences between the epilepsy subgroups on the psychological tests that yield continuous data and a logistic regression analysis (with forced entry) for the categorical data of the CIDI. To compensate for multiple testing a significance level of $\mathrm{p}<0.01$ was used.

Linear multiple regression (with forced entry) and logistic regression (with forced entry) analyses were used to explore the association of the different psychological measures with epilepsy-related variables (age at onset, duration of epilepsy, number of anti-epileptic drugs and seizure frequency).

\section{RESULTS}

\section{Subjects}

The patients in the TLE group had a higher proportion of females $\left(x^{2}=8.356, \mathrm{df}=\right.$ $1, \mathrm{p}<0.01)$, were older $(\mathrm{t}(129)=2.618, \mathrm{p}<0.01)$, had a longer duration of epilepsy $(t(119)=2.615, p<0.01)$, and had fewer seizures $\left(x^{2}=22.590, d f=3, p<0.001\right)$ compared with the extra-TLE patients. No differences in patient characteristics were found between patients with antero-mesial-TLE and latero-basal-TLE.

The patients with a lateralization of the epilepsy in the left hemisphere were not different from the right hemisphere group on demographic and epilepsy characteristics, except for seizure frequency $\left(x^{2}=9.535, d f=3, p<0.05\right)$ (patients in the left group had less seizures).

Inpatients did differ from outpatients in that they had more seizures $\left(X^{2}=11.066\right.$, $d f=3, p<0.05)$ and they used more anti-epileptic drugs $(t(129)=3.699, p<0.001)$.

\section{Depression}

In table 5, mean depression scores on the BDI and prevalence rates of DSM-IV mood disorders are shown for the TLE and extra-TLE patients.

No differences on depression were found between TLE and extra-TLE patients. Similarly, no differences were found between patients with a lateralization of 
Table 5. Mean depression scores (BDI) and prevalence rates of mood disorders (CIDI) for the TLE and extra-TLE patients.

\begin{tabular}{llll}
\hline Instruments & TLE & Extra-TLE & P \\
BDI & $\mathrm{n}=63$ & $\mathrm{n}=63$ & NS \\
Mean (corrected) total score (SD) & $9.82(8.46)$ & $10.55(8.68)$ & \\
CIDI (last year) (\%) & $\mathrm{n}=66$ & $\mathrm{n}=64$ & NS \\
- Major depression & 21.2 & 21.9 & \\
- Dysthymia & 6.1 & 3.1 & \\
- Mood disorders total & 21.2 & 23.4 &
\end{tabular}

Note: For the BDI: ANCOVA with group and sex as fixed factors, age as covariate; For the CIDI: logistic regression analysis (correcting for sex and age); TLE: Temporal Lobe Epilepsy; SD: Standard deviation; NS: Not significant

the epilepsy in the left and right hemispheres, and antero-mesial-TLE and laterobasal-TLE.

\section{Anxiety}

Anxiety scores on the ZBV and the prevalence of anxiety disorders according to the DSM-IV in patients with TLE and extra-TLE, are shown in table 6.

Table 6. Mean anxiety scores (ZBV) and prevalence rates of anxiety disorders (CIDI) for the TLE and extra-TLE patients.

$\begin{array}{llll}\text { Instruments } & \text { TLE } & \text { Extra-TLE } & \text { P } \\ \text { ZBV (corrected means (SD)) } & \mathrm{n}=67 & \mathrm{n}=62 & \text { NS } \\ \text { - Anxiety state } & 38.48(10.05) & 34.83(10.29) & \\ \text { - Anxiety trait } & 42.60(12.22) & 39.65(12.51) & \\ \text { CIDI (last year) (\%) } & \mathrm{n}=66 & \mathrm{n}=64 & \mathrm{NS} \\ \text { - Panic disorder } & 7.6 & 3.1 & \\ \text { - General anxiety disorder } & 6.1 & 7.8 \\ \text { - Agoraphobia } & 1.5 & 1.6 \\ \text { - Social phobia } & 6.1 & 10.9 \\ \text { - Simple phobia } & 4.5 & 12.7 \\ \text { - Obsessive compulsive disorder } & 0 & 0 & \\ \text { - Anxiety disorders total } & 15.2 & 21.9\end{array}$

Note: For the ZBV: ANCOVA with group and sex as fixed factors, age as covariate; For the CIDI: logistic regression analysis (correcting for sex and age); TLE: Temporal Lobe Epilepsy; SD: Standard deviation; NS: Not significant

No differences on anxiety measures were found between TLE and extra-TLE patients, either between the left and right patient group, or between patients with anteromesial-TLE and latero-basal-TLE.

\section{Personality}

The results of the VKP and the NEO-FFI are displayed in table 7. Again, no differences between the various subgroups (TLE versus extra-TLE, left versus right, antero-mesial-TLE versus latero-basal-TLE) were found on any personality subscale. 
Table 7. Mean scores on the VKP and NEO-FFI for the TLE and extra-TLE patients.

$\begin{array}{llll}\text { Instruments } & \text { TLE } & \text { Extra-TLE } & \text { P } \\ \text { VKP traits (corrected means (SD)) } & \mathrm{n}=62 & \mathrm{n}=61 & \text { NS } \\ \text { - Paranoid } & 1.88(1.69) & 1.75(1.75) & 1.08(1.32) \\ \text { - Schizoid } & 1.40(1.28) & 1.59(1.62) \\ \text { - Schizotypical } & 1.47(1.57) & 1.78(2.09) \\ \text { - Antisocial } & 1.05(2.02) & 1.95(1.87) \\ \text { - Borderline } & 1.71(1.81) & 1.22(1.52) \\ \text { - Histrionic } & 1.36(1.47) & 1.47(1.62) \\ \text { - Narcissistic } & 1.07(1.57) & 1.80(2.07) \\ \text { - Avoidant } & 2.14(2.01) & 1.85(2.12) \\ \text { - Dependent } & 2.03(2.06) & 1.89(1.79) \\ \text { - Obsessive-compulsive } & 2.02(1.74) & 1.24(1.33) \\ \text { - Passive-aggressive } & 1.00(1.28) & 1.47(1.73) \\ \text { - Depressive } & 1.83(1.67) & 17.52(14.11) \\ \text { - Total } & 17.97(13.69) & \mathrm{n}=60 \\ \text { NEO-FFI (corrected means (SD)) } & \mathrm{n}=60 & 32.35(8.95) \\ \text { - Neuroticism } & 35.88(8.74) & 39.77(6.68) \\ \text { - Extraversion } & 37.20(6.52) & 37.40(6.26) \\ \text { - Openness } & 34.55(6.11) & 43.73(5.10) \\ \text { - Agreeableness } & 43.35(4.98) & 44.73(6.55) \\ \text { - Conscientiousness } & 43.60(6.40) & \end{array}$

Note: ANCOVA with group and sex as fixed factors, age as covariate; TLE: Temporal Lobe Epilepsy; SD: Standard deviation; NS: Not significant

\section{General Psychopathology}

In table 8 the results of the SCL-90 and HADS are shown. No differences were found between TLE and extra-TLE, either between left and right hemisphere, or between antero-mesial-TLE and latero-basal-TLE.

Table 8. Mean scores on the SCL-90 and HADS sub-scales for the TLE and extra-TLE patients.

\begin{tabular}{llll}
\hline Instruments & TLE & Extra-TLE & P \\
SCL-90 (corrected means (SD)) & $\mathrm{n}=63$ & $\mathrm{n}=62$ & NS \\
Anxiety & $16.29(6.64)$ & $16.23(6.73)$ & \\
- Agoraphobia & $9.09(3.64)$ & $9.80(3.69)$ & \\
- Depression & $27.18(9.60)$ & $27.07(9.76)$ & \\
- Somatic complaints & $19.26(6.75)$ & $19.12(6.85)$ & \\
- Insufficiency & $17.81(7.21)$ & $17.70(7.32)$ \\
- Sensitivity & $28.06(10.49)$ & $28.42(10.65)$ \\
- Hostility & $8.07(2.87)$ & $8.42(2.91)$ & \\
- Sleeping problems & $5.66(2.75)$ & $5.56(2.80)$ \\
- Psychoneuroticism (total score) & $144.48(42.54)$ & $145.17(43.18)$ & \\
HADS (corrected means (SD)) & $\mathrm{n}=41$ & $\mathrm{n}=51$ \\
- Anxiety & $6.30(4.07)$ & $5.60(4.51)$ \\
- Depression & $4.61(3.60)$ & $4.53(3.98)$ \\
- Total & $10.91(6.76)$ & $10.13(7.48)$
\end{tabular}

Note: ANCOVA with group and sex as fixed factors, age as covariate; TLE: Temporal Lobe Epilepsy; SD: Standard deviation; NS: Not significant 
Table 9. Mean scores on the DIS.Q sub-scales for the TLE and extra-TLE patients.

$\begin{array}{llll}\text { Instruments } & \text { TLE } & \text { Extra-TLE } & \text { P } \\ \text { DIS.Q (corrected means (SD)) } & \mathrm{n}=60 & \mathrm{n}=59 & \text { NS } \\ \text { - Identity confusion / fragmentation } & 1.43(0.49) & 1.48(0.50) & \\ \text { - Loss of control } & 1.72(0.51) & 1.71(0.52) & \\ \text { - Amnesia } & 1.62(0.59) & 1.67(0.60) & \\ \text { - Absorption } & 2.06(0.78) & 2.16(0.80) \\ \text { - Total score } & 1.61(0.47) & 1.65(0.48) & \end{array}$

Note: ANCOVA with group and sex as fixed factors, age as covariant; TLE: Temporal Lobe Epilepsy; SD: Standard deviation; NS: Not significant

Table 10. Multiple Regression (forced entry) with significant regression coefficients (Beta's) and Squared Multiple Correlations ( $R^{2}$ ) with the psychological tests as dependent variables and the epilepsy-related variables as independent variables.

\begin{tabular}{|c|c|c|c|c|c|}
\hline \multirow[b]{2}{*}{ Psychological measures } & \multicolumn{5}{|c|}{ Epilepsy-related variables } \\
\hline & $\begin{array}{l}\text { Age at } \\
\text { onset } \\
\text { epilepsy }\end{array}$ & $\begin{array}{l}\text { Duration } \\
\text { Epilepsy }\end{array}$ & $\begin{array}{l}\text { Seizure } \\
\text { frequency }\end{array}$ & $\begin{array}{l}\text { Number } \\
\text { of AEDs }\end{array}$ & $\mathbf{R}^{2}$ \\
\hline BDI total score & & & 0.23 & & 0.14 \\
\hline ZBV & & & & & \\
\hline - Anxiety state & & -0.28 & & & 0.07 \\
\hline - Anxiety trait & & -0.33 & & & 0.10 \\
\hline VKP & & & & & \\
\hline - Paranoid & -0.31 & -0.25 & & & 0.15 \\
\hline $\begin{array}{ll}\text { - } & \text { Schizoid } \\
\text { - } & \text { Schizotypical }\end{array}$ & & 0.32 & & & 0.12 \\
\hline - Antisocial & -0.26 & -0.24 & 0.21 & & 0.12 \\
\hline - Borderline & & & 0.21 & & 0.09 \\
\hline - Histrionic & & & & 0.24 & 0.12 \\
\hline - Narcissistic & & & & 0.25 & 0.13 \\
\hline $\begin{array}{l}\text { - Avoidant } \\
\text { - Dependent }\end{array}$ & & & & 0.23 & 0.08 \\
\hline$-O C D$ & & & 0.26 & 0.27 & 0.15 \\
\hline $\begin{array}{l}\text { - Passive-aggressive } \\
\text { - Depressive }\end{array}$ & & & 0.20 & & 0.11 \\
\hline NEO & & & & & \\
\hline $\begin{array}{l}\text { - } \text { Neuroticism } \\
\text { - Extraversion } \\
\text { - Openness }\end{array}$ & & -0.33 & & & 0.09 \\
\hline $\begin{array}{l}\text { - Agreeableness } \\
\text { - Conscientiousness }\end{array}$ & & & & -0.28 & 0.11 \\
\hline $\begin{array}{l}\text { SCL-90 } \\
\text { - } \text { Anxiety } \\
\text { - } \text { Agoraphobia }\end{array}$ & & & & & \\
\hline - Depression & & -0.28 & 0.25 & & 0.14 \\
\hline - Somatic complaints & & -0.24 & 0.21 & & 0.11 \\
\hline $\begin{array}{l}\text { - Insufficiency } \\
\text { - Sensitivity }\end{array}$ & & -0.25 & & & 0.07 \\
\hline $\begin{array}{l}\text { - Hostility } \\
\text { - Sleeping problems }\end{array}$ & -0.30 & -0.32 & & & 0.12 \\
\hline - Total score (psychoneuroticism) & & -0.29 & & & 0.11 \\
\hline
\end{tabular}




\section{Psychological dissociation}

The results of the DIS.Q are shown in table 9. Again, no differences between the various subgroups were found.

\section{Inpatients versus outpatients}

For all the psychological inventories, we also compared the results of inpatients with those of outpatients. No differences between these subgroups were found.

\section{Potential risk factors}

No associations were found between the prevalence of mood and anxiety disorders with the epilepsy-related variables 'age at onset', 'duration of epilepsy', 'seizure frequency' and 'number of anti-epileptic drugs'. The results of the linear multiple regression analyses, in which the association of the psychological measures (with continuous data) with epilepsy-related variables was explored, are shown in table 10. Several associations were found, especially with the variables 'duration of epilepsy' and 'seizure frequency'. No associations were found for the HADS and DIS.Q total scores. These findings show no specific preference for an association of these epilepsy-related variables with more state or trait oriented measures of psychopathology.

\section{Summary}

Because of the multitude of data, table 11 provides a summary of the findings.

Table 11. Summary of the study results.

Psychopathology
Depression, anxiety, general
psychopathology, personality,
psychological dissociation
Risk factors

\section{Results}

No differences were found between TLE vs. extra-TLE; antero-mesial-TLE vs. latero-basal-TLE; left vs. right; inpatients vs. outpatients

A higher level of psychiatric disturbances in patients with more seizures and a shorter duration of the seizure disorder

\section{DISCUSSION}

Our study assesses psychiatric comorbidity and personality characteristics in patients with partial epilepsy. The majority of these patients were difficult to treat. Some patients were admitted for presurgical evaluation. However, overall the study population consisted of a broad selection of 'regular' epilepsy patients in an epilepsy centre, not a highly selected subgroup of surgical candidates. Strict criteria were ap- 
plied for the psychiatric diagnosis and a comprehensive psychological assessment was performed in which symptoms of interictal depression, anxiety, personality traits and psychological dissociation were determined. Contrary to many previous studies, however, our patients were diagnosed according to the localization related concept of the 1989 ILAE Classification of Epilepsies and Epileptic Syndromes ${ }^{58}$ and the localization and lateralization of the epileptogenic zone was established for each patient using the clinical criteria for (preliminary) non-invasive presurgical evaluation, including ictal EEG/video monitoring in slightly over $50 \%$ of the cases. For a non-selected epilepsy population this is quite exceptional and since also in other cases the localizing diagnosis was made with a 'surgically oriented' approach, our series compares favourably to many of the previous published studies (tables 1 and 2).

In this relatively large group of clinically distinct and identified patients, the popular hypothesis that patients with TLE will show more psychiatric symptoms, compared to extra-TLE patients, could not be confirmed. Our data also do not show the expected overrepresentation of psychiatric symptoms, notably, depressive symptoms, in epilepsy patients for whom temporo-mesial limbic structures are supposed to be most prominently involved. Of course these findings should be interpreted with caution. While the TLE and extra-TLE groups are reasonably large, the specific TLE patient subgroups were relatively small (26 patients in each TLE subgroup), which makes it difficult to find significant differences (assuming that these differences exist). Moreover the localization related syndrome was established using non-invasive criteria only, which leaves room for uncertainty. Nevertheless, our diagnostic criteria compare favorably to those in most of the studies claiming to find more psychopathology or personality disorders in TLE (table 1), which moreover tend to compare the TLE subjects with other non-epileptic subjects or generalized epilepsy patients with no extra-TLE. In table 2, showing studies failing to find more psychopathology or personality disorders in TLE, a number of studies did indeed compare TLE to extra-TLE partial seizure patients. Many of the more recent studies did use non-invasive or even invasive presurgical localizing criteria comparable to ours. This suggests that our 'negative' findings are indeed relevant and indicate no gross differences between TLE and extra-TLE regarding parameters of psychopathology.

An often cited cause of the supposed excess of psychopathology in TLE, is the claimed excessive involvement of the limbic system in (mesial) TLE. It has been suggested that limbic activation during seizures is associated with interictal psychopathology, because repeated seizure involvement of limbic tissue may lead to kindling-like processes that can alter limbic function interictally ${ }^{79}$. However, only a minority of patients with TLE develops significant psychopathology, and the ex- 
tensive limbic involvement in extra-TLE seizures, notably those originating in the anterior cingular region of the frontal lobe, has by now been well established. This suggests that the supposed change in limbic functioning may not directly cause pathology but rather increase the vulnerability to psychological problems ${ }^{80,81}$.

Our results of the analyses of other potential (epilepsy-related) risk factors, showed that especially the duration of epilepsy and seizure frequency were frequently associated with psychiatric symptoms. In general we found that patients with more seizures and a shorter duration of their seizure disorder showed more psychiatric problems. So it seems that coping and adjusting to a new medical problem is difficult for the patient, especially in the short term and when seizures are poorly controlled.

Another assumption concerns the role of concomitant frontal lobe dysfunction in the association between (left) TLE and psychopathology. Functional imaging techniques have shed some light on the possible link with frontal lobe dysfunction and hypometabolism. Using the PET scan, Bromfield et al. ${ }^{45}$ found more depressive symptoms in patients with left temporal foci and hypometabolism in the inferior frontal lobes bilaterally. Some years later, Schmitz et al. ${ }^{52}$ confirmed these findings with SPECT. Hermann et al. ${ }^{51}$ also hypothesized that there is an association between depression and frontal lobe dysfunction that partly explains the previous conflicting results of depression and left TLE relations. So, variations in the intactness of frontal lobe function may also be considered as a potential (additional) risk factor for interictal psychopathology in epilepsy, and should be studied in the future.

Aside from the negative findings with regard to the localization of the epilepsy syndrome, we found no difference between patients with lateralization of epilepsy in the left versus right hemisphere and between inpatients and outpatients. Notably, the comparable level of psychopathology of both inpatient and outpatients was surprising because more psychiatric problems were expected in the inpatient subgroup related to their more severe epilepsy (i.e. more seizures and more antiepileptic medications). These results, again, support the theory that probably other (non-brain-related) factors are involved in the development of psychiatric symptoms in patients with epilepsy.

As for the total level of psychopathology, we found fairly comparable levels of mood and anxiety disorders as found in a previous study ${ }^{9}$. The prevalence of both mood and anxiety disorders is higher than what is generally found in the general population. The same applies to the personality traits. However, in comparison with our previous investigation ${ }^{16}$, more personality disorder traits were found in these specific subgroups of epilepsy patients.

In summary, epilepsy carries with it an increased risk for developing interictal psychiatric disturbances. It is assumed that the risk is higher for patients with partial 
epilepsy in comparison to patients with idiopathic generalized epilepsy. Besides, the chronicity (i.e. psychosocial impact of epilepsy) of the medical condition seems to be an important factor for this increased risk ${ }^{82}$.

In spite of the quite large patient groups, strict diagnostic criteria applied to present day epilepsy diagnosis, and the wide variety of diagnostic instruments (both rating-scales and objective and standardized diagnostic instruments) that were used for the assessment of depression, anxiety, personality and dissociative symptoms, our findings consistently yielded no evidence for associations between the different parameters of psychopathology and the localization and lateralization of the epilepsy syndromes. This applies for both subjective self reports and the more objective interviews. Nevertheless, one should bear in mind that some of the instruments that were used in this study possibly reflect the same constructs.

Moreover, our findings do not correspond with the cited studies in which more outdated methods of epilepsy classification were used but are more in accordance with studies whereby a more recent and sound methodology of epilepsy classification and localization is used.

It seems therefore that temporal lobe epilepsy per se, cannot be considered as a higher risk condition for developing different psychiatric problems. Concomitant factors, such as duration of the epilepsy, seizure frequency and frontal lobe dysfunction may play an important role. Our findings support the hypothesis of a multifactorial explanation for the psychiatric symptomatology in patients with epilepsy. Despite the growing evidence that several factors may contribute to psychiatric disorders in epilepsy, these factors are frequently not controlled for in studies of epilepsy and psychopathology. Apart from these (brain-related) epilepsy factors, the psychosocial impact of having a chronic epileptic condition (e.g. unemployment, stigmatization) should also not be underestimated and be more integrated in future studies on psychopathology. Continued investigation of these factors therefore is certainly recommended.

\section{ACKNOWLEDGMENTS}

This study was sponsored by 'De Christelijke Vereniging voor de Verpleging van Lijders aan Epilepsie', Heemstede, The Netherlands (Teding van Berkhout Fellowship). We thank A. Tierlier-Long for manuscript preparation. 


\section{REFERENCES}

1. Pond DA, Bidwell BH. A survey of epilepsy in fourteen general practices: II. Social and psychological aspects. Epilepsia 1959/1960;1:285-299.

2. Zielinski JJ. Epidemiology and medical social problems of epilepsy in Warsaw. Warsaw: Warsaw Psychoneurological Institute, 1974.

3. Kogeorgos J, Fonagy P, Scott DF. Psychiatric symptom patterns of chronic epileptics attending a neurological clinic: A controlled investigation. Br J Psychiatry 1982;140:236-243.

4. Whitman S, Hermann BP, Gordon AC. Psychopathology in epilepsy: how great is the risk? Biol Psychiatry 1984;19:213-236.

5. Mendez MF, Cummings JF, Benson DF. Depression in epilepsy: significance and phenomenology. Arch Neurol 1986;43:766-770.

6. Dodrill CB, Batzel LW. Interictal behavioural features of patients with epilepsy. Epilepsia 1986;27(suppl 2):S64-76.

7. Jalava M, Sillanpaa M. Concurrent illnesses in adults with childhood-onset epilepsy: a populationbased 35-year follow-up study. Epilepsia 1996;37:1155-1163.

8. Ettinger AB, Weisbrot DM, Krupp LB, Jandorf L, Gaudino E, Cramer J. Symptoms of psychiatric disturbance in epilepsy. J Epilepsy 1998;11:10-14.

9. Swinkels WAM, Kuyk J, De Graaf EH, Van Dyck R, Spinhoven Ph. Prevalence of psychopathology in Dutch epilepsy patients: A comparative study. Epilepsy \& Behavior 2001;2:441-447.

10. Betts TA. Depression, anxiety and epilepsy. In: Reynolds EH, Trimble MR, eds. Epilepsy and Psychiatry. Edinburgh: Churchill Livingstone, 1981:60-71.

11. Robertson MM, Trimble MR. Depressive illness in patients with epilepsy: a review. Epilepsia 1983;24(suppl 2):S109-116.

12. Hermann BP, and Whitman S. Behavioral and personality correlates of epilepsy: a review, methodological critique, and conceptual model. Psychol Bull 1984;95:451-497.

13. Hermann BP, Seidenberg M, Bell B. Psychiatric comorbidity in chronic epilepsy: Identification, consequences, and treatment of major depression. Epilepsia 2000;41(suppl 2):S31-S41.

14. Bear DM, Fedio P. Quantitative analysis of interictal behavior in temporal lobe epilepsy. Arch of Neurol 1977;34:454-467.

15. Schwartz J, Cummings JL. Psychopathology in epilepsy: An outpatient consultation-liaison experience. Psychosomatics 1988; 29(3):295-300.

16. Swinkels WAM, Duijsens IJ, Spinhoven Ph. Personality disorder traits in patients with epilepsy. Seizure 2003;12:587-594.

17. Gibbs FA, Gibbs EL, Furster B. Psychomotor epilepsy. Arch Neurol Psychiatry 1948;60:331-339.

18. Gibbs FA. Ictal and non-ictal psychiatric disorders in temporal lobe epilepsy. J Nerv Ment Dis $1951 ; 11: 522-528$.

19. Gudmundsson G. Epilepsy in Iceland. Acta Neurol Scand 1966;43(suppl 25):1-124.

20. Rodin EA, Katz M, Lennox K. Differences between patients with temporal lobe seizures and those with other forms of epileptic attacks. Epilepsia 1976;17:313-320.

21. Shukla GD, Srivastava ON, Katiyar BC, Joshi V, Mohan PK. Psychiatric manifestations in temporal lobe epilepsy: a controlled study. Br J Psychiatry 1979;135:411-417.

22. Brown SW, McGowan MEL, Reynolds EH. The influence of seizure type and medication on psychiatric symptoms in epileptic patients. Br J Psychiatry 1986;148:300-304.

23. Gureje O. Interictal psychopathology in epilepsy: Prevalence and pattern in a Nigerian clinic. Brit J Psychiatry 1991;158:700-705.

24. Perini Gl, Tosin C, Carraro C, Bernasconi G, Canevini MP, Canger MP, Pellegrini A, Testa G. Interictal mood and personality disorders in temporal lobe epilepsy and juvenile myoclonic epilepsy. J of Neurol, Neurosurg, and Psychiatry 1996;61:601-605.

25. Quiske A, Helmstaedter C, Lux S, Elger CE. Depression in patients with temporal lobe epilepsy is related to mesial temporal sclerosis. Epilepsy Res 2000;39:121-125.

26. Altshuler LL, Devinsky O, Post RM, Theodore W. Depression, axniety, and temporal lobe epilepsy. Arch Neurol 1990;47:284-288.

27. Small JG, Milstein V, Stevens JR. Are psychomotor epileptics different? A controlled study. Arch Neurol 1962;7:187-194. 
28. Guerrant J, Anderson WW, Fischer A, Weinstein MR, Jaros RM, Deskins A (eds). Personality in epilepsy. Springfield, 111: Charles C Thomas, 1962.

29. Stevens JR. Psychiatric implications of psychomotor epilepsy. Arch Gen Psychiatry 1966;14:461471.

30. Small JG, Small IF, Hayden MP. Further psychiatric investigations of patients with temporal and nontemporal lobe epilepsy. Am J Psychiatry 1966;123:303-310.

31. Matthews CG, Klove H. MMPI performances in major motor, psychomotor and mixed seizure classifications of known and unknown etiology. Epilepsia 1968;9:43-53.

32. Mignone RJ, Donnelly EF, Sadowsky D. Psychological and neurological comparisons of psychomotor and non-psychomotor epileptic patients. Epilepsia 1970;11:345-359.

33. Standage KF, Fenton GW. Psyuchiatric symptom profiles of patients with epilepsy: a controlled investigation. Psychol Med 1975;5:152-160.

34. Dikmen S, Hermann BP, Wilensky AJ, Rainwater G. Validity of the Minnesota Multiphasic Personality Inventory (MMPI) to psychopathology in patients with epilepsy. J Nerv Ment dis 1983;171:114122.

35. Robertson MM, Trimble MR, Townsend HRA. Phenomenology of depression in epilepsy. Epilepsia 1987;28(4):364-372.

36. Fiordelli E, Beghi E, Graziella B, Crespi V. Epilepsy and psychiatric disturbance. Brit J Psychiatry 1993;163:446-450.

37. Manchanda R, Schaefer B, McLachlan RS, Blume WT. Interictal psychiatric morbidity and focus of epilepsy in treatment-refractory patients admitted to an epilepsy unit. Am J Psychiatry 1992;149:1096-1098.

38. Manchanda R, Schaefer B, McLachlan RS, Blume WT. Relationship of site of seizure focus to psychiatric morbidity. J epilepsy 1995;8:23-28.

39. Edeh J, Toone B. Relationship between interictal psychopathology and the type of epilepsy. Brit J Psychiatry 1987;151:95-101.

40. Isaacs KL, Philbeck JW, Barr WB, Devinsky O, Alper K. Obsessive-compulsive symptoms in patients with temporal lobe epilepsy. Epilepsy \& Bahavior 2004;5:569-574.

41. Feddersen B, Herzer R, Hartmann U, Gaab MR, Runge U. On the psychopathology of unilateral temporal lobe epilepsy. Epilepsy \& Behavior 2005;6:43-49.

42. Flor-Henry P. Psychosis and temporal lobe epilepsy. Epilepsia 1969;10:363-395

43. Kohler C, Norstrand JA, Baltuch G, O'Connor MJ, Gur RE, French JA, Sperling MR. Depression in temporal lobe epilepsy before epilepsy surgery. Epilepsia 1999;40(3):336-340.

44. Perini G, Mendius R. Depression and anxiety in complex partial seizures. J Nerv Ment Dis 1984; 172:287-290.

45. Bromfield EB, Altshuler L, Leiderman DB, Balish M, Ketter TA, Devinsky O, Post RM, Theodore $\mathrm{WH}$. Cerebral metabolsim and depression in patients with complex partial seizures. Arch Neurol 1992;49:617-623.

46. Septien L, Giroud M, Didi-Roy R. Depression and partial epilepsy: relevance of laterality of the epileptic focus. Neurol Res 1993;15:136-138.

47. Victoroff Jl, Benson DF, Crafton ST, Engel J, Mazziotta JC. Depression in complex partial seizures. Arch Neurol 1994;51:155-163.

48. Mendez MF, Taylor JL, Doss RC, Salguero P. Depression in secondary epilepsy: relation to lesion laterality. J Neurol Neurosurg Psychiatry 1994;57:232-233.

49. Hermann BP, Wyler AR. Depression, locus of control, and the effects of epilepsy surgery. Epilepsia 1989;30(3):332-338.

50. Naugle RI, Rodgers DA, Stagno SJ, Lalli J. Unilateral temporal lobe epilepsy: An examination of psychopathology and psychosocial behavior. J Epilepsy 1991;4:157-164.

51. Hermann BP, Seidenberg M, Haltiner A, Wyler AR. Mood state in unilateral temporal lobe epilepsy. Biol Psychiatry 1991;30:1205-1218.

52. Schmitz EB, Moriarty J, Costa J DC, Ring HA, Ell PJ, Trimble MR. Psychiatric profiles and patterns of cerebral blood flow in focal epilepsy: interactions between depression, obsessionality, and perfusion related to the laterality of the epilepsy. J Neurol Neurosurg Psychiatry 1997;62:458-463. 
53. Helmstaedter C, Sonntag-Dillender M, Hoppe C, Elger CE. Depressed mood and memory impairment in temporal lobe epilepsy as a function of focus lateralisation and localisation. Epilepsy \& Behavior 2004;5:696-701.

54. Feddersen B, Herzer R, Hartmann U, Gaab MR, Runge U. On the psychopathology of unitemporal lobe epilepsy. Epilepsy \& Behavior 2005;6:43-49.

55. Commission on Classification and Terminology of the International League Against Epilepsy: Proposal for revised clinical and electroencephalographic classification of epileptic seizures. Epilepsia 1981;22:489-501.

56. Wieser H.G. Electroclinical features of the psychomotor seizure. A stereoelectroencephalographic study of ictal symptoms and chronotopographical seizure patterns including clinical effects of intracerebral stimulation. Stuttgart: Gustav Fisher, 1983:1-242.

57. Paradiso S, Hermann BP, Robinson RG. The heterogeneity of Temporal Lobe epilepsy. J of Nerv Ment Dis 1995; 183:538-547.

58. Commission on Classification and Terminology of the International League Against Epilepsy: Proposal for revised classification of epilepsies and epileptic syndromes. Epilepsia 1989;30:389-399.

59. Kuyk J, Spinhoven Ph, Van Emde Boas W, Van Dyck R. Dissociation in temporal lobe epilepsy and pseudo-epileptic seizure patients. J Nerv Ment Dis 1999;187(12):713-720.

60. Drevets WC, Videen TO, Price JL, Preskorn SH, Carmichael ST, Raichle ME. A functional anatomical study of unipolar depression. J Neurosci 1992;12(9):3628-3641.

61. Grasso MG, Pantano P, Ricci M, Pace A, Pandovani A, Orzi F, Pozzilli C, Lenzi GL. Mesial temporal cortex hypoperfusion is associated with depression in subcortical stroke. Stroke 1994;25(5):980985.

62. Sabatini U, Pozzilli C, Pantano P, Koudiavtseva t, Pandovani A, Millefiorini E, Di Biasi C, Gualdi GF, Salvetti M, Lenzi GL. Involvement of the limbic system in multiple sclerosis patients with depressive disorders. Biol Psychiatry 1996;39(11):970-975.

63. Emde Boas W van, Parra Gomez J. Long term non-invasive EEG/Video monitoring in temporal lobe epilepsy. In: Luders HO, Comair Y, eds. Epilepsy surgery, $2^{\text {nd }}$ edition. Philadelphia: Lippincott, Williams \& Wilkins, 2001:413-429.

64. Maillard L, Vignal JP, Gavaret M, Guye M, Biraben A, McGonigal A, Chauvel P, Bartolomei F. Semiologic and electrophysiological correlations in temporal lobe seizure subtypes. Epilepsia 2004;45(12):1590-1599.

65. Beck AT, Rush AJ, Shaw BF, Emery G. Cognitive therapy of depression. New York: Wiley \& Sons, 1979.

66. Bouman TK, Luteijn F, Albersnagel FA, Van der Ploeg FAE. Enige ervaringen met de Beck Depression Inventory (BDI). Gedrag - Tijdschrift voor Psychologie 1985;13:13-24.

67. Composite International Diagnostic Interview (CIDI). Geneva: World Health Organization, 1993.

68. Ter Smitten MH, Smeets RMW, Van den Brink W. Composite International Diagnostic Interview (CIDI), version 2.1. Amsterdam: World Health Organization, 1997.

69. Spiegelberger CD, Gorsuch RL, Lushene RE. Manual for the State-Trait Anxiety Inventory (Selfevaluation questionnaire). Palo Alto, CA: Consulting Psychologists Press, 1970.

70. Van der Ploeg HM, Defares PB, Spielberger CD. Handleiding bij de Zelf Beoordelings Vragenlijst, ZBV. Lisse: Swets \& Zeitlinger, 1980.

71. Duijsens IJ, Haringsma R, Eurelings-Bontekoe EHM. De VKP handleiding, DSM-IV \& ICD-10. Leiderdorp: Datec, 1999.

72. World Health Organisation. In: International Personality Disorder Examination (IPDE) DSM-IV Module: Dutch adaptation (Eds. Duijsens IJ, Eurelings-Bontekoe EHM, Diekstra RFW). Leiderdorp: Datec, 1995.

73. Costa PT, McCrae RR. Revised NEO Personality Inventory (NEO-PI-R) and the Five Factor Inventory (NEO-FFI): Professional manual, Odessa, Florida: Psychological Assessment Resources Inc.

74. Hoekstra HA, Ormel J, De Fruyt F. NEO PI-R and NEO-FFI. Big Five Persoonlijkheidsvragenlijsten. Handleiding. Lisse: Swets \& Zeitlinger, 1996.

75. Derogatis LR. SCL-90: Administration, scoring and procedures manual-I for the Revised Version. Baltimore: John Hopkins University School of Medicine, clinical psychometrics research unit, 1977.

76. Arrindell WA, Ettema JHM. Handleiding SCL-90. Lisse: Swets \& Zeitlinger, 1986. 
77. Spinhoven Ph, Ormel J, Sloekers PPA, Kempen GIJM, Specksens AEM, Van Hemert AM. A validation study of the Hospital Anxiety and Depression Scales (HADS) in different groups of Dutch subjects. Psychol Med 1997;27:363-370.

78. Vanderlinden J, Van Dyck R, Vandereycken W, Verkes RJ. The Dissociation Questionnaire: Development and characteristics of a new self-reporting questionnaire. Clin Psychol Psychother 1993;1:21-27.

79. Robertson M. Mood disorders associated in epilepsy. In: Psychiatric comorbidity in epilepsy. Eds. McConnell HW \& Snyder PJ. American Psychiatric Press, UK: London, 1998.

80. Ring HA, Way R. Depression in epilepsy: biological links. Biol Psychiatry 1991;2:215-218.

81. Adamec RE. Does kindling model anything clinically relevant? Biol Psychiatry 1990;27:249-279.

82. Swinkels WAM, Kuyk J, Van Dyck R, Spinhoven Ph. Psychiatric comorbidity in epilepsy. Epilepsy \& Bahavior 2005;7:37-50. 


\section{Psychometric properties of the Dutch version of the Washington Psychosocial Seizure Inventory}

WAM Swinkels, J Kuyk, R van Dyck, Ph Spinhoven

Epilepsia 2004;45(7):844-848 


\section{ABSTRACT}

Purpose: The psychometric properties of the Dutch version of the Washington Psychosocial Seizure Inventory (WPSI) were investigated.

Methods: The dimensional structure, reliability, and validity of the WPSI scales were assessed in 218 patients with epilepsy. The association with relevant patient and epilepsy characteristics also was studied.

Results: An exploratory seven-factor principal components analysis was compared with a confirmatory factor analysis, and a loss of $3.36 \%$ of total variance was found. To increase the homogeneity of the scales, 30 items with low factor loadings or highest factor loading on the wrong clinical scale were excluded. This resulted in a higher amount of explained variance and improvement of the factor loadings of the remaining items. The reliability and validity of the WPSI scales was satisfactory to good. No clinically relevant associations were found between the WPSI scales and patient and epilepsy characteristics.

Conclusions: The factor structure, reliability, and validity of the Dutch translation of the WPSI are good and comparable to the original English version of Dodrill. The results demonstrate that shortening the WPSI makes the inventory more reliable and the clinical scales less dependent on each other. 


\section{INTRODUCTION}

Epilepsy is a condition frequently accompanied by psychosocial problems and a reduced quality of life ${ }^{1-9}$. Objective methods to assess psychosocial problems in epilepsy are, however, sparse. Roughly, two approaches can be identified, procedures based on personal "ratings" made by professionals, family, or the patients themselves, and tests or inventories. The majority of personal rating methods used to assess psychosocial problems in epilepsy patients are rather informal, time-consuming, not comparable, and hardly objective. Inventories frequently have the disadvantage that they are not explicitly designed for investigating psychosocial problems in patients with epilepsy ${ }^{10}$. In this way, the Minnesota Multiphasic Personality Inventory (MMPI) ${ }^{11}$ was often used to study psychosocial functioning in epilepsy patients. However, the MMPI really evaluates not psychosocial functioning but rather emotional or psychiatric adjustment. Dodrill et al. ${ }^{12}$ introduced the Washington Psychosocial Seizure Inventory (WPSI) ${ }^{12}$, an instrument specifically developed for patients with epilepsy. The WPSI evaluates different areas of psychological and social functioning, which are frequently described as affected in these patients.

The WPSI was developed in two steps. First, a group of behavioral scientists familiar with psychological and social problems in epilepsy identified relevant areas of psychosocial functioning. Second, items were developed covering the different psychosocial areas. The assignment of each item to one of the scales was done on empirical grounds ${ }^{10,12}$. In addition to the clinical scales, validity scales were developed to detect unreliable response tendencies. In the end, an inventory was accomplished with standardized findings that approximate those that would be obtained by a detailed professional evaluation.

Since its introduction in 1980, the WPSI has been frequently used in epilepsy studies. We searched in the computerized database MEDLINE with the keyword "WPSI" and found 39 articles on this subject. The original WPSI has been translated in several countries, and their results are published in international studies ${ }^{13-15}$. Recently, we also investigated the level of psychosocial functioning in two Dutch patient groups and compared the results with those found in other countries ${ }^{16}$.

We studied the reliability and validity of the WPSI. For this purpose, we assessed the dimensional structure and internal consistency of the WPSI scales, and the association between the WPSI scales and the demographic and epilepsy-related variables. Finally, the (concurrent) validity was determined by investigating the relation between overall psychosocial functioning and general psychopathology. 


\section{METHODS}

\section{Subjects}

One hundred inpatients and 166 outpatients from the Stichting Epilepsie Instellingen Nederland (SEIN: a tertiary epilepsy center) participated in this study. Of the total number of 266 subjects, 144 were participants in a larger study about psychiatric comorbidity in epilepsy. As part of the comorbidity study, they filled in the WPSI. The remaining 122 subjects were approached by mail. This was achieved by sending the questionnaire to a total number of 295 patients derived from five epilepsy outpatient clinics. One hundred and twenty-nine patients (44\%) returned the WPSI, of whom seven were excluded because of inaccuracies in responding. Statistical analysis was performed with 218 subjects who completed the WPSI with no missing items. The Medical Ethics Committee approved this study, and all patients gave their informed consent.

\section{Instruments}

The WPSI ${ }^{12}$ is an inventory measuring psychosocial functioning in adults with epilepsy. It contains 132 items pertaining to different areas of psychosocial functioning, to which subjects must respond with yes or no. The results are represented on seven clinical scales, Family Background (problems in upbringing, familial interrelationships), Emotional Adjustment (general emotional concerns), Interpersonal Adjustment (the ability to relate effectively to others), Vocational Adjustment (adjustment on the area of work or employment), Financial Status (financial problems or worries), Adjustment to seizures (response to the seizures, including feelings of embarrassment, acceptance, etc.) and Medicine and Medical Management (view of the medical treatment for seizures). A total scale (Overall Psychosocial Functioning) consists of a subset of items from the seven clinical scales. In addition, three validity scales determine the accuracy of the responses [i.e., Blanks (number of items left blank), Lie (tendencies to make one's self look better) and Rare (sensitive to random responding) scale]. A native speaker of the English language translated the original English version of the WPSI into Dutch. A committee consisting of psychologists and neurologists retranslated the Dutch version into English. Then, the different translations were discussed, and final consensus was reached.

For validity purposes, in a subgroup of patients, the Symptom Checklist (SCL-90; $\mathrm{n}=139){ }^{17,18}$ was administered to assess the level of psychological distress. The SCL90 consists of 90 questions about recent physical and psychological complaints that can be scored on a 5-point scale. For the statistical analysis, only the total score (general psychoneuroticism) was used. 


\section{Data analysis}

Factor analysis was executed by an exploratory principal components analysis (PCA) on the correlation matrix of the 110 WPSI items corresponding to the seven clinical scales, with orthogonal rotation by using the Varimax procedure. The number of constituting factors was determined on the basis of the scree test ${ }^{19}$. The percentage of explained variance was compared with the amount of variance accounted for by the seven dimensions of Dodrill et al. ${ }^{12}$ by means of a Multiple Group Method Analysis (MGM) ${ }^{20}$ [i.e., a matrix with binary elements only, such that each scale has a weight of one on the component of whose group it is supposed to be a member (e.g., Family Background), and zero on the other six groups]. The appropriateness of the factor solution was determined by (a) the amount of total variance accounted for by the a priori matrix in comparison to the amount of variance accounted for by exploratory factor PCA; (b) a substantial factor loading $(\geq 0.45)$ on the appropriate component, and (c) the size of the correlations between the components. To assess homogeneity, interitem correlations, item-remainder correlations, and the internal consistency (Cronbachs a) was computed for the WPSI scales. Paired $t$ tests were used to investigate differences in mean item scores. Pearson $r$ correlation coefficients were used to analyze the interrelation between overall psychosocial functioning (WPSI total score) and SCL-90 psychoneuroticism, and the relation between WPSI scales and demographic and epilepsy-related characteristics, if appropriate. For statistical analysis, SPSS for Windows release 11.0 was used.

\section{RESULTS}

The outcomes of the statistical analyses of the WPSI are based on 218 subjects who completed the inventory with no missing items. The characteristics of these patients are summarized in Table 1. Factor analysis was performed on the 110 items corresponding to the seven clinical scales. The total scale was not included in the statistical analysis because it consists of a subset of items from the other scales. The scree test on the 110 items showed a one-factor solution that accounted for $16.88 \%$ of the total variance. An exploratory seven-factor PCA accounted for $35.12 \%$ of the total variance. Multiple group method analyses revealed that the a priori matrix with seven components accounted for $31.76 \%$ of the total variance, which is a loss of $3.36 \%$.

Subsequently, 30 items were removed because of low factor loadings $(<0.45)$ and/or highest loadings on the wrong clinical scale. The component loadings of the remainder of 80 items ranged between 0.45 and 0.82 . Again, the scree test suggested a one-factor model that accounted for $19.68 \%$ of the total variance. The 
Table 1. Patient characteristics $(n=218)$.

\begin{tabular}{lc} 
Patient characteristics & \\
\hline Sex & \\
$\quad \%$ males & 48.4 \\
$\quad \%$ females & 51.6 \\
Mean age (yr) & 40.54 \\
Sd & 12.64 \\
range & $18-72$ \\
Education (\%) & \\
$\quad$ primary education & 7.7 \\
$\quad$ secondary education & 74.2 \\
Migher education & 18.0 \\
$\quad$ marrital status (\%) & \\
$\quad$ single & 46.6 \\
Mean number of AEDs & 53.4 \\
Sd & 2.11 \\
Mean age at onset seizures (yr) & 1.08 \\
Sd & 17.18 \\
Mean duration epilepsy (yr) & 11.62 \\
Sd & 23.27 \\
AEDs antiepler & 14.58
\end{tabular}

AEDs = antiepileptic drugs; $S d=$ standard deviation

Table 2. Pearson correlations ( $r$ ) between the WPSI scales (110-item version / 80-item version).

\begin{tabular}{llllllll} 
Scale & FB & EA & IA & V & F & AS & MMM \\
FB & 1.00 & & & & & & \\
EA & $.48 / .43$ & 1.00 & & & & & \\
IA & $.48 / .44$ & $.77 / .73$ & 1.00 & & & & \\
V & $.29 / .28$ & $.48 / .40$ & $.51 / .44$ & 1.00 & & & \\
F & $.15 / .16$ & $.45 / .46$ & $.38 / .36$ & $.35 / .31$ & 1.00 & & \\
AS & $.38 / .36$ & $.62 / .60$ & $.61 / .56$ & $.44 / .43$ & $.32 / .29$ & 1.00 & \\
MMM & $.27 / .16$ & $.49 / .23$ & $.40 / .22$ & $.30 / .18$ & $.29 / .09$ & $.46 / .30$ & 1.00 \\
\hline
\end{tabular}

WPSI, Washington Psychosocial Seizure Inventory.

$\mathrm{FB}=$ Family Background; $\mathrm{EA}=$ Emotional Adjustment; $\mathrm{IA}=$ Interpersonal Adjustment; $\mathrm{V}=$ Vocational Adjustment; $\mathrm{F}=$ Financial Status; $\mathrm{AS}=$ Adjustment to Seizures; MMM= Medicine and Medical Management.

seven-factor PCA accounted for $41.59 \%$, and the a priori matrix solution accounted for $39.50 \%$ of total variance (which is a loss of only $2.09 \%$ ). The relatively small loss of total variance accounted for by using the original seven components suggests that the seven-factor structure of the WPSI of Dodrill et al. ${ }^{12}$ adequately accounts for the factor structure of the Dutch version of the WPSI.

Pearson correlations between the components ranged from 0.15 to 0.77 for the 110 -item version and 0.09 to 0.73 for the 80 -item version (Table 2). The correlations 
Table 3. Reliability for the clinical scales of the WPSI (110-item version / 80-item version).

$\begin{array}{lccc}\text { WPSI Scales } & \text { Mean }_{\text {rii }} & \text { Range } \mathbf{r}_{\text {ir }} & \mathbf{a} \\ \text { Family Background (11/10 items) } & .27 / .29 & .25-.64 / .30-.66 & .80 / .81 \\ \text { Emotional Adjustment (34/22 items) } & .19 / .28 & .08-.65 / .39-.65 & .88 / .89 \\ \text { Interpersonal Adjustment (22/16 items) } & .21 / .27 & .12-.65 / .37-.67 & .85 / .86 \\ \text { Vocational Adjustment (13/8 items) } & .16 / .31 & .12-.58 / .27-.63 & .71 / .78 \\ \text { Financial Status (7/7 items) } & .40 / .40 & .28-.74 / .28-.74 & .81 / .81 \\ \text { Adjustment to Seizures (15/12 items) } & .23 / .29 & .15-.56 / .37-.58 & .81 / .82 \\ \text { Medicine Medical Management (8/5 items) } & .15 / .32 & .13-.45 / .19-.54 & .57 / .67 \\ \text { WPSI= Washington Psychosocial Seizure Inventory; } r_{i i}=\text { mean inter-item correlation; } r_{\text {ir }}=\text { item-remainder correlation; } a=\text { Cronbach's } \\ \text { coefficient alpha. }\end{array}$

found indicate that not all scales measure independent constructs. Especially the scales Emotional Adjustment, Interpersonal Adjustment and Adjustment to Seizures have much in common. Comparing the 110-item version with the 80 -item version, the scales of the 80 -item version are slightly more independent of each other. Notably, the correlations with the Medicine and Medical Management scale decreased considerably when the items with lowest component loadings were excluded, making this scale more independent of the other clinical scales.

Homogeneity of the seven WPSI scales was determined by calculating mean interitem correlations, item-remainder correlations, and Cronbach's coefficient $a$ for both the 110-item and 80-item versions of the WPSI. As can be seen from Table 3, mean interitem correlations of the seven scales lie between 0.15 and 0.40 for the 110-item version and 0.27 and 0.40 for the 80 -item version. The correlations lie inside the range of 0.10 to 0.50 for an acceptable level of homogeneity ${ }^{20}$. The item-remainder correlations ranged between 0.08 and 0.74 for the 110 -item version and 0.19 and 0.74 for the 80 -item version, which is also satisfactory. Furthermore, the Cronbach's $a$ ranged between 0.57 and 0.88 for the 110-item version and 0.67 and 0.89 for the 80 -item version, which is satisfactory to good ${ }^{19}$.

Mean item scores and standard deviations for the clinical scales of the 110-item version and 80 -item version are shown in Table 4. Paired $t$ tests showed significant differences between the mean item scores of the 110-item and 80-item version, for the Family Background scale $[\mathrm{t}(217)=5.036 ; \mathrm{P}<0.001]$ and Emotional Adjustment scale $[\mathrm{t}(217)=7.551 ; \mathrm{P}<0.001]$.

The correlation between overall psychosocial functioning (WPSI total scale) and general psychoneuroticism (SCL-90 total scale) was determined to study the concurrent validity of the WPSI. Of the 218 subjects who fully completed the WPSI, 139 subjects also completed the SCL-90. The Pearson correlation between both total scales was 0.72 for the 110 -item version and 0.70 for the 80 -item version of the 
Table 4. Mean item scores and standard deviations (SD) for the seven clinical scales for the 110 -item version and 80 -item version of the WPSI.

\begin{tabular}{|c|c|c|c|c|}
\hline \multirow[b]{2}{*}{ WPSI Scales (number of items, 110-item version / 80-item version) } & \multicolumn{2}{|c|}{$\begin{array}{l}\text { WPSI } 110 \text { items } \\
\quad(n=218)\end{array}$} & \multicolumn{2}{|c|}{$\begin{array}{l}\text { WPSI } 80 \text { items } \\
\quad(n=218)\end{array}$} \\
\hline & Mean & SD & Mean & SD \\
\hline Family Background (11/10) & 0.24 & 0.24 & 0.23 & 0.25 \\
\hline Emotional Adjustment (34/22) & 0.36 & 0.20 & 0.33 & 0.25 \\
\hline Interpersonal Adjustment (22/16) & 0.26 & 0.21 & 0.25 & 0.24 \\
\hline Vocational Adjustment (13/8) & 0.37 & 0.22 & 0.37 & 0.30 \\
\hline Financial Status (7/7) & 0.23 & 0.28 & 0.23 & 0.28 \\
\hline Adjustment to Seizures (15/12) & 0.32 & 0.24 & 0.33 & 0.26 \\
\hline Medicine and Medical Management (8/5) & 0.20 & 0.19 & 0.19 & 0.25 \\
\hline
\end{tabular}

WPSI, Washington Psychosocial Seizure Inventory.

WPSI, indicating that psychosocial functioning in epilepsy is strongly associated with general stress-related symptoms.

Finally, the relationship between the WPSI scales and some patient and epilepsy characteristics was investigated. Pearson $r$ correlations between WPSI scale scores and age varied from 0.00 to -0.23 for the 110 -item version, and 0.05 to -0.18 for the 80 -item version. Point-biserial correlations between the WPSI scale scores and sex varied from 0.01 to 0.22 for the 110 -item version, and from 0.01 to 0.20 for the 80 -item version. Small correlation coefficients were found between age at onset of epilepsy and WPSI scale scores, for both the 110-item version (range $r$, between 0.04 and 0.07 ) and 80 -item version (range $r$, between 0.00 and 0.11 ). Slightly higher correlation coefficients were found for the variable "duration of epilepsy". For both the 110-item and 80-item versions, the association with the WPSI scale scores varied from -0.02 to -0.18 . According to Cohen ${ }^{22}$ correlation coefficients of 0.10 are regarded as small, 0.30 as medium and 0.50 as large. These results indicate that no clinically relevant associations between patient and epilepsy characteristics and WPSI scale scores were found.

\section{DISCUSSION}

The primary aim of the present study was to investigate the psychometric properties of the Dutch translation of the WPSI. The WPSI has been used in different international studies and therefore been translated into several languages. As far as we know, the psychometric properties of only the original English version ${ }^{12}$ and the Spanish version ${ }^{21}$ of the WPSI have been investigated. In a recent study, we used the 
WPSI to investigate psychosocial functioning in Dutch epilepsy patients ${ }^{16}$. In this study, we concluded it to be necessary to further investigate the reliability, validity, and dimensional structure of the Dutch version of the WPSI.

Regarding the dimensional structure, we compared the exploratory seven-factor PCA with a confirmatory factor analysis and found a loss of $3.36 \%$ of total variance (35.12\% versus $31.76 \%$ ). The factor loadings of the 110 items varied considerably. Therefore to increase the homogeneity of the clinical scales, we excluded 30 items with low factor loadings and or items that had highest loadings on the incorrect clinical scale. This time, $41.59 \%$ of total variance was explained by the exploratory seven-factor PCA and $39.50 \%$ by the a priori solution (a loss of only $2.09 \%$ ). The a priori seven components [such as empirically established by Dodrill et al. ${ }^{12}$ ] accounted for a satisfactory amount of explained variance, which was almost $8 \%$ higher for the 80 -item version compared with the 110 -item version. By excluding 30 items, most of the component loadings of the remaining 80 items improved.

For the 80 -item version, the correlations between the clinical scales varied from 0.09 to 0.73 , which was slightly less than for the 110 -item version. In particular, the scales Emotional Adjustment, Interpersonal Adjustment, and Adjustment to Seizures are strongly related. Dodrill et al. ${ }^{12}$ found correlations between 0.27 and 0.76 , with especially high correlations between Emotional Adjustment and Interpersonal Adjustment ( $r=0.76)$ and Emotional Adjustment and Adjustment to Seizures $(r=0.66)$. Intercorrelations between the clinical scales were not examined for the Spanish version of the WPSI ${ }^{21}$. In comparison with the results Dodrill found, the clinical scales of our Dutch translation seem somewhat more independent of each other, in particular for the 80 -item version. These are positive findings, because a maximum of independence of the clinical scales is generally recommended. Yet considerable overlap was found between the Emotional Adjustment, Interpersonal Adjustment, and Adjustment to Seizures scales, just as in the original English version ${ }^{12}$.

The homogeneity of the seven clinical scales as determined by mean interitem correlations, item-remainder correlations, and Cronbach's coefficient $a$ was satisfactory to good. Dodrill et al. ${ }^{12}$, as well as Tiberia and Froman ${ }^{21}$ used split-half reliability coefficients instead of Cronbach's coefficient $a$ to investigate the internal consistency of the WPSI scales. The reliability coefficients varied from 0.68 to 0.92 for the original English version and 0.69 to 0.91 for the Spanish version of the WPSI. The lowest reliabilities were found for Family Background (both English and Spanish version), Medicine and Medical Management (English version) and Financial Status (Spanish version). The internal consistency of the Dutch scales were quite similar to what was found for the English and Spanish versions. The reliability coefficients for the 80 -item version were somewhat higher than for the 110-item version. In particular, the Medicine and Medical Management scale, and the Vocational Adjustment scale 
improved when "weak" items were removed. This is remarkable, considering that a linear association exists between the number of items and coefficient $a$.

Given the satisfactory amount of explained variance, higher factor loadings, less dependence of the clinical scales, and good reliability, the 80 -item version seems to be preferred above the original 110-item version.

However, nothing is said about the external validity that will determine the usefulness of each version of the WPSI. It, therefore, remains to be seen if the 80-item version will be superior to the 110-item version in reflecting the actual psychosocial functioning of patients with epilepsy.

By reason of methodologic considerations, we did not include the validity scales in the statistical analysis because these scales consist of items also included in the clinical scales. However, excluding the validity scales in the statistical analysis does not mean that these validity scales should be excluded when using the WPSI when investigating psychosocial functioning in epilepsy patients.

This study shows a strong correlation between psychosocial functioning and the level of psychoneurotic complaints patients with epilepsy experience. This is not surprising, because it is obvious that psychological and social problems can easily generate complaints of distress. Nevertheless, the results also suggest that despite the considerable overlap, the psychosocial inventory gives enough additional information about psychological and social problems specific for the population of epilepsy patients. Moreover, we did not found clinically relevant associations between patient and epilepsy characteristics (age, sex, age at onset and duration of epilepsy) and the WPSI scales, indicating that probably the "epilepsy condition" is responsible for the psychosocial problems.

The results of this study are in line with our previous published findings of Dutch patients with active epilepsy who were not seizure free or hospitalized ${ }^{16}$. The reliability and validity of the Dutch translation of the WPSI is good and comparable to what is found in the original English version. Furthermore, our findings demonstrate that shortening the WPSI makes the inventory more reliable and the clinical scales less dependent on each other.

\section{ACKNOWLEDGEMENTS}

This study was supported by “De Christelijke Vereniging voor de Verpleging van Lijders aan Epilepsie", Heemstede, The Netherlands (Teding van Berkhout Fellowship). We thank Ann Tierlier-Long for manuscript preparation. 


\section{REFERENCES}

1. Floyd M. A review of published studies in epilepsy and employment. In: Edwards F, Espir M, Oxley $J$, eds. Epilepsy and employment: a medical symposium on recurrent problems and best practice. London: Royal Society of Medicine Services, 1986.

2. Gloag D. Epilepsy and employment. BMJ 1985;291:2-3.

3. Fraser RT, Clemmons D, Trejo W, Temkin NR. Program evaluation in epilepsy rehabilitation. Epilepsia 1983;24:734-46.

4. Scambler G, Hopkins A. Being epileptic: coming to terms with stigma. Soc Health IIIness 1986;8:2643.

5. Jacoby A. Felt versus enacted stigma: a concept revised. Soc Sci Med 1994; 38: 269-74.

6. Arntson $P$, Drodge $D$, Norton R, Murray E. The perceived psychosocial consequences of having epilepsy. In: Whitman S, Hermann B, eds. Psychopathology in epilepsy: social dimension. Oxford, UK: Oxford University Press, 1986:143-61.

7. Collings J. Psychosocial well being and epilepsy: an empirical study. Epilepsia 1990;31:418-26.

8. Barrow R, Fabing H. Drivers licensing laws. In: Barrow R, Fabing H, eds. Epilepsy and the law: a proposal for legal reform in the light of medical progress. New York: Harper \& Row, 1966:57-89.

9. Spudis E, Penry J, Gibson P. Driving impairment caused by episodic brain dysfunction. Arch Neurol 1986;43:558-64.

10. Dodrill CB, Batzel LW. The Washington Psychosocial Seizure Inventory and Quality of Life in epilepsy. In: Trimble MR, Dodson WE, eds. Epilepsy and Quality of Life. New York: Raven Press, 1994:109-122.

11. Dahlstrom WG, Welsh GS, Dahlstrom LE. A MMPI Handbook. Vol 1. Minneapolis, MN: University of Minnesota Press, 1972.

12. Dodrill CB, Batzel, Queisser HR, Temkin NR. An objective method for the assessment of psychological and social problems among epileptics. Epilepsia 1980; 21:123-35.

13. Dodrill CB, Beier R, Kasparick M, Tacke I, Tacke U, Tan S-Y. Psychosocial problems in adults with epilepsy: comparison of findings from four countries. Epilepsia 1984; 25:176-83.

14. Hosokawa K, Kugoh T, Mino S. Washington Psychosocial Seizure Inventory: a multi-institutional study in Japan. Epilepsia 1994;35:1265-70.

15. Alvarado L, Ivanovic-Zuvic F, Candia X, Mendéz M, Ibarra X, Alarcón J. Psychosocial evaluation of adults with epilepsy in Chile. Epilepsia 1992;33:651-6.

16. Swinkels WAM, Shackleton DP, Kasteleijn-Nolst Trenité. Psychosocial impact of epileptic seizures in a Dutch epilepsy population: A comparative Washington Psychosocial Seizure Inventory study. Epilepsia 2000;41(10):1335-41.

17. Derogatis LR. SCL-90: Administration, scoring and procedures manual-I for the R(evised) version. Baltimore: John Hopkins University School of Medicine, Clinical Psychometrics Research Unit, 1977.

18. Arrindell WA, Ettema JHM. Handleiding SCL-90. Lisse: Swets en Zeitlinger, 1986.

19. Cattell RB. The scree test for the number of factors. Multivariate Behavioral Research 1966;1:245276.

20. Nunnally J. Psychometric theory. New York: McGraw-Hill, 1978.

21. Tiberia VA, Froman T. The development and standardization of a Spanish version of the Washington Psychosocial Seizure Inventory. Epilepsia 1986; 27(1):51-54.

22. Cohen J. Statistical power analysis for the behavioral sciences. New York: Academic Press, 1977. 



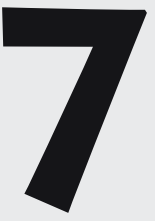

Psychosocial impact of epileptic seizures in a Dutch epilepsy population: a comparative Washington Psychosocial Seizure Inventory study

WAM Swinkels, DP Shackleton, DGA Kasteleijn-Nolst Trenité Epilepsia 2000;41(10):1335-1341 


\section{ABSTRACT}

Purpose: Psychosocial functioning of epilepsy patients from the Netherlands was investigated and compared with results from other countries. The impact of epilepsy was also studied in two different groups of Dutch epilepsy patients, inpatients and outpatients.

Methods: The Washington Psychosocial Seizure Inventory (WPSI) was used to study the psychosocial problems of 134 Dutch outpatients and 181 Dutch inpatients. WPSI profiles were compared with those of the former German Democratic Republic (West Germany), Finland, Canada, the United States, Chile and Japan.

Results: For the Dutch epilepsy patients, most of the psychosocial problems were experienced by inpatients; they had serious problems in emotional, interpersonal, and vocational adjustment, adjustment to seizures, and overall psychosocial functioning. Seizure-free outpatients, however, experienced significant problems only in the emotional adjustment area. Comparing the outcomes of various countries, Dutch outpatients and patients from West Germany and Finland experienced the least psychosocial difficulties, whereas epilepsy patients from Chile, Japan and Canada have serious problems in most areas of psychosocial functioning.

Conclusions: Patients with epilepsy experience psychosocial problems, although the amount of psychosocial difficulties depends on the seizure frequency and the culture that patients live in. 


\section{INTRODUCTION}

Epilepsy is a disorder that can have substantial psychological and social consequences for everyday life. Patients with epilepsy have higher rates of unemployment and underemployment $(1-3)$; they feel more stigmatized $(4,5)$ and have increased levels of anxiety and depression $(6,7)$ compared with the general population. Furthermore, people with epilepsy have a lower marriage rate and fewer friends than people without epilepsy $(8,9)$. The quality of life of people with epilepsy is often restricted by driving bans, with may cause additional problems in socialization, employment and self-esteem $(10,11)$.

For many years, psychologists used the Minnesota Multiphasic Personality Inventory (MMPI) to investigating psychiatric problems in many patient groups. For patients with epilepsy, the MMPI was frequently used to evaluate psychosocial and psychiatric problems $(12,13)$. Because the MMPI was not designed specifically for epilepsy patients, however, certain epilepsy-related psychosocial problems were not addressed. Therefore, an objective inventory was needed to investigate psychosocial problems in adults with epilepsy. In 1980, Dodrill et al. introduced the Washington Psychosocial Seizure Inventory (WPSI). It gives standardized findings that approximate those that would be obtained from a detailed professional evaluation (14).

Using this WPSI, investigators in different countries studied the degree of psychosocial problems in patients with epilepsy (15-17). The observed variations in psychosocial problems between the different countries can be explained either by social and cultural differences or by differences in study populations.

Because no such data were available for patients with epilepsy in the Netherlands, this study aimed to investigate the psychosocial functioning of epilepsy patients from the Netherlands and to compare their psychosocial problems with those of patients in other countries. We also wanted to investigate the impact of epilepsy itself by comparing two different Dutch epilepsy populations: former and actual outpatients of the greater Heemstede area (second-line referrals) and inpatients of Stichting Epilepsie Instellingen Nederland (third- or fourth-line referrals). The outpatient group was divided into a group of patients who had been seizure-free for at least 5 years and a group of patients who continued to have seizures. By this means, we created three Dutch patient groups: inpatients, outpatients still having seizures, and seizure-free outpatients. The psychosocial profiles of these three patient groups were compared with each other as well as with data from published studies from other countries. 


\section{METHODS}

\section{Subjects}

The two patient groups in our study came from the Stichting Epilepsie Instellingen Nederland in Heemstede, the Netherlands. The first Dutch cohort (group A) consisted of 332 epilepsy patients who visited the institute for the first time between 1953 and 1967 and lived in the greater Heemstede area. Patients with acute or remote symptomatic epilepsy were excluded. All the 332 patients received a questionnaire by mail in 1995 that included the WPSI. Of the 243 returned questionnaires, all inventories that had more than $10 \%$ blanks were excluded because of their questionable validity. This left 134 study subjects, 69 men and 65 women, with an average age of 47.8 years (range, 31-81 years). Subsequently, we divided group A into two separate groups. Group A1 consisted of 59 patients, 36 men and 23 women, with an average age of 50.0 years (range, 33-82 years), who were seizure-free for at least 5 years. Group A2 consisted of 71 patients, 32 men and 39 women, with an average age of 48.8 years (range, 33-73 years), who experienced seizures during the last 5 years. Four patients in group A had no seizure data and could not be included in either group $\mathrm{A} 1$ or group $\mathrm{A} 2$.

Table 1. Characteristics of study patients from the Netherlands, GDR, Finland, Canada, the United States, Chile, and Japan.

\begin{tabular}{|c|c|c|c|c|}
\hline Country (year of investigation) & Sex & $\begin{array}{l}\text { Average } \\
\text { age (yr) }\end{array}$ & $\begin{array}{l}\text { Average age } \\
\text { at onset (yr) }\end{array}$ & Origin \\
\hline $\begin{array}{l}\text { Dutch group A (1995) } \\
(n=134)\end{array}$ & $\begin{array}{l}52 \% \mathrm{M} \\
48 \% \mathrm{~F}\end{array}$ & 47.8 & 15.7 & Outpatients \\
\hline $\begin{array}{l}\text { Dutch group B (1996) } \\
(n=181)\end{array}$ & $\begin{array}{l}54 \% \mathrm{M} \\
46 \% \mathrm{~F}\end{array}$ & 35.2 & Unknown & Inpatients \\
\hline $\begin{array}{l}\operatorname{GDR}(1984)^{*} \\
(n=100)\end{array}$ & $\begin{array}{l}65 \% \mathrm{M} \\
35 \% \mathrm{~F}\end{array}$ & 35.8 & 19.3 & Outpatients \\
\hline $\begin{array}{l}\text { Finland (1984)* } \\
(n=84)\end{array}$ & $\begin{array}{l}44 \% \mathrm{M} \\
56 \% \mathrm{~F}\end{array}$ & 33.2 & 15.6 & Outpatients \\
\hline $\begin{array}{l}\text { Canada }(1984)^{*} \\
(n=100)\end{array}$ & $\begin{array}{l}45 \% \mathrm{M} \\
55 \% \mathrm{~F}\end{array}$ & 29.4 & 15.1 & In- and outpatients \\
\hline $\begin{array}{l}\text { United States }(1984)^{*} \\
(n=127)\end{array}$ & $\begin{array}{l}53 \% \mathrm{M} \\
47 \% \mathrm{~F}\end{array}$ & 29.2 & 13.7 & Outpatients \\
\hline $\begin{array}{l}\text { Chile }(1992)^{* *} \\
(n=116)\end{array}$ & $\begin{array}{l}46 \% \mathrm{M} \\
54 \% \mathrm{~F}\end{array}$ & 33.7 & 15.3 & Outpatients \\
\hline $\begin{array}{l}\text { Japan }(1991)^{* * *} \\
(n=652)\end{array}$ & $\begin{array}{l}50 \% \mathrm{M} \\
50 \% \mathrm{~F}\end{array}$ & 33.7 & 17.1 & Unknown \\
\hline
\end{tabular}


The second Dutch cohort (group B) consisted of 181 patients who had been hospitalized at the institute between 1993 and 1996. Because the WPSI was computerized by then, no answers were left blank, and no inventories were excluded from this group. There were 97 men and 84 women in group B, with an average age of 35.2 years (range, 14-93 years).

The patient characteristics of the Dutch patient groups and those from other countries are listed in Table 1.

\section{Washington Psychosocial Seizure Inventory}

The WPSI is an objective patient inventory for measuring psychosocial problems. It is designed solely for adults having seizures and consists of 132 items to which subjects must respond either yes or no. The WPSI takes 15 to 20 minutes to complete. It evaluates eight psychosocial areas through the following scales: Family Background, Emotional Adjustment, Interpersonal Adjustment, Vocational Adjustment, Financial Status, Adjustment to Seizures, Medicine and Medical Management, and Overall Psychosocial Functioning. In addition, there are three validity scales, i.e., Blanks, Lie and Rare. These three scales were developed to determine the probable accuracy of the responses. A visual display of the patient scores is made by plotting the eight psychosocial areas on a profile. This profile is divided into four areas, each of which is assigned a number that represents the severity of the patient's difficulties: 1, no problems; 2 , possible problems; 3 , definite problems; and 4 , severe problems (14).

\section{Data analysis}

Because the scores on the WPSI scales had abnormal distributions, the Mann-Whitney $U$ test was used for statistical analyses. Differences between the Dutch patient groups on the eight clinical scales and three validity scales of the WPSI were analyzed for all patients with valid blank scores (number of blanks $\leq 13$ ). Subsequently, separate statistical analyses were performed for all Dutch patients also having valid lie scores (lie score $\leq 3$ ).

The analyses were preformed using the Statistical Package for the Social Sciences (SPSS Inc., Chicago, IL, U.S.A.) for Windows, release 9.0.

\section{RESULTS}

Mean scores and standard deviations for both Dutch patient groups are shown in Table 2 and 3. Because we wanted to compare our results with data from other studies, scores for all patients with valid blank scores are displayed in Table 2, and 
Table 2. Mean WPSI scores (and SD) for Dutch patients with valid blank scores.

\begin{tabular}{|c|c|c|c|c|}
\hline WPSI Scales & $\begin{array}{l}\text { Group A } \\
(n=134)\end{array}$ & $\begin{array}{l}\text { Group A1 } \\
\text { Seizure free } \\
(n=59)\end{array}$ & $\begin{array}{l}\text { Group A2 } \\
\text { Not seizure free } \\
(n=71)\end{array}$ & $\begin{array}{l}\text { Group B } \\
(n=181)\end{array}$ \\
\hline Family Background & $2.46(2.85)$ & $1.76(2.27)$ & $2.99(3.08)$ & $2.61(2.47)$ \\
\hline Emotional Adjustment & $9.89(5.84)$ & $8.29(4.8)$ & $11.0(6.12)$ & $12.35(6.80)$ \\
\hline Interpersonal Adjustment & $4.81(4.43)$ & $3.39(3.59)$ & $5.89(4.62)$ & $5.76(4.65)$ \\
\hline Vocational Adjustment & $3.51(2.40)$ & $2.25(1.5)$ & $4.54(2.5)$ & $5.65(2.78)$ \\
\hline Financial Status & $1.47(1.89)$ & $0.88(1.39)$ & $1.87(2.03)$ & $2.01(1.95)$ \\
\hline Adjustment to Seizures & $2.75(2.93)$ & $1.12(1.57)$ & $4.11(3.16)$ & $5.25(3.03)$ \\
\hline Medicine \& Medical Management & $1.13(1.35)$ & $0.95(1.27)$ & $1.3(1.43)$ & $1.67(1.54)$ \\
\hline Overall Functioning & $13.62(10.06)$ & $9.49(7.38)$ & $16.77(10.47)$ & $18.71(10.80)$ \\
\hline Blanks & $2.85(3.6)$ & $2.61(3.56)$ & $3.03(3.61)$ & $0.0(0.0)$ \\
\hline Lie & $4.25(2.18)$ & $4.2(2.2)$ & $4.31(2.23)$ & $3.67(2.23)$ \\
\hline Rare & $2.34(1.69)$ & $2.08(1.51)$ & $2.55(1.83)$ & $2.82(2.16)$ \\
\hline
\end{tabular}

WPSI, Washington Psychosocial Seizure Inventory.

scores for patients with both valid blank scores and valid lie scores are displayed in Table 3.

Looking at all epilepsy patients (Table 2), the mean scale scores for group A (outpatients) had a severity level of 1 and 2, which means no or possible problems. The mean scale scores for group B (inpatients) had a severity level of 2 and 3, except for the Medicine and Medical Management scale, for which the severity level was 1 . This means that group B had definite problems in emotional adjustment, vocational adjustment, and adjustment to seizures and possible problems in family background, interpersonal adjustment, financial status, and overall psychosocial functioning. Compared with group A, group B scored significantly higher on the Emotional Adjustment $(U=9457, p<0.001)$, Vocational Adjustment $(U=6697, p<0.001)$, Financial Status ( $U=9646, p<0.001)$, Adjustment to Seizures $(U=6223, p<0.001)$, Medicine and Medical Management $(U=9536, p<0.001)$, and Overall Psychosocial Functioning $(\mathrm{U}=8553, \mathrm{p}<0.001)$ scales. Group A scored significantly higher on the validity scales Blanks $(U=3620, p<0.001)$ and Lie $(U=10342, p<0.05)$.

All scores on the WPSI clinical scales increased when patients with lie scores of greater than 3 points were excluded (Table 3). The mean scores for the Emotional Adjustment and Interpersonal Adjustment scales for group A increased to severity level 3, as did the Interpersonal Adjustment and Overall Psychosocial Functioning scale for group B. Comparing both groups, statistically significantly higher scores were found in group B for the Emotional Adjustment $(U=2014, p<0.05)$, Vocational Adjustment $(U=1350, p<0.001)$, Adjustment to Seizures $(U=1295, p<0.001)$, and 
Table 3. Mean WPSI scores (and SD) for Dutch patients with valid blank and valid lie scores.

\begin{tabular}{|c|c|c|c|c|}
\hline WPSI Scales & $\begin{array}{l}\text { Group A } \\
(n=55)\end{array}$ & $\begin{array}{l}\text { Group A1 } \\
\text { Seizure free } \\
(n=24)\end{array}$ & $\begin{array}{l}\text { Group A2 } \\
\text { Not seizure free } \\
(n=29)\end{array}$ & $\begin{array}{l}\text { Group B } \\
(n=91)\end{array}$ \\
\hline Family Background & $3.76(3.04)$ & $2.92(2.73)$ & $4.24(3.08)$ & $3.09(2.45)$ \\
\hline Emotional Adjustment & $13.58(6.34)$ & $10.71(4.98)$ & $15.38(6.39)$ & $15.88(6.99)$ \\
\hline Interpersonal Adjustment & $7.22(5.23)$ & $4.88(4.53)$ & $8.79(5.12)$ & $7.89(4.7)$ \\
\hline Vocational Adjustment & $3.91(2.64)$ & $2.25(1.54)$ & $5.17(2.62)$ & $6.19(2.84)$ \\
\hline Financial Status & $2.09(2.01)$ & $1.42(1.67)$ & $2.38(1.99)$ & $2.32(2.04)$ \\
\hline Adjustment to Seizures & $3.44(3.29)$ & $1.0(1.18)$ & $5.45(3.21)$ & $6.20(3.11)$ \\
\hline Medicine \& Medical Management & $1.62(1.63)$ & $1.58(1.5)$ & $1.62(1.8)$ & $1.92(1.65)$ \\
\hline Overall Functioning & $19.2(11.5)$ & $13.00(8.46)$ & $23.41(11.49)$ & $23.87(11.09)$ \\
\hline Blanks & $2.96(3.29)$ & $3.0(3.6)$ & $3.03(3.18)$ & $0.0(0.0)$ \\
\hline Lie & $2.16(0.96)$ & $2.04(0.95)$ & $2.21(0.98)$ & $1.82(1.05)$ \\
\hline Rare & $2.13(1.85)$ & $1.79(1.98)$ & $2.34(1.76)$ & $2.05(1.5)$ \\
\hline
\end{tabular}

WPSI, Washington Psychosocial Seizure Inventory.

Overall Psychosocial Functioning $(U=1892, \mathrm{p}<0.05)$ scales. Group A scored higher on the Blanks scale $(U=364, p<0.001)$. Because patients in group $A$ showed a greater increase on most of the clinical scale scores than group $B$, differences between the patient groups became less significant or diminished, as was seen on the Financial Status and the Medicine and Medical Management scales.

The mean scores for all patients in group A1 (seizure-free outpatients) mainly had a severity level of 1 (no problems), except for the Emotional Adjustment and Interpersonal Adjustment scales, for which the severity level was 2. The outpatients who were still having seizures (group A2) had definite problems in the emotional adjustment area and possible or no problems in the other areas. Compared to group A1, the patients in group A2 scored significantly higher on the Family Background $(U=1559, p<0,01)$, Emotional Adjustment $(U=1540, p<0.01)$, Interpersonal Adjustment $(U=1355, p<0.001)$, Vocational Adjustment $(U=951, p<0.001)$, Financial Status $(U=1506, p<0.01)$, Adjustment to Seizures $(U=839, p<0.001)$, and Overall Psychosocial Functioning $(U=1170, p<0.001)$ scales. Epilepsy patients who are still having seizures definitely have more problems in their psychosocial functioning. Because both patient groups still consult doctors and take medication, no differences were found on the Medicine and Medical Management scale. Also, no differences were found between group $A 1$ and $A 2$ on the validity scales. Even more psychosocial problems were found when only those subjects with valid lie scores were evaluated (Table 3). Seizure-free outpatients experienced problems only in the emotional adjustment area, whereas outpatients who were still having seizures experienced 
definite problems in family background, emotional adjustment, interpersonal adjustment, adjustment to seizures, and overall psychosocial functioning. Differences between both subgroups were statistically significant for the Emotional Adjustment $(U=208, p<0.05)$, Interpersonal Adjustment $(U=194, p<0.01)$, Vocational Adjustment $(U=109, p<0.001)$, Adjustment to Seizures $(U=63, p<0.001)$, and Overall Psychosocial Functioning $(U=162, p<0.001)$ scales.

We then compared the results of the two Dutch populations with previously published findings from different countries (15-17). Table 4 and 5 show the mean scores for each WPSI scale. In Figure 1, the results of the Dutch cohorts A and B are plotted along with the profiles of patients from Chile (highest scores) and the former

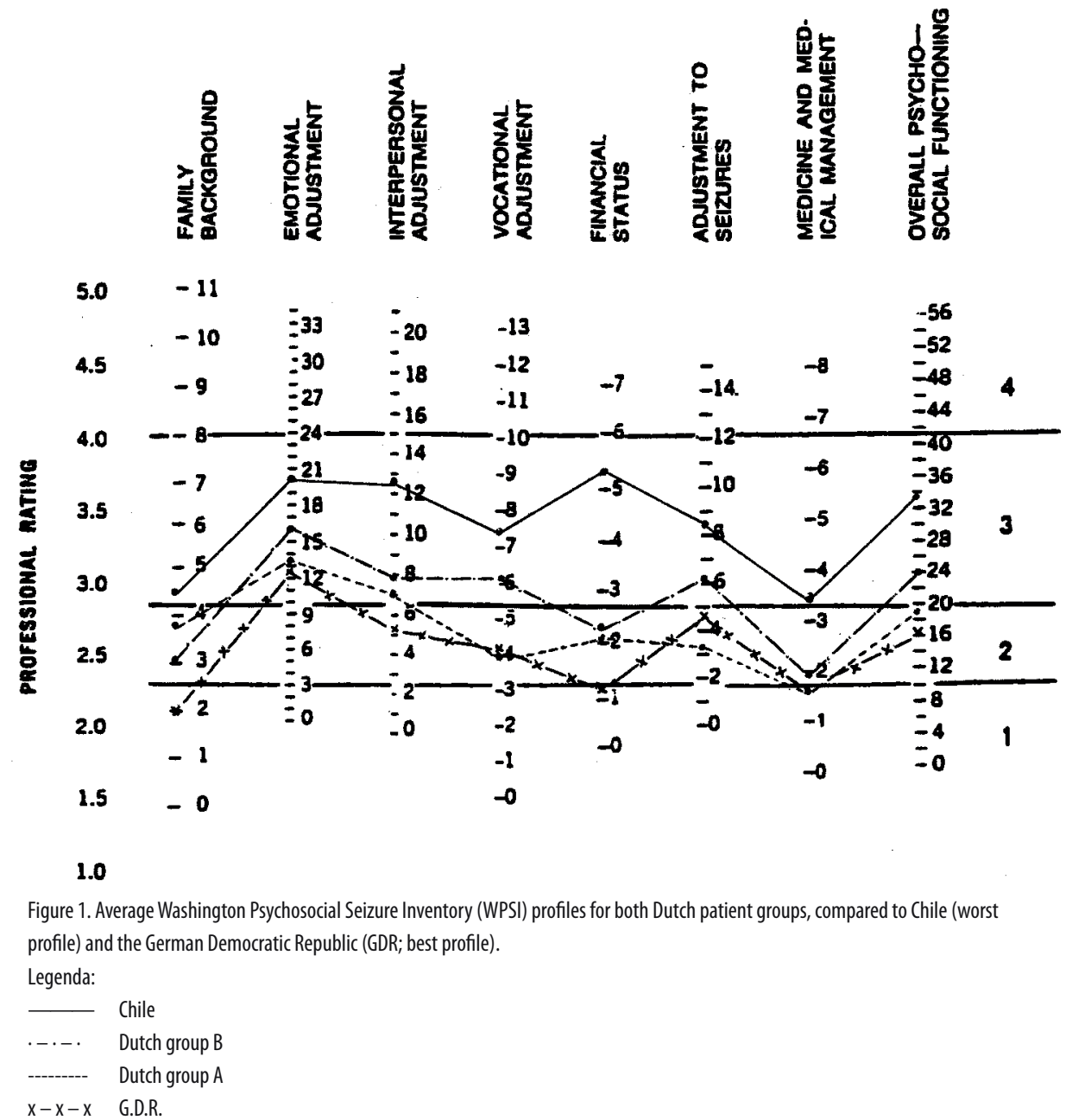




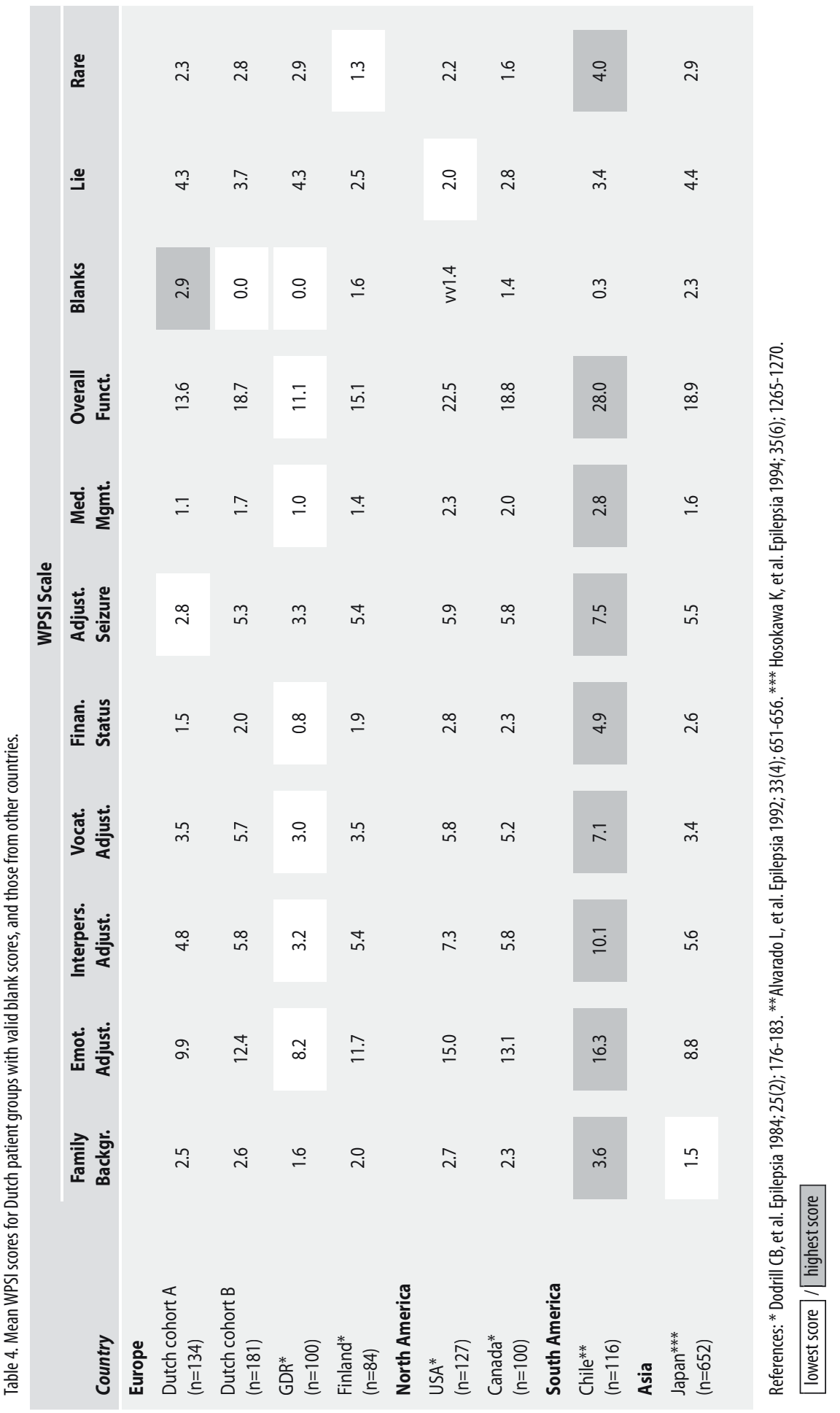




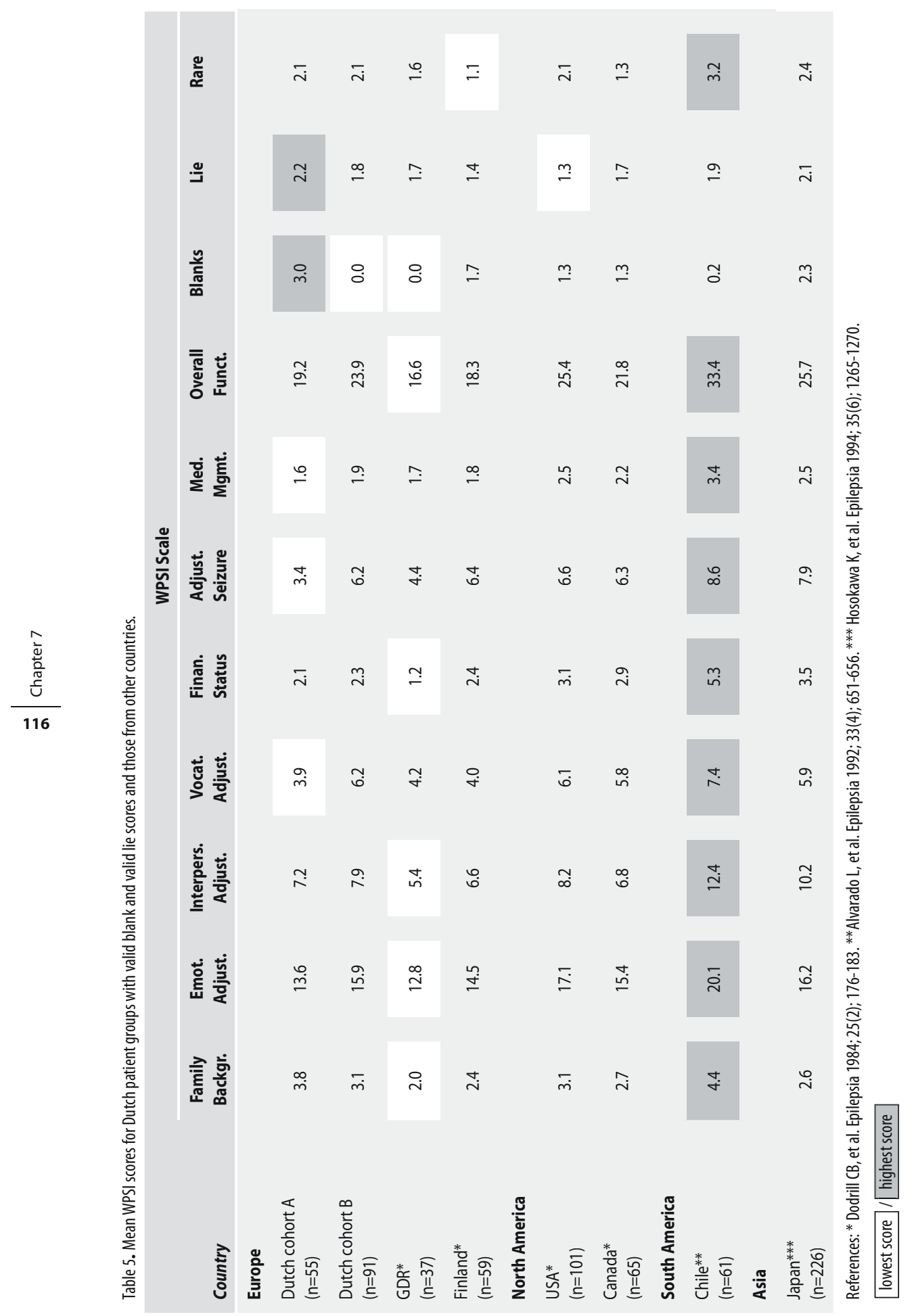


German Democratic Republic (GDR) (lowest scores) on a WPSI profile form for all patients with valid lie scores.

Comparing the results of all countries, the highest scores were obtained by Chile, with Chilean epilepsy patients experiencing definite problems in all areas of psychosocial functioning. Also, patients from the United States, Japan, and Canada experienced serious problems in most areas of psychosocial functioning, except for family background and medicine and medical management. The lowest scores on the WPSI scales were displayed by patients from the GDR, the Dutch cohort A, and Finland. The results of Dutch cohort $B$ show great similarities with the profile of patients from Canada.

\section{DISCUSSION}

Patients with epilepsy do experience psychosocial problems, although the severity of such difficulties depends on several factors. Combining the findings of Table 1 and the psychosocial profiles of all countries, we cannot conclude that inpatients have more psychosocial problems than outpatients. Considerable psychosocial problems were found for outpatients in Chile and the United States. Compared with patients in these countries, Dutch inpatients (group B) had fewer psychosocial problems. This means that a patient's status as an inpatient or outpatient does not explain the differences found among the different countries. Sex, mean age, and average age at onset of the epilepsy also cannot explain the differences found in the psychosocial profiles. Neither can the date of the study. The results from four of the countries were published in 1984, and although no more recent comparable studies are available, there is no reason to believe that the results of these countries are outdated.

Cultural differences seem to play an important role in the development of certain psychosocial problems $(15,18)$. Patients with epilepsy living in Chile experienced definite problems in all areas of psychosocial functioning. According to Alvarado et al. (1992), these findings are typical for patients with epilepsy living in developing countries, where high scores on Financial Status and Vocational Adjustment scales are a result of low socioeconomic status and high levels of unemployment (frequently as a result of epilepsy). The high scores on the Emotional Adjustment and Interpersonal Adjustment scales can be interpreted as attributable to a lack of treatment facilities for epilepsy in such countries and little emotional and psychosocial support (17).

Epilepsy patients in Japan, Canada, and the United States experienced serious problems in six of eight areas of psychosocial functioning. This could be related 
to the fact that health care systems and publicly supported programs are less well developed in such countries $(15,16,18)$. For example, because of the absence of solid vocational training programs, more financial and vocational difficulties were experienced by epilepsy patients in Japan, the United States, and Canada.

The results of this study show that European epilepsy patients have far fewer psychosocial problems than patients living on other continents. European patients have no serious financial problems or problems in finding and keeping a job, except for the Dutch inpatients (group B), who experienced problems in vocational adjustment. This latter finding is probably attributable to the fact that the Dutch patients in this group had more severe disorders, which resulted in higher levels of unemployment and other vocational problems. If European patients with epilepsy experience psychosocial problems, the problems are mostly related to emotional adjustment and adjustment to seizures, with difficulty in being accepted, shame of seizures, and various other emotional problems mentioned frequently.

In addition to cultural influences, the frequency of seizures contributes to problems in psychosocial functioning (19). Unfortunately, results about seizure frequency cannot be derived from most countries, except for the Dutch epilepsy patients. Comparing the three Dutch epilepsy cohorts, the fewest psychosocial problems were found among epilepsy outpatients who were seizure-free (group A1). These patients experienced serious psychosocial problems only in the emotional adjustment area, whereas the Dutch inpatients with severe epilepsy (group B) had serious problems in several areas of psychosocial functioning. Considerable problems were found in emotional adjustment, interpersonal adjustment, vocational adjustment, adjustment to seizures, and overall psychosocial functioning in this latter group. The psychosocial problems of the outpatients who were not seizure-free (group A2) are comparable with those of the inpatients (group B). These results support the idea that having seizures has more impact on major psychosocial issues than being hospitalized.

In summary, comparing the psychosocial profiles of all countries, we conclude that in spite of cultural differences, epilepsy patients experience psychosocial problems in similar areas, regardless of their country of residence, with the highest scores generally found on the Emotional Adjustment, Interpersonal Adjustment, and Adjustment to Seizures scales and the lowest scores on the Family Background and Medicine and Medical Management scales.

The results of this study show that patients who are still having seizures experience more psychosocial problems than patients who are seizure-free. Both outpatients and inpatients who were not seizure-free experienced serious problems in emotional adjustment, interpersonal adjustment, adjustment to seizures, and 
overall psychosocial functioning. Furthermore, cultural influences contribute to the severity of psychosocial difficulties that patients with epilepsy experience, with European patients appearing to have less severe difficulties.

\section{ACKNOWLEDGMENTS}

We thank E.H. de Graaf for her cooperation and A. Tierlier-Long for preparation of the manuscript. 


\section{REFERENCES}

1. Floyd M. A review of published studies in epilepsy and employment. In: Edwards F, Espir M, Oxley J, eds. Epilepsy and employment-a medical symposium on current problems and best practice. London: Royal Society of Medicine Services, 1986.

2. Gloag D. Epilepsy and employment. BMJ 1985;291:2-3.

3. Fraser RT, Clemmons D, Trejo W, Temkin NR. Program evaluation in epilepsy rehabilitation. Epilepsia 1983;24:734-46.

4. Scambler G, Hopkins A. Being epileptic: coming to terms with stigma. Soc Health IIIness 1986;8:2643.

5. Jacoby A. Felt versus enacted stigma; a concept revised. Soc Sci Med 1994;38:269-74.

6. Arntson P, Drodge D, Norton R, Murray E. The perceived psychosocial consequences of having epilepsy. In: Whitman S, Hermann B. eds. Psychopathology in epilepsy: social dimension. Oxford: Oxford University Press, 1986.

7. Collings J. Psychosocial well-being and epilepsy: an empirical study. Epilepsia 1990;31: 418-26.

8. Dansky LV, Andermann E, Andermann F. Marriage and fertility in epileptic patients. Epilepsia 1980;21:261-71.

9. Lechtenberg R. Epilepsy and the family. Cambridge, MA: Harvard University Press, 1984.

10. Barrow R, Fabing $\mathrm{H}$. Drivers licensing laws. In: Barrow R, Fabing $\mathrm{H}$, eds. Epilepsy and the law: $a$ proposal for legal reform in the light of medical progress. New York: Harper \& Row, 1966:57-89.

11. Spudis E, Penry J, Gibson P. Driving impairment caused by episodic brain dysfunction. Arch Neurol 1986;43:558-64.

12. Dahlstrom WG, Welsh GS and Dahlstrom LE. An MMPI Handbook, Vol I, University of Minnesota Press, Minneapolis, 1972.

13. Dodrill CB, Breyer DN, Diamond MB, et al. Psychosocial Problems Among Adults with Epilepsy. Epilepsia 1984;25(2):168-175.

14. Dodrill CB, Batzel LW, Queisser HR et al. An Objective Method for the Assessment of Psychological and Social Problems Among Epileptics. Epilepsia 1980; 21;123-135.

15. Dodrill CB, Beier R, Kasparick M, et al. Psychosocial Problems in Adults with Epilepsy; Comparison of Findings from Four Countries. Epilepsia 1984;25(2);176-183.

16. Hosokawa K, Kugoh T and Mino S. Washington Psychosocial Seizure Inventory; A Multiinstitutional Study in Japan. Epilepsia 1994;35(6);1265-1270.

17. Alvarado L, Ivanovic-Zuvic F, Candia X, et al. Psychosocial Evaluation of Adults with Epilepsy in Chile. Epilepsia 1992;33(4);651-656.

18. Collings JA. International differences in psychosocial well-being: a comparative study of adults with epilepsy in three countries. Seizure 1994;3:183-190.

19. Chovaz CJ, McLachlan RS, Derry PA, and Cummings AL. Psychosocial functioning following temporal lobectomy: influence of seizure control and learned helplessness. Seizure 1994;3:171-176. 


\section{Psychopathology in patients with nonepileptic seizures with and without comorbid epilepsy: how different are they?}

J Kuyk, WAM Swinkels, Ph Spinhoven

Epilepsy \& Bahavior 2003;4:13-18 


\section{ABSTRACT}

The underlying psychopathology in patients with nonepileptic seizures (NES) is diverse and poorly understood. The prevalence of epilepsy in NES patients is higher than in the general population, so epilepsy can be understood as a risk factor for NES. The question emerges if psychopathology differs in NES patients with and without epilepsy. Retrospective data concerning psychopathology and personality in both groups show two differences: 1) somatoform disorders are more prevalent in NES-only patients, and 2) personality disorders are more typical in NES patients with epilepsy and resemble the pattern of psychopathology found in epilepsy-only patients. If true, then NES in epilepsy patients may be associated with an epilepsy condition. Consequently, in studies of psychopathology in epilepsy patients, patients with comorbid nonepileptic seizures have to be included. 


\section{INTRODUCTION}

Psychogenic epileptic-like events are still poorly understood. There is no consensus about the definition and terminology, nor is there clarity about the underlying psychopathology or the most suitable treatment. A definition of these phenomena has to be descriptive and without theoretical implications, because generally the diagnosis is achieved by exclusion of epilepsy and other physiologic conditions associated with seizure-like symptoms (1). These events can be defined as paroxysmal, involuntary behavior patterns, characterized by a sudden and time-limited disturbance in controlling motor, sensory, autonomic, cognitive, emotional and/or behavioral functions (i.e., resembling epileptic events), but supposed to be mediated by psychological factors. The term psychogenic pseudoepileptic attack (PPEA), as used in our centre, covers this definition, as it reflects the psychogenic origin and the resemblance with epileptic manifestations. The Anglo-Saxon connotation of the term 'pseudo' is considered negative and pejorative for patients, so we use in this paper the term nonepileptic seizure (NES).

From a psychiatric perspective, a NES is a 'symptom' of an underlying psychopathologic syndrome. Within the classification of DSM-IV psychiatric disorders, these seizure-like symptoms are included in several diagnostic categories such as somatoform, anxiety, and dissociative disorders (1).

The prevalence of patients with NES is not known, but calculated between 1/50000 and $1 / 3000$ (2). It is estimated that between 5 and $25 \%$ of patients referred to comprehensive epilepsy centers suffer from NES $(3,4)$. The prevalence of epilepsy in NES patients is estimated to be between 12 and 50\% (5-8). The prevalence of epilepsy in Western countries is estimated as $0.6-0.7 \%$ (9). As the prevalence of epilepsy in NES patients is much higher than in the general population, epilepsy can be seen as a risk factor for developing NES. The prevalence of psychopathology in epilepsy patients is raised compared with a general population (10). The question arises if NES are associated with different underlying psychopathology in epilepsy patients than in patients without epilepsy. In other words: is there a difference in psychopathology in patients with concomitant NES and epileptic seizures (mixed seizures) compared to patients with NES only? In this paper we compare both patient groups in relation to several psychiatric syndromes and personality disorders. 


\section{METHODS}

\section{Subjects}

We selected retrospectively 60 patients with a diagnosis of NES and 25 patients with a combination of epilepsy and NES (mixed group). All were consecutively admitted from January 1997 to June 1999 to the observation ward of the Stichting Epilepsie Instellingen Nederland, a specialized epilepsy center, and underwent psychological testing for DSM-III-R Axis I psychiatric disorders and DSM-IV Axis II personality disorders.

For the diagnosis epilepsy and NES we accepted the final clinical diagnosis at the time of discharge by the expert team of neurologists, clinical neurophysiologists, nursing staff, and neuropsychologists, irrespective of whether this diagnosis was

Table 1. Demographic characteristics of the NES and mixed-seizure patients.

\begin{tabular}{|c|c|c|}
\hline Demographic variables & NES $^{1}(n=60)$ & Mixed-group ${ }^{2}(n=25)$ \\
\hline \multicolumn{3}{|l|}{ Sex (\%) } \\
\hline male & 30 & 24 \\
\hline female & 70 & 76 \\
\hline \multicolumn{3}{|l|}{ Age (year) ${ }^{3}$} \\
\hline mean & 31.7 & 40.7 \\
\hline sd & 12.2 & 14.4 \\
\hline \multicolumn{3}{|l|}{ Age (years) at onset seizures ${ }^{4}$} \\
\hline mean & 24.5 & 18.1 \\
\hline$s d$ & 12.9 & 15.9 \\
\hline \multicolumn{3}{|l|}{ Marital state (\%) } \\
\hline married/living together & 40.7 & 40 \\
\hline single & 59.3 & 60 \\
\hline \multicolumn{3}{|l|}{ Labor (\%) } \\
\hline housekeeping & 8.5 & 24 \\
\hline employed (paid) & 40.7 & 32 \\
\hline disability pension/welfare & 27.1 & 36 \\
\hline other (school, retired, volunteer) & 23.7 & 8 \\
\hline \multicolumn{3}{|l|}{ Education (\%) } \\
\hline primary & 19 & 25 \\
\hline secondary & 65.5 & 75 \\
\hline higher & 15.5 & 0 \\
\hline
\end{tabular}


achieved on the basis of clinical observation, seizure history, inter-ictal EEG, EEG and video documentation of the seizures, effects of withdrawal of anti-epileptic drugs, or any combination of these. Patient characteristics of both groups are summarized in Table 1.

\section{Instruments}

DSM-III-R Axis I psychiatric disorders were determined by means of the computerized version of the Composite International Diagnostic Interview (CIDI-auto), Dutch Version $1.1(11,12)$. The CIDI is a fully structured diagnostic interview aimed at determining psychiatric syndromes according to the DSM-III-R Axis I. It is a reliable and valid instrument suitable for use in different settings, cultures, and countries (13). The CIDI was administrated in all cases by the same interviewer (M.S). We analyzed the DSM-III-R last year prevalence of mood disorders (subdiagnoses major depression, dysthymia, bipolar disorder), anxiety disorders (subdiagnoses panic disorder, agoraphobia, simple phobia, social phobia, generalized anxiety disorder, obsessive compulsive disorder), and somatoform disorders (subdiagnoses somatisation disorder and somatoform pain disorder). In the evaluation of Axis I disorders, NES themselves are not included as a symptom of pathology.

DSM-IV personality disorders were assessed by the Questionnaire on Personality Traits (VKP: Vragenlijst voor Kenmerken van de Persoonlijkheid) (14). The VKP is a self-report questionnaire, based on the International Personality Disorder Examination (IPDE), assessing personality disorders (15). The questionnaire covers cluster A disorders (paranoid, schizoid, schizotypical), cluster B disorders (antisocial, borderline, histrionic, narcissistic), and cluster $\mathrm{C}$ disorders (avoidant, dependent, obsessive-compulsive). In addition, the passive-aggressive and depressive personality disorders are assessed. The VKP outcome results in categorical diagnosis as well as in a dimensional score. The dimensional score indicates the number of DSM-IV criteria that are fulfilled for each disorder and reflects in this way traits of personality disorders. The dimensional score contains therefore more information than the categorical scores, which are based on the minimal number of criteria that had to be met to diagnose a personality disorder.

Bivariate analysis was performed by means of Chi-square tests for categorical variables. Two-tailed t-tests were used for continuous data. Homogeneity of variances was tested with the Levine test for equality of variance. Because of multiple testing for VKP personality traits, a Bonferroni correction was applied and alpha individual was set at 0.004 (.05 divided by the number of comparisons). For statistical analysis SPSS for Windows release 10.1 was used. 


\section{RESULTS}

The DSM-III-R Axis I diagnoses for the NES and mixed group are summarized in Table 2. It shows that the (past year) prevalence of mood and anxiety disorders is relatively high, but not significantly different for both groups. Somatoform disorders, however, were found about five times more often in NES patients than in the mixed group.

In DSM-IV, the personality disorders are grouped into three clusters based on descriptive similarities (Table 3). Our data show that, although not statistically significant, twice as many patients from the mixed group satisfy the criteria for a cluster $A$ disorder. The prevalence of cluster B disorders are comparable. Cluster $C$ disorders are two-fold more prevalent in the mixed than in the NES group, a difference which reaches statistical significance (Table 3 ).

The mean number of criteria fulfilled (dimensional scores) for the separate DSM-IV personality disorders are shown in Table 4. The variances for each personality disorder in both groups were not statistically different as measured with the Levine test. For all personality disorders, the mean dimensional score is higher for the mixedseizure group compared to the NES patients. The results show also that the mixed group meets significantly more criteria for the histrionic and the obsessive-compulsive disorder than NES patients. The number of traits of the passive-aggressive disorder and the dependent disorder show a tendency to significance. Also the total number of criteria met by the mixed group tends to be higher than the number of criteria found in the NES group.

Table 2. Prevalence (last year) of DSM-III-R Axis I disorders in NES and mixed-seizure patients.

\begin{tabular}{llll}
\hline DSM-III-R Axis I disorders & NES' $^{\prime}(\mathbf{n = 6 0})$ & Mixed-group $^{2}(\mathbf{n}=\mathbf{2 5})$ & p-value \\
\hline Mood disorders & $28.3 \%$ & $32 \%$ & n.s. $^{3}$ \\
Anxiety disorders & $38.3 \%$ & $48 \%$ & n.s. \\
Somatoform disorders & $21.7 \%$ & $4 \%$ & .045
\end{tabular}

'NES: patients with nonepileptic seizures. ${ }^{2}$ Mixed-group: patients with epilepsy and NES.

${ }^{3}$ n.s.: not statistically significant.

Table 3. The prevalence of DSM-IV Cluster A, B and C personality disorders in NES and mixed-seizure patients.

\begin{tabular}{llll} 
Clusters & NES' $^{1}(\mathbf{n}=\mathbf{6 0})$ & Mixed-group $^{2}(\mathbf{n}=\mathbf{2 5})$ & p-value \\
\hline Cluster A & $23 \%$ & $40 \%$ & n.s. $^{3}$ \\
Cluster B & $18.3 \%$ & $24 \%$ & n.s. \\
Cluster C & $18.3 \%$ & $40 \%$ & .035
\end{tabular}

${ }^{1} \mathrm{NES}$ : patients with nonepileptic seizures. ${ }^{2}$ Mixed-group: patients with epilepsy and NES.

${ }^{3}$ n.s.: not statistically significant. 
Table 4. Mean number and standard deviations (between parenthesis) of DSM-IV criteria for personality disorders in NES and mixed-seizure patients.

$\begin{array}{lccl}\text { Personality Disorders } & \text { NES }{ }^{1}(\mathbf{n}=60) & \text { Mixed-group }^{2} \text { (n=25) } & \text { p-value }^{3} \\ \text { Paranoid } & 1.57(1.80) & 1.88(1.79) & .465 \\ \text { Schizoid } & 1.33(1.61) & 1.52(1.39) & .614 \\ \text { Schizotypical } & 1.17(1.76) & 1.92(1.58) & .067 \\ \text { Antisocial } & 1.43(2.01) & 1.76(2.03) & .766 \\ \text { Borderline } & 1.83(2.39) & 2.44(2.47) & .295 \\ \text { Histrionic } & 0.88(1.22) & 1.92(1.58) & .002 \\ \text { Narcissistic } & 0.77(1.37) & 1.20(1.61) & .211 \\ \text { Dependent } & 1.50(1.73) & 2.52(1.85) & .018 \\ \text { Avoidant } & 1.50(1.90) & 2.08(2.04) & .213 \\ \text { Obsessive-Compulsive } & 1.38(1.45) & 2.36(1.22) & .004 \\ \text { Passive-aggressive } & 0.88(1.12) & 1.68(1.55) & .009 \\ \text { Depressive } & 1.45(1.77) & 2.24(1.71) & .062 \\ \text { Total score } & 14.42(14.9) & 21.96(12.95) & .030\end{array}$

${ }^{1} \mathrm{NES}$ : patients with nonepileptic seizures. ${ }^{2}$ Mixed-group: patients with epilepsy and NES. ${ }^{3}$ Alpha is set on .004

\section{DISCUSSION}

Most studies concerning psychopathology in NES patients report high rates of psychiatric abnormalities, but a unifying pattern cannot be detected (16). Our data suggest that Axis I disorders occur frequently in NES patients as well as in patients with NES and concomitant epileptic seizures, but somatoform disorders (conversion disorder is not taken into account) are quite characteristic in NES patients and not in mixedseizure patients. Mixed-seizure patients are more often characterized by personality disorders traits compared with NES patients and especially cluster $C$ disorders. The pattern of our findings is in line with a recent study by Devinsky (17), who found more than twice as many DSM-III Axis II personality disorders (unspecified) in a mixed-seizure group compared with a NES group. Also the Axis I disorders are comparable with our data (more mood and anxiety disorders in mixed seizure patients and more somatoform (conversion) symptoms other than seizures in the NES group).

In a previous study of Swinkels and co-workers (10) it was found that the prevalence of Axis I psychiatric disorders as measured with the CIDI (especially mood and anxiety disorders) was significantly higher in epilepsy patients compared with the general Dutch population. In Figure 1 the prevalence of the different DSM-III-R Axis I diagnoses (past year) of our two groups are shown together with the epilepsy group from the Swinkels study. 
Figure 1. Prevalence of DSM-III-R Axis I disorders in NES patients with and without epilepsy in comparison with patients with epilepsy only. *Data from Swinkels et al. (10).

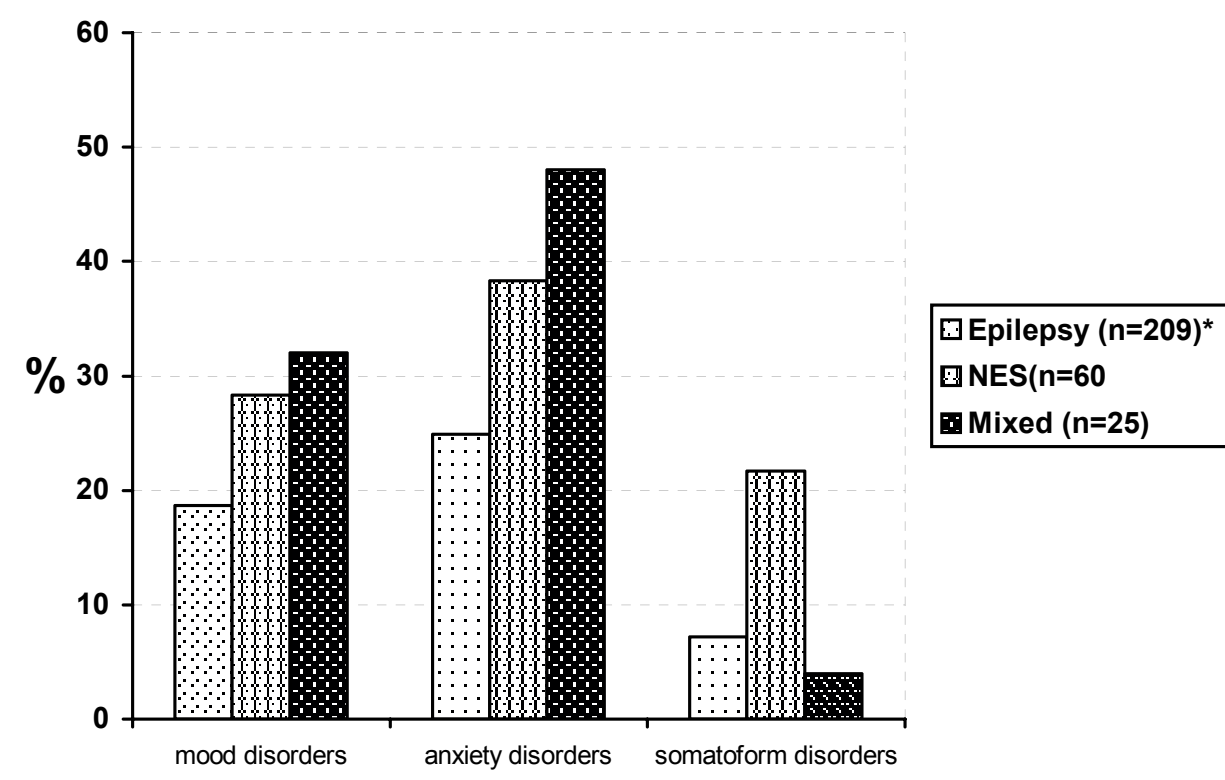

It shows that, although mood and anxiety disorders are less prevalent in epilepsy patients than in the NES-only and the mixed-seizure patients, somatoform disorders continue to be specific in NES-only patients.

Furthermore, we found that cluster $\mathrm{C}$ personality disorders are more prevalent in the mixed group than in the NES group. In another study of Swinkels and co-workers (18), it was found that epilepsy patients fulfilled significantly more criteria for DSM-IV personality disorders than normals on the schizoid, antisocial, histrionic, avoidant, dependent, passive-aggressive, and depressive disorder. In Figure 2 the prevalence of cluster $\mathrm{C}$ disorders is shown for our two groups along with the epilepsy data from the Swinkels study. These data suggest that the prevalence of cluster $C$ disorders compared to NES patients is increased not only in the mixed-seizure group, but also in epilepsy patients.

There is a much higher prevalence of epilepsy in NES patients than in the general population. Consequently, the following question arises: are NES in patients with epilepsy related to the same types of psychopathology as NES in patients without epilepsy? Our data do not confirm this hypothesis: the type of pathology in the mixed-seizure group is different from the pathology found in the group of NES patients. The latter group is above all characterized by the presence of somatoform disorders and the relative low rate of personality disorders, while the mixed group shows a high rate of personality disorders and no somatoform pathology. In 
Figure 2. Prevalence of DSM-IV cluster C personality disorders in epilepsy patients, NES patients and mixed-seizure patients. *Data from Swinkels et al. (18).

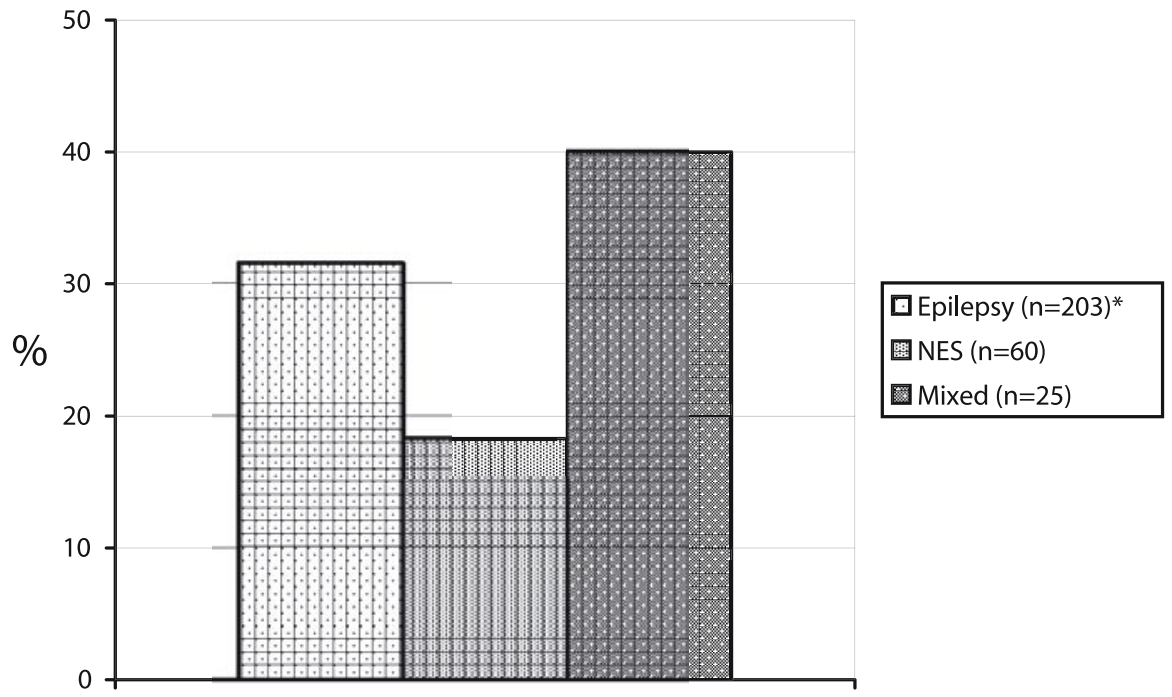

Cluster $\mathrm{C}$ personality disorders

comparison to epilepsy patients it is notable that the mixed group follows about the same pattern of personality pathology, but to a more serious extent. Cluster $C$ personality disorders emerge in both groups and are more prominent in the mixedseizure group. It may be that the NES in epilepsy patients are in some way epilepsyrelated and are characterized by other types of underlying psychopathology than in NES-only patients.

For DSM psychiatric disorders, a NES can be understood as a symptom of a psychiatric disorder. If it can be demonstrated that an epileptic-like manifestation is not epileptic (and is not an expression of another non-epileptic physiologic disorder), then several psychiatric disorders can be considered. DSM-IV Axis I symptoms that are characterized by a 'sudden and time-limited disturbance in controlling motor, sensory, autonomic, cognitive, emotional and/or behavioral functions' (see our previous definition) can be considered. Included are, for example, generalized anxiety disorder (black-outs), posttraumatic stress-disorder (flash-backs), panic disorder (attacks of sudden intensive anxiety), dissociative disorders (dissociative amnesia, fugue, depersonalization disorder), somatoform disorders (somatization and conversion disorder), impulse-control disorders (paroxysmal anger, motor agitation), and the factitious disorder in which NES can be understood as a reinforced behavior pattern (secondary gain) (1). A careful and systematic screening for psychiatric diagnoses with validated and reliable instruments would be helpful. 
To answer the question if NES in epilepsy patients belong to the domain of epilepsy is of importance to obtain a better insight into the psychopathology of NES patients, as well as in comorbid psychopathology in epilepsy patients. How should patients with mixed seizures be handled in patient studies? Several authors included mixedseizure patients in their NES patient group (e.g.,19-22), others excluded them (e.g., 23-25). According to the results of the current study the outcome of these studies that include patients with mixed seizures could be inconclusive, because epilepsyspecific factors were introduced by the patient selection. Further, an important area of psychopathology is disregarded if mixed-seizure patients are excluded in studies about psychopathology in epilepsy patients, as most studies do (e.g., 10, 26-27). The outcome of studies in which NES and epilepsy patients are compared (often for differential diagnostic purposes) are also influenced by the inclusion or exclusion of mixed-seizure patients in either patient group. If our findings hold, the inclusion of mixed-seizure patients in the NES group may result in an overestimation of psychopathology in NES patients, while exclusion of mixed-seizure patients from the epilepsy study group may lead to an underestimation of psychopathology in the epilepsy patients (e.g., 28-31).

In this paper we discuss if patients with combined NES and epileptic seizures differ with respect to underlying psychopathology from patients with NES only. This poses the possibility that psychopathology in most mixed-seizure patients is associated with the epilepsy condition. Of course, our data do not permit us to draw a firm conclusion. They are retrospectively collected and the number of mixed-seizure patients was limited. Another issue is the fact that the diagnosis NES was not exclusively based on video-EEG documentation in all patients, so the reliability of the diagnostic grouping was not optimal. Also, our measures for psychopathology, the CIDI and VKP, were merely screening instruments, which tend to over-score respectively DSM Axis I and Axis II disorders.

However, if these findings can be confirmed, then the conclusion is that NES in epilepsy patients originate from other (maybe epilepsy-related) psychopathological conditions than NES in NES-only patients. Future research has to reveal to what extent mixed-seizure patients are a subgroup of NES patients with some homogeneity, which should be studied separately from NES patients without epilepsy.

\section{ACKNOWLEDGMENTS}

We thank Ann Tierlier-Long for manuscript preparation and Edward H. Bertram for his critical review of the manuscript. 


\section{REFERENCES}

1. Gates JR. Epidemiology and Classification of Non-Epileptic Events. In: Gates JR and Rowan AJ, eds. Non-Epileptic Seizures, 2nd ed. Boston, Butterworth-Heinemann, 2000: 3-14.

2. Benbadis SR, Hauser WA. An estimate of the prevalence of psychogenic non-epileptic seizures. Seizure 2000;9:280-281.

3. Jongsma MJ, Mommers JM, Renier WO, Meinardi H. Follow-up of psychogenic, nonepileptic seizures: a pilot study - experience in a Dutch special centre for epilepsy. Seizure 1999;8:146-148.

4. Gumnit RJ. Psychogenic seizures. In: Wyllie E, ed. The treatment of epilepsy: principles and practice. Philadelphia: Lea \& Febiger, 1993: 692-696.

5. Lesser RP Psychogenic seizures. In: Pedley TA, Meldrum BS, eds. Recent advances in Epilepsy Vol. 2. Edinburgh, Churchill Livingstone, 1985: 274-296.

6. Lempert T, Schmidt D. Natural History and Outcome of Psychogenic Seizures: A Clinical Study in 50 Patients. J Neurol 1990;237:35-38.

7. Betts T, Boden S. Diagnosis, management and prognosis of a group of 128 patients with non-epileptic attack disorder. Part II. Previous childhood sexual abuse in the aetiology of these disorders. Seizure 1992;1:27-32.

8. Sigurdardottir KR, Olafsson E. Incidence of psychogenic seizures in adults: a population-based study in Iceland. Epilepsia 1998;39:749-752.

9. Hauser WA, Hesdorffer DC. Epilepsy, frequency, causes and consequences. Demos. New York, 1990.

10. Swinkels WAM, Kuyk J, De Graaf EH, Van Dyck R, Spinhoven Ph. Prevalence of psychopathology in Dutch Epilepsy Inpatients: a comparative study. Epilepsy Behav 2001;2:441-447.

11. Composite International Diagnostic Interview (CIDI), Geneva: World Health Organization, 1993.

12. Smeets RMW, Dingemans PMAJ. Composite International Diagnostic Interview (CIDI), version 1.1 Amsterdam: World Health Organization, 1993

13. Wittchen HU. Reliability and validity studies of the WHO- Composite International Diagnostic Interview (CIDI): a critical review. J Psychiatr Res 1994;28:57-84.

14. Duijsens IJ, Eurelings-Bontekoe EH, Diekstra RFW. The VKP, a self-report instrument for DSM III$\mathrm{R}$ and ICD-10 personality disorders: construction, and psychometric properties. Personality and Individual Differences 1996;20:171-182.

15. International Personality Disorder Examination (IPDE), Geneva: World Health Organization, 1993.

16. Kuyk J, Van Dyck R, Spinhoven Ph. The case for a dissociative interpretation of pseudo-epileptic seizures. J Nerv Ment Dis 1996;184:468-474.

17. Devinsky O, Mesad S, Alper K. Nondominant hemisphere lesions and conversion nonepileptic seizures. J Neuropsychiatry Clin Neurosci 2001;13:367-73.

18. Swinkels WAM, Duijsens IJ, Spinhoven Ph. Personality disorder traits in patients with epilepsy. Seizure 2003;12:587-594.

19. Bowman ES. The etiology and clinical course of pseudoseizures. Relationship to trauma, depression and dissociation. Psychosomatics 1993;34:333-342.

20. Bowman ES, Markand ON. Psychodynamics and psychiatric diagnosis of pseudoseizure subjects. Am J Psychiatry 1996;153:57-63.

21. Alper K, Devinsky O, Perrine K, Vazquez B, Luciano D. Psychiatric classification of nonconversion nonepileptic seizures. Arch Neurol1995;52:199-201.

22. Kalogjera-Sackellares D, Sackellares JC. Analysis of MMPI patterns in patients with psychogenic pseudoseizures. Seizure 1997;6:419-427.

23. Meierkord H, Will B, Fish D, Shorvon S. The clinical features and prognosis of pseudoseizures diagnosed using video-EEG telemetry. Neurology 1991;41:1643-1646.

24. Lancman ME, Brotherton TA, Asconape JJ, Penry JK. Psychogenic seizures in adults: a longitudinal analysis. Seizure 1993;2:281-286.

25. Jawad SSM, Jamil N, Clarke EJ, Lewis A, Whitecross S, Richens A. Psychiatric morbidity and psychodynamics of patients with convulsive pseudoseizures. Seizure 1995;4:201-206.

26. Robertson MM, Trimble MR, Townsend HRA. Phenomenology of depression in epilepsy. Epilepsia 1987;28:364-372. 
27. Lopez-Rodriguez F, Altshuler L, Kay J, Delarhim S, Mendez M, ngel J. Personality disorders among medically refractory epileptic patients. J europsychiatry Clin Neurosci 1999;11:464-469.

28. Kuyk J, Spinhoven Ph, Van Emde Boas W, Van Dyck R. Dissociation in temporal lobe epilepsy and pseudo-epileptic seizure patients. J Nerv Ment Dis 1999;187:713-720.

29. Alper K, Devinsky O, Perrine K, Luciano D, Vazquez B, Pacia S, Rhee E. Dissociation in epilepsy and conversion nonepileptic seizures. Epilepsia 1997;38:991-997.

30. Brown MC, Levin BE, Ramsay RE, Katz DA, Duchowny MS. Characteristics of patients with nonepileptic seizures. J Epilepsy 1991;4:225-229.

31. Krishnamoorthy ES, Brown RJ, Trimble MR. Personality and psychopathology in nonepileptic attack disorder and epilepsy: a prospective study. Epilepsy Behav 2001;2:418-422. 


\section{Summary and general discussion}

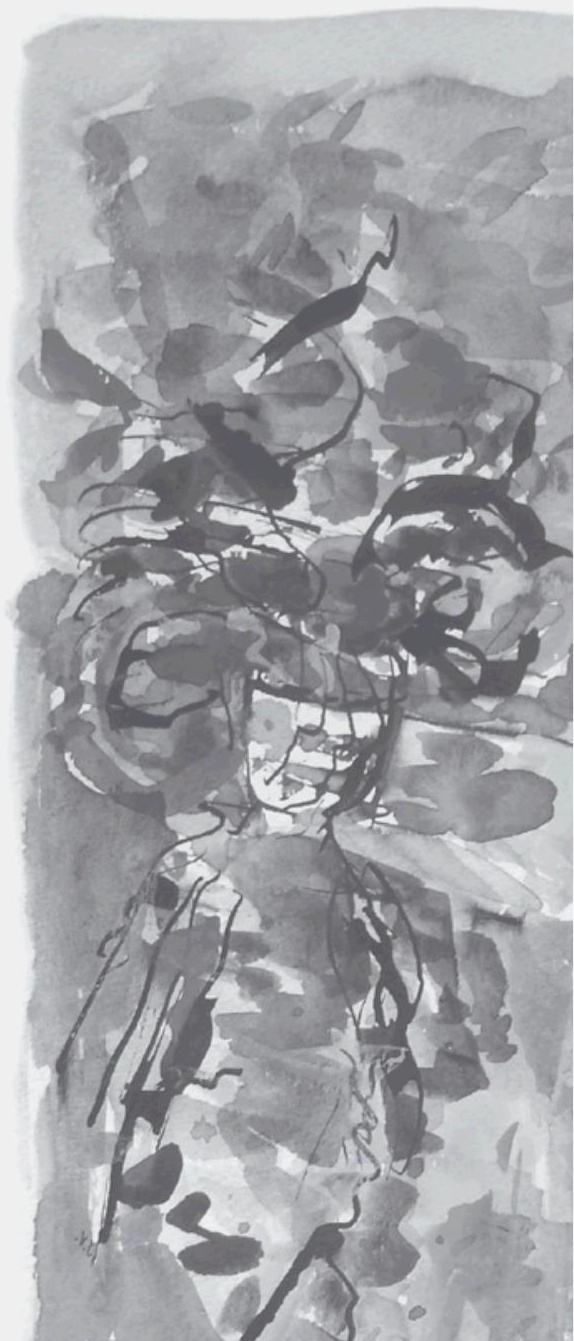


The main purpose of this thesis was to investigate the relationship between epilepsy and psychiatric disorders. Therefore, the following key objectives were determined at the onset of the project:

- The prevalence of psychiatric disorders, both DSM axis I clinical disorders and axis II personality disorders, in patients with epilepsy.

- The relationship between psychiatric disorders and specific epilepsy syndromes.

- The contribution of epilepsy-related variables to psychiatric disorders.

- Psychosocial functioning of patients with epilepsy.

In this final chapter the general findings of the studies will be summarised according to these key objectives. Subsequently, the methodological considerations together with the strengths and limitations of the studies will be discussed and, finally, clinical implications and suggestions for future investigations are presented. 


\subsection{SUMMARY}

This dissertation starts with a review of the literature on psychiatric comorbidity in epilepsy in chapter 2. Both DSM axis I clinical disorders and axis II personality disorders were discussed. Prevalence rates of axis I disorders ranged between 19\% and $80 \%$. This large variation in percentages is probably attributable to the different patient groups investigated and the great variety in diagnostic methods, with some studies using no standardised diagnostic instrument at all. Generally, it can be stated that the prevalence of axis I disorders is higher for patients with epilepsy, compared to healthy (non-medical) subjects but is equal compared to other chronic medical patients. Prevalence rates of axis II personality disorders ranged between $4 \%$ and $38 \%$. This smaller variation is probably the result of the fact that almost all studies used standardised diagnostic instruments based on the DSM criteria for personality disorders. The figures found seem to be slightly increased compared to what is found in the general population. They also appear to be increased compared to patients with other chronic medical conditions, yet this observation is based on too a small number of studies to draw definitive conclusions. Considering the available investigations on psychiatric comorbidity in epilepsy, it must be concluded that there still is a need for better controlled studies using representative patient groups and valid and standardised diagnostic methods. At present, relatively little is known of the contribution of the different brain and no-brain related variables to the relationship between epilepsy and psychiatric disorders.

\section{Prevalence of psychiatric disorders in patients with epilepsy}

The prevalence of DSM-III-R axis I clinical disorders (chapter 3) and DSM-IV axis II personality disorders (chapter 4) was studied in over 200 adult patients suffering from epilepsy who were consecutively admitted to the observation department of a tertiary epilepsy centre. A structured diagnostic interview (viz. Composite International Diagnostic Interview: CIDI) was used to determine axis I disorders, and a self-report questionnaire (viz. Questionnaire on Personality Traits: VKP) to investigate axis II personality disorder traits. In both studies the results were compared with a control group of subjects from the general population. Axis I disorders most frequently found were anxiety and mood disorders. Compared to the general population, the prevalence of these disorders was higher. Furthermore, patients with epilepsy exhibited more personality disorder traits compared with the control group from the general population. This could not be attributed to a higher prevalence of mood and anxiety disturbances in epilepsy patients. In both studies, no differences were found between patients with temporal lobe epilepsy (TLE) and patients with extra-TLE. From both investigations it can be concluded that it is likely that suffering 
from epileptic seizures is associated with an increase in psychiatric disorders and more dysfunctional personality disorder traits compared to the general population. Whether these findings are specific for epilepsy remains to be investigated.

\section{The relationship between psychiatric disorders and specific epilepsy syndromes}

Following the findings of the preceding investigations, the study described in chapter $\mathbf{5}$ was performed to determine in more detail the relationship between symptoms of interictal depression, anxiety, personality traits and psychological dissociation on the one hand with, on the other hand the localisation and lateralisation of the epileptogenic zone in patients with cryptogenic or symptomatic partial epilepsy. For the diagnosis of the epilepsy syndromes, as well as for the psychiatric classification, well-defined and solid diagnostic criteria were applied. Patients were diagnosed according to the localisation related concept of the 1989 ILAE classification of epilepsies and epileptic syndromes ${ }^{1}$ and both localisation and lateralisation of the epileptogenic zone was established for each patient using the clinical criteria for (preliminary) non-invasive presurgical evaluation. Moreover, psychiatric assessment was comprehensive and for each aspect of psychopathology, several instruments were used.

Sixty-seven patients with TLE were compared with 64 extra-TLE patients on the different measures of psychopathology. We did not find the hypothesised excess of psychiatric symptoms in patients with TLE, just as we did not find an overrepresentation of psychiatric symptoms in patients in whom tempero-mesial limbic structures were notably involved. Furthermore, no noticeable differences were found between patients with lateralisation of their epilepsy in the left and right hemisphere, nor between inpatients and outpatient. These findings are in accordance with previous studies with comparable diagnostic localising criteria which also failed to find more psychiatric symptoms in (mesial) TLE patients. We concluded from our findings, that TLE per se could not be considered as a risk factor for patients with partial epilepsy for developing more (or more severe) symptoms of psychopathology. A multifactorial explanation for the psychiatric symptomatology is more likely.

\section{Contribution of epilepsy-related variables to psychiatric disorders}

In chapter 4, the association of personality disorders (PD) traits with several epilepsy-related variables was explored, and several modest positive associations were found between especially DSM-IV cluster C PD traits with the number of anti-epileptic drugs, duration of epilepsy, seizure frequency and age at onset of the epilepsy. From these results it was concluded that patients with more severe epilepsy (i.e. 
high seizure frequency, more anti-epileptic medication) are often more prone to develop a behaviour pattern that corresponds with these cluster $C$ personality traits.

The subject of potential risk factors for psychiatric symptoms and disorders was more extensively studied in chapter $\mathbf{5}$. No associations were found between the prevalence of mood and anxiety disorders with the epilepsy-related variables age at onset, duration of epilepsy, seizure frequency and number of anti-epileptic drugs. On the other hand, several associations were found between especially the duration of epilepsy and seizure frequency with symptoms of general psychopathology, depression, anxiety and PD traits. In general, more psychiatric problems were found in patients with a higher seizure frequency and a shorter duration of their seizure disorder.

\section{Psychosocial functioning of patients with epilepsy}

The Washington Psychosocial Seizure Inventory (WPSI) is an inventory that evaluates different areas of psychological and social functioning in adults with epilepsy. In chapter $\mathbf{6}$ is described how we translated the original English version into Dutch, after which the psychometric properties of the Dutch translation were investigated. We found that the factor structure, reliability and validity of the Dutch translation of the WPSI were good and comparable to the original English version. Shortening the original 110-item version into an 80-item version even makes the inventory more reliable and the different clinical sub-scales less dependent on each other.

Subsequently, chapter $\mathbf{7}$ portrays the level of psychosocial difficulties in a large group of Dutch inpatients and outpatients with epilepsy. The results showed that patients still having seizures experience more psychosocial problems compared to patients who are seizure-free. Both inpatients and outpatients still having seizures experienced serious problems in several areas of psychosocial functioning. Seizurefree outpatients had the least problems. These findings suggest that having seizures may have more impact on psychosocial issues than hospitalisation.

These results were also compared to the results of studies from other countries in which the WPSI was implemented. Patients from different countries display variations in the level of psychosocial problems. Patients from countries in North and South America and Asia experience considerably more psychosocial difficulties than their European counterparts. These results clearly indicate that cultural influences contribute to the degree of psychosocial difficulties patients with epilepsy experience, with European patients appearing to have the best prospects. But in spite of the cultural differences, epilepsy patients generally experience psychosocial problems in similar areas. 
An extra chapter, chapter 8, was dedicated to explore the question whether patients with a mix of epileptic and psychogenic non-epileptic seizures (PNES) should be included or excluded in studies on psychiatric comorbidity in epilepsy. Sixty patients with a diagnosis of PNES were compared with 25 patients with a mixed diagnosis of PNES and epilepsy on axis I and axis II disorders. We also compared the results with findings from previous studies (described in chapter 3 and 4). The data of this study indicate that the type of pathology in the mixed seizure group is different from the pathology found in the group of PNES patients. The latter group is characterised by the presence of somatoform disorders and a relatively low rate of personality disorder (traits), whereas the mixed group shows a high rate of personality disorder (traits) and no somatoform disorder pathology (except the non-epileptic seizure itself). The mixed seizure patients follow about the same pattern of personality pathology as the epilepsy patients, but to a more serious extent. We hypothesise that an important area of psychopathology is disregarded when mixed seizure patients are excluded from studies about psychiatric disorders in epilepsy, which may lead to an underestimation of the level of psychopathology. We therefore conclude that psychopathology in most patients with a combination of epilepsy and PNES is typical of the pattern found in pure epilepsy.

\subsection{METHODOLOGICAL CONSIDERATIONS}

In this paragraph, the methodological choices that were made concerning the inclusion of epilepsy patients will be discussed, together with the classification of epilepsy and the instruments used to assess psychiatric disorders and psychosocial problems.

The first comment concerns the representativeness of the patient group that was investigated. For the prevalence studies of axis I clinical disorders and axis II personality disorders (chapter 3 and 4), the findings were based on inpatients who were admitted to a tertiary epilepsy clinic. The patients were hospitalised for several reasons, mainly because of poor seizure control and change of anti-epileptic medication, but also for psychosocial evaluation and/or psychological assessment and support. It may be assumed that all patients had a severe form of epilepsy or epilepsy-related (psychosocial) problems. More psychiatric disturbances are expected to be found in this highly selected patient group, compared to epilepsy patients derived from outpatient clinics or general hospitals, where we have to do with patients with a relatively well-controlled epilepsy. So, it remains to be established whether the present study results can be generalised to the total population of epilepsy patients. Future 
studies should be directed at investigating psychiatric problems in a representative sample of epilepsy patients originating from (epilepsy) outpatient clinics, general hospitals, as well as inpatient clinics.

For the study described in chapter 5 (relation between psychiatric disorders and epilepsy syndromes), patients were selected from both in- and outpatient clinics of the specialised epilepsy centre. Because we compared patients with different epilepsy syndromes on the level of psychiatric disturbances, the representativeness of the patient group was of less importance. The fact that all patients were derived from a specialised epilepsy clinic was in view of our study purpose rather an advantage, because more psychiatric problems were expected in these patients. Therefore, it can be claimed that this study was biased to positive results. Despite of this bias, no differences in psychopathology were found between the different subgroups of epilepsy patients.

For the psychometric study described in chapter 6, patients were also recruited from the in- and outpatient clinics of the tertiary epilepsy centre. Because this study was focussed on investigating the psychometric properties of the research instrument (viz. the Dutch translation of the Washington Psychosocial Seizure Inventory (WPSI)), a representative patient group is not a prerequisite. However, the selection of the patients was important in the comparative WPSI study described in chapter 7. Generalisation of the results presented in this study should be done with some caution, because the findings were based on a specific patient group of inpatients and (former) outpatients of the tertiary epilepsy centre.

All patients who participated in the studies described in chapter 3 to 7 were derived from a specialised epilepsy centre. In spite of the fact that these patients constitute a selective population of epilepsy patients, they form an interesting and valuable patient group because the epilepsy diagnosis is reliably determined and additional information on the patients and their epilepsy is available.

Another aspect concerning the representativeness of the patient group is illustrated in chapter 8 , directed at the question whether patients with comorbid psychogenic non-epileptic seizures (PNES) should be included or excluded in studies concerning psychiatric disorders in epilepsy. In all our studies we excluded the patients with comorbid PNES, which possibly did lead to an underestimation of psychopathology in the epilepsy patients. It is recommended to include patients with comorbid PNES in future studies on psychiatric comorbidity in epilepsy.

The second point of concern is the classification of epilepsy. For the prevalence studies of chapter 3 and 4, several neurologists were involved in the epilepsy classification and patients were classified on the basis of clinical information obtained during hospital admission. Consequently, for a number of patients the classification 
of epilepsy was determined solely on clinical and EEG data, and not on anatomical information. The study described in chapter 5 did overcome this weakness. For all patients an epilepsy diagnosis was formulated as if for initial presurgical patient selection, according to the localisation related concept of the 1989 ILAE classification of epilepsies and epilepsy syndromes ${ }^{1}$, and based on all available clinical information, neuro-imaging, and the best available EEG (and Video) data. Moreover, for more than half of the patients we had EEG/video seizure recordings.

The final point concerns the diagnostic instruments that were used to investigate psychiatric disorders and psychosocial problems. We used reliable and valid diagnostic instruments to assess psychiatric disorders following the DSM classification. For clinical disorders according to axis I of the DSM, we used a structured diagnostic interview (Composite International Diagnostic Interview; CIDI) that is used for epidemiological research in different cultures and countries. For personality disorders according to axis II of the DSM, we used a self-report questionnaire (Questionnaire on Personality Traits; VKP). The advantage of the VKP is that for each personality disorder, a dimensional score (number of criteria met) and a categorical diagnosis (negative, probable, and positive) are given. In the statistical analyses, we used the dimensional scores, which is more accurate when comparing the different subject groups. Although the VKP is a valid instrument, it does not give accurate diagnoses because it is rather a screener for personality disorders and it overestimates the number of positive diagnoses. However, because we used the dimensional scores of different subgroups of patients and subjects with this instrument, relative instead of absolute differences could be investigated unbiased by a possible overestimation of the presence of personality disorder (traits). For the study described in chapter 5 we used, besides the instruments described above, also several other reliable and widely used self-reporting questionnaires.

Psychosocial problems were studied with an instrument that was specifically developed for patients with epilepsy, namely the Washington Psychosocial Seizure Inventory (WPSI). This inventory, that evaluates seven areas of psychological and social functioning, was translated into Dutch and the psychometric properties were determined. Just as for the original English version, the factor structure, reliability and validity of the Dutch translation were good, which makes the WPSI a suitable instrument to investigate psychosocial problems in epilepsy patients. Because a number of investigators in different countries use the WPSI as an instrument, comparison of psychosocial problems among epilepsy patients in different parts of the world was possible. 


\subsection{STRENGTHS AND LIMITATIONS OF THE PRESENT STUDIES}

The studies described in this dissertation are based on large patient groups consisting of in- and/or outpatients with epilepsy. For the studies described in chapter 5 and 6, the representativeness of the patient group is less crucial depending on the hypothesis that is investigated. This is different for the prevalence studies where a representative patient group is of importance. Therefore, the prevalence rates of clinical disorders and personality disorders that were found in the studies described in chapter 3 and 4 are valid for inpatients with epilepsy, but generalisation to the total epilepsy population should be done with the necessary caution.

We also used control groups to compare our findings. For the prevalence studies (chapter 3 and 4) the results were compared with data of a large group of control subjects from the general population, and for the psychosocial investigation described in chapter 7 we compared our results with those of other countries using the same instrument. However, we did not use a control group of other chronic medical patients to compare our findings.

Besides the large patient groups and control groups to put our findings in perceptive, we used good classification and localisation criteria for the diagnosis of the epileptic seizures and syndromes. Notably, for the study described in chapter 5 , patients were diagnosed according to the localisation related concept of the 1989 ILAE classification of epilepsies and epileptic syndromes ${ }^{1}$ and the localisation and lateralisation of the epileptogenic zone was established for each patient using the clinical criteria for preliminary non-invasive presurgical evaluation.

For the psychiatric classification we used reliable and valid diagnostic instruments aimed at determining psychiatric syndromes according to the objective criteria of the DSM. The study described in chapter 5 even uses a comprehensive battery of psychological and psychiatric instruments to determine in more detail psychiatric symptoms and disorders that were previously found in these patients. Comparing our method of psychiatric classification with similar investigations on psychiatric comorbidity in epilepsy, we can conclude that only a few studies use standardised diagnostic instruments based on objective criteria.

The use of large patient groups and 'healthy' (non-medical) control groups, and especially the reliable and objective classification of both epilepsy syndromes and psychiatric diagnoses constitute the strengths of the studies described in this dissertation. The unrepresentativeness of the patient group, in particular for the prevalence studies, and the absence of a control group of chronic medical patients can be considered as a weakness that has to be overcome in future studies. 


\subsection{CLINICAL IMPLICATIONS}

The findings of this thesis as well as findings in the literature show that epilepsy is a disorder that is, just like other chronic medical conditions frequently accompanied by anxiety and depressive disorders. Suffering from epileptic seizures can also cooccur with dysfunctional personality disorder traits. When treating patients with epilepsy one should keep in mind that these psychiatric disorders frequently co-exists and sometimes these disorders are even more disrupting than the epilepsy itself. Treatment of psychiatric disorders in epilepsy should be primarily concentrated on axis I disorders. We must be aware that patients with epilepsy can also exhibit some specific personality disorder traits, but we must not treat them as personality disordered because the mean number of criteria met for each personality disorder was relatively low. Furthermore, our findings showed only a small number of modest associations between psychiatric symptoms with epilepsy-related variables, notably, duration of epilepsy and seizure frequency (i.e. patients with a high seizure frequency and shorter duration of their seizure disorder experienced more psychiatric problems). From a clinical point of view it means that there are no epilepsy variables that can be considered as strong predictors (risk factors) for the development of psychiatric disorders. Nevertheless, the fact that patients with recently diagnosed epilepsy relatively run the highest risk of developing psychiatric problems signifies that these higher levels of psychopathology can be better conceived as indicating problems in emotional adaptation to a new disease, instead of the result of longterm psychosocial impact of the epileptic condition.

\subsection{SUGGESTIONS FOR FUTURE STUDIES}

The findings of the different studies that are part of this dissertation strongly suggest that the topic of psychiatric comorbidity in epilepsy is sufficiently explored. However, new developments in the knowledge of epilepsy as well as in psychopathology can generate new hypothesis or give rise to use yet better suited instruments. Furthermore, improvement can be achieved by using more representative samples of epilepsy patients because our data were all based on in- and outpatients of a specialised epilepsy centre which is a disadvantage for the prevalence studies in particular. Secondly, the study design can be further improved when apart from the epilepsy patients, also a control group of other chronic medical patients (e.g. asthma patients) is included in the investigation.

Our data did furthermore demonstrate that epilepsy-related factors seem to be of less importance in the predisposition of psychiatric symptoms. The supposed 
increased risk for patients with TLE for developing interictal psychiatric disorders was consistently not found in the studies in this dissertation. Also other epilepsy-related variables were not or only moderately associated with more (or more severe) psychopathology. Together with the fact that there are generally no differences found between epilepsy patients and patients with other chronic medical illnesses, we assume that emotional adaptation to a recently diagnosed illness is the most important factor in the predisposition of epilepsy patients to these interictal psychiatric disorders. This implies that future studies should be more focussed on coping behaviour. The use of inadequate coping strategies (which is not epilepsy specific) is probably a better predictor for the pathogenesis of interictal psychiatric disorders than epilepsy-specific factors.

The theory that TLE is considered as a risk factor for psychiatric disorders, especially for affective disorders, because of the involvement of the limbic system in affect and mood regulation, probably refers more to post-ictal symptoms instead of interictal behaviour disturbances. Future studies should be directed at investigating this association between TLE and, for example, postictal symptoms of depression, anxiety or psychosis. It can be hypothesised that the relationship between TLE and postictal psychiatric symptoms is stronger than the relationship with interictal psychiatric disorders, all the more because the latter association was consistently not found in our studies. In contrast to interictal behaviour disturbances, postictal psychiatric symptoms are more directly related to the seizure activity, which is a derivative of the location in the brain were the increased electric activity arises. When an epileptic seizure arises from limbic brain structures, more psychiatric symptoms, post-ictally, would be expected.

In this thesis, the emphasis was on depression, anxiety, personality traits and psychological dissociation. We did not study, for example, psychotic disorders in these patients. Concerning our recommendation to focus on postictal psychiatric symptoms, psychotic symptoms should be definitely included when performing such investigations.

A final suggestion for future studies is the use of more dimensional measurements of psychopathology. Because sub-clinical psychiatric syndromes such as depression, often occurs in chronic patient groups, dimensional instruments are recommended.

\section{REFERENCE}

1. Commission on Classification and Terminology of the International League Against Epilepsy: Proposal for revised classification of epilepsies and epileptic syndromes. Epilepsia 1989;30:389-399. 



\section{Samenvatting}

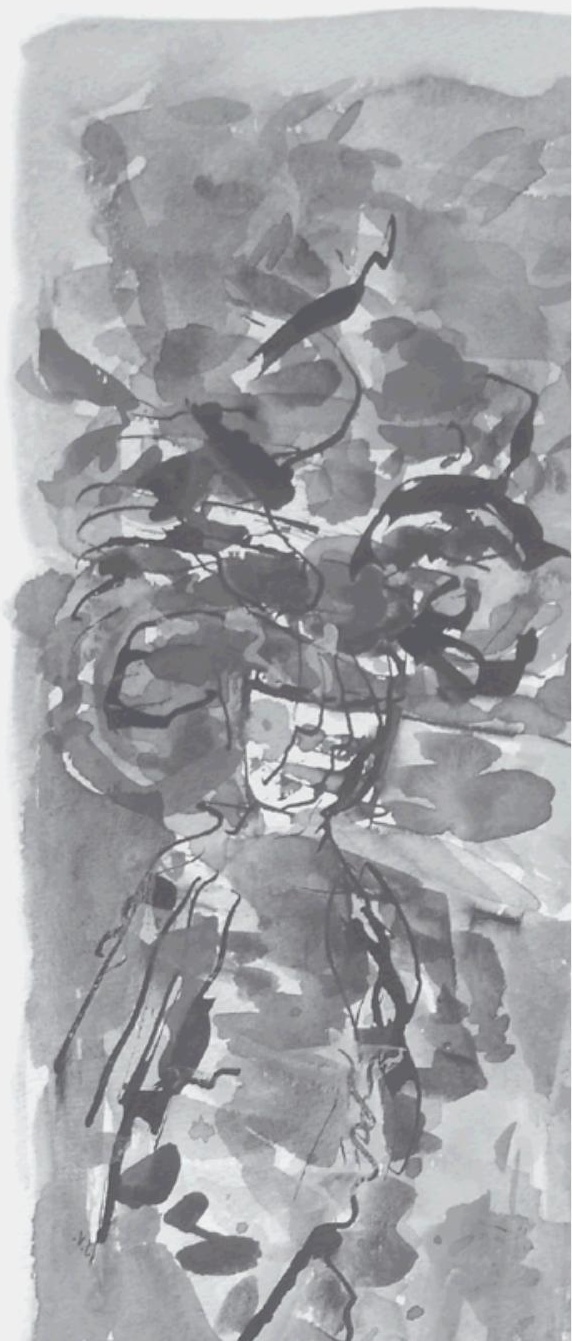


Dit proefschrift beschrijft de relatie tussen epilepsie en psychiatrische stoornissen. Daarbij wordt ingegaan op de volgende vier onderwerpen:

- De prevalentie van psychiatrische stoornissen, zowel DSM as I klinische stoornissen als as II persoonlijkheidsstoornissen, bij patiënten met epilepsie.

- De relatie tussen psychiatrische stoornissen en specifieke epilepsie syndromen.

- De invloed van epilepsiegerelateerde variabelen op psychiatrische stoornissen.

- Het psychosociale functioneren van patiënten met epilepsie.

Allereerst wordt in hoofdstuk 2 een overzicht gegeven van de literatuur over psychiatrische co-morbiditeit bij epilepsie. Zowel DSM as I klinische stoornissen als as II persoonlijkheidsstoornissen worden bediscussieerd. De prevalenties van as I stoornissen variëren tussen de $19 \%$ en $80 \%$. Deze grote variatie in percentages is waarschijnlijk te wijten aan de verschillen in patiëntgroepen die zijn onderzocht en de grote variëteit in diagnostische methoden, waarbij sommige studies geen gestandaardiseerde diagnostische instrumenten gebruikten. In het algemeen kan worden gesteld dat de prevalentie van as I stoornissen hoger is voor patiënten met epilepsie in vergelijking met gezonde personen uit de algemene bevolking, maar vergelijkbaar is met die van andere chronisch medische patiënten.

De prevalenties voor as II persoonlijkheidsstoornissen variëren tussen de $4 \%$ en $38 \%$. Deze kleinere variatie is waarschijnlijk te wijten aan het feit dat vrijwel alle onderzoeken gestandaardiseerde diagnostische instrumenten gebruiken, uitgaande van de DSM criteria voor persoonlijkheidsstoornissen. De percentages lijken enigszins verhoogd ten opzichte van wat er in de algemene populatie wordt gevonden. In vergelijking met patiënten met andere chronische medische condities zijn de prevalenties ook verhoogd, echter gezien het kleine aantal studies is het niet goed mogelijk daar definitieve conclusies over te formuleren.

Op grond van de aanwezige onderzoeken naar psychiatrische co-morbiditeit bij epilepsie kan geconcludeerd worden dat er behoefte is aan goed gecontroleerde studies met representatieve patiëntgroepen en valide en gestandaardiseerde diagnostische instrumenten. Tevens blijkt uit de literatuur dat er relatief weinig bekend is over de invloed van de verschillende 'hersen-' en 'niet-hersen-' gerelateerde variabelen op de relatie tussen epilepsie en psychiatrische stoornissen. 


\section{De prevalentie van psychiatrische stoornissen bij patiënten met epilepsie}

In hoofdstuk 3 wordt de prevalentie van DSM-III-R as I klinische stoornissen beschreven en in hoofdstuk 4 de prevalentie van DSM-IV as II persoonlijkheidsstoornissen bij patiënten met epilepsie. Voor beide onderzoeken zijn ruim 200 volwassen patiënten met epilepsie onderzocht die waren opgenomen op de observatiekliniek voor volwassenen van een gespecialiseerd epilepsie centrum (SEIN). Een gestructureerd diagnostisch interview, de CIDI (Composite International Diagnostic Interview), wordt gebruikt om de prevalentie van DSM as I stoornissen mee te bepalen. Voor het onderzoeken van DSM as II persoonlijkheidsstoornissen wordt een zelf- invulvragenlijst, de VKP (Vragenlijst voor Kenmerken van de Persoonlijkheid), gebruikt. In beide studies worden de resultaten vergeleken met een controlegroep van personen uit de algemene bevolking.

As I stoornissen die het meeste voorkomen bij de epilepsiepatiënten zijn angst- en stemmingsstoornissen. De gevonden prevalenties voor deze stoornissen zijn hoger dan die voor de algemene bevolking. Tevens vertonen epilepsiepatiënten meer trekken van diverse persoonlijkheidsstoornissen in vergelijking met de controlegroep uit de algemene bevolking. Uit het onderzoek blijkt eveneens dat dit niet kan worden toegeschreven aan de hogere prevalentie van angst- en stemmingstoornissen bij de epilepsiepatiënten. In beide studies zijn geen verschillen gevonden tussen patiënten met temporaalkwabepilepsie (TLE) en patiënten waarbij de epilepsie niet vanuit de temporaalkwab ontstaat (extra-TLE).

Geconcludeerd kan worden dat het waarschijnlijk is dat het hebben van epilepsie kan samenhangen met een toename van psychiatrische stoornissen en meer dysfunctionele trekken van persoonlijkheidsstoornissen. In hoeverre dit specifiek is voor epilepsie moet echter nog verder worden onderzocht.

\section{De relatie tussen psychiatrische stoornissen en specifieke epilepsie syndromen}

Op grond van de voorgaande onderzoeken wordt in hoofdstuk 5 de relatie onderzocht tussen enerzijds de symptomen van interictale (niet direct aan de aanvallen gerelateerde) depressie, angst, persoonlijkheidstrekken en dissociatieve kenmerken en anderzijds de lokalisatie en lateralisatie van de epileptogene zone bij patiënten met cryptogene of symptomatische lokalisatiegebonden epilepsie. Zowel voor de diagnose van de epilepsie syndromen als voor de psychiatrische classificatie worden goed gedefinieerde en solide diagnostische criteria toegepast. De patiënten worden gediagnostiseerd volgens het lokalisatiegerelateerde concept van de in 1989 opgestelde International League Against Epilepsy (ILAE) classificatie van epilepsie en epilepsie syndromen. Voor iedere patiënt wordt zowel de lokalisatie als de lateralisatie van de epileptogene zone vastgesteld door gebruik te maken van de klinische criteria voor niet-invasieve prechirurgische evaluatie. Daarnaast is het psychiatrisch 
onderzoek zeer uitgebreid en zijn voor elk aspect van psychopathologie meerdere onderzoeksinstrumenten gebruikt.

Zevenenzestig patiënten met TLE werden vergeleken met 64 patiënten met extra-TLE voor de diverse metingen van psychopathologie. De uit de literatuur veronderstelde overmaat van psychiatrische symptomen in TLE-patiënten werd niet gevonden, evenmin als de overmaat van psychiatrische symptomen in patiënten waarbij met name tempero-mesiale limbische structuren betrokken zijn. Evenmin zijn er verschillen gevonden tussen patiënten met de lateralisatie van de epilepsie in de linker dan wel de rechter hemisfeer. Tot slot zijn er ook geen verschillen gevonden in psychiatrische symptomen tussen opgenomen patiënten en poliklinische patiënten. Opvallend is dat deze bevindingen in overeenstemming zijn met eerdere studies waarbij vergelijkbare diagnostische lokalisatiecriteria zijn gebruikt en waarbij ook geen overrepresentatie van psychiatrische symptomen is gevonden bij (mesiale) TLE-patiënten.

Uit deze bevindingen kan worden geconcludeerd dat TLE op zichzelf geen risicofactor is voor het ontwikkelen van meer of ernstigere symptomen van psychopathologie. De bevindingen suggereren dat een multi-factoriële verklaring voor de psychiatrische symptomatologie meer waarschijnlijk is.

\section{De bijdrage van epilepsiegerelateerde variabelen aan psychiatrische stoornissen}

In hoofdstuk 4 wordt de samenhang tussen trekken van persoonlijkheidsstoornissen (PS) en de verschillende epilepsiegerelateerde variabelen onderzocht. Diverse positieve samenhangen worden gevonden tussen met name DSM-IV cluster C PStrekken (ontwijkende en obsessief-compulsieve trekken) en de volgende variabelen: aantal anti-epileptica, duur van de epilepsie, aanvalsfrequentie en debuutleeftijd epilepsie. Geconcludeerd kan worden dat patiënten met een ernstiger epilepsie (d.w.z. hogere aanvalsfrequentie en meer anti-epileptica) mogelijk meer kwetsbaar zijn voor het ontwikkelen van een gedragspatroon dat overeenstemt met cluster $C$ persoonlijkheidstrekken.

In hoofdstuk 5 worden de potentiële risicofactoren voor psychiatrische symptomen en stoornissen uitvoeriger onderzocht. Er wordt geen samenhang gevonden tussen de prevalentie van stemmings- en angststoornissen en de epilepsiegerelateerde variabelen: debuutleeftijd, duur van de epilepsie, aanvalsfrequentie en aantal anti-epileptica. Daarentegen zijn er wel diverse samenhangen gevonden tussen voornamelijk de duur van de epilepsie en aanvalsfrequentie enerzijds en algemene symptomen van psychopathologie, depressie, angst en PS-trekken anderzijds. In het algemeen worden meer psychiatrische problemen gevonden bij patiënten met een hogere aanvalsfrequentie en een kortere duur van de epilepsie. Geconcludeerd 
kan worden dat het veelal moeilijk is voor de patiënt om met een relatief nieuw (en vaak onbekend) medisch probleem om te gaan, vooral in de beginfase en wanneer de aanvallen nog niet goed onder controle zijn. Hierdoor lopen ze een verhoogd risico op het ontwikkelen van psychiatrische symptomen.

\section{Psychosociaal functioneren van patiënten met epilepsie}

De Washington Psychosocial Seizure Inventory (WPSI) is een vragenlijst die de verschillende gebieden van psychisch en sociaal functioneren bij volwassenen met epilepsie onderzoekt. In hoofdstuk 6 wordt beschreven dat de originele Engelse versie van Dodrill is vertaald voor het Nederlandse taalgebied en hoe de psychometrische eigenschappen van de Nederlandse vertaling is onderzocht. De factorstructuur, betrouwbaarheid en validiteit van de Nederlandse vertaling van de WPSI is goed en vergelijkbaar met de originele Engelse versie. Het verkorten van de originele 110item versie naar 80 items maakt de vragenlijst zelfs meer betrouwbaar en de diverse klinische subschalen minder afhankelijk van elkaar.

Vervolgens beschrijft hoofdstuk 7 de mate van psychosociale problemen in een grote groep Nederlandse epilepsiepatiënten. Zowel klinische patiënten als poliklinische patiënten deden aan het onderzoek mee. De resultaten geven aan dat patiënten met actieve epilepsie meer psychosociale problemen ervaren in vergelijking met patiënten die aanvalsvrij zijn. Zowel klinische patiënten als poliklinische nietaanvalsvrije patiënten vertonen significante problemen op diverse gebieden van het psychosociaal functioneren. Aanvalsvrije poliklinische patiënten rapporteren de minste problemen. De bevindingen suggereren dat het hebben van aanvallen een belangrijkere invloed heeft op het psychosociaal functioneren dan het al of niet opgenomen zijn.

De resultaten zijn tevens vergeleken met de resultaten van studies uit andere landen waarbij ook de WPSI is gebruikt. Epilepsiepatiënten uit de verschillende landen laten verschillen zien in de mate van psychosociale problemen. Zo rapporteren patiënten afkomstig uit landen in Noord- en Zuid-Amerika en Azië aanzienlijk meer psychosociale problemen in vergelijking met patiënten afkomstig uit Europa. Hieruit blijkt dat culturele en maatschappelijke invloeden bijdragen aan de mate van psychosociale problematiek van epilepsiepatiënten, waarbij Europese patiënten de gunstigste verwachtingen hebben. Echter ondanks deze culturele invloeden vertonen epilepsiepatiënten over het algemeen psychosociale problemen op vergelijkbare gebieden.

In een extra hoofdstuk, hoofdstuk 8, wordt aandacht besteed aan de vraag of patiënten met een mengbeeld van epileptische en psychogene pseudo-epileptische aanvallen (PPEA's), geïncludeerd dan wel geëxcludeerd moeten worden in studies over psychiatrische co-morbiditeit bij epilepsie. Zestig patiënten met de diagnose 
PPEA werden vergeleken met 25 patiënten met een gemengde diagnose epilepsie én PPEA op zowel as I als as II stoornissen. De resultaten worden tevens vergeleken met voorgaande onderzoeken (beschreven in hoofdstuk 3 en 4). De bevindingen van dit onderzoek suggereren dat het type pathologie van de patiënten met een dubbele diagnose (epilepsie én PPEA) verschilt van die van de PPEA-patiënten. Deze laatste patiëntengroep wordt gekenmerkt door meer somatoforme stoornissen en relatief weinig PS-trekken. De gemengde groep laat een gelijksoortig patroon zien van persoonlijkheidspathologie in vergelijking met de epilepsiepatiënten uit eerdere studies, echter in ernstiger vorm.

Hiermee veronderstellen we dat een belangrijk gebied van psychopathologie wordt veronachtzaamd wanneer patiënten met een mengbeeld van aanvallen worden geëxcludeerd van studies naar psychiatrische co-morbiditeit bij epilepsie, waardoor de mate van psychopathologie wordt onderschat. Geconcludeerd kan worden dat psychopathologie bij de meeste patiënten met een mengbeeld van epileptische en psychogene pseudo-epileptische aanvallen, typerend is voor het patroon dat wordt gevonden bij patiënten met uitsluitend epilepsie. 


\section{Dankwoord}

Het onderzoek beschreven in dit proefschrift werd mede mogelijk gemaakt door subsidie van het Nationaal Epilepsie Fonds/De Macht van het Kleine en de Christelijke Vereniging voor de Verpleging van Lijders aan Epilepsie, in de vorm van de Teding van Berkhout Fellowship. Het onderzoek werd uitgevoerd in een samenwerkingsverband tussen Stichting Epilepsie Instellingen Nederland (SEIN) te Heemstede en de afdelingen Klinische en Gezondheidspsychologie van de Universiteit Leiden en Psychiatrie van de Vrije Universiteit Amsterdam.

In eerste instantie gaat mijn dank uit naar alle patiënten die aan dit onderzoek hebben deelgenomen. Ik ben hen zeer erkentelijk voor hun bijdrage en zonder hen zouden deze artikelen niet tot stand zijn gekomen.

Ook wil ik de neurologen bedanken voor de vele inspanningen die zij hebben geleverd om de patiënten te selecteren en te enthousiasmeren voor het onderzoek.

Tevens ben ik de verpleegkundigen van de observatiekliniek voor volwassenen veel dank verschuldigd voor hun logistieke ondersteuning bij het onderzoek.

De verschillende secretaresses ben ik erkentelijk voor hun hulp bij het opzoeken van de vele statussen.

Het Bureau Ondersteuning Wetenschappelijk Onderzoek wil ik bedanken, met in het bijzonder Koen Gilissen in de beginperiode en Ann Tierlier, Trusjen Punte en Nine de Beer die mij op vele manieren hebben ondersteund.

Mijn speciale dank gaat uit naar Dorothée Kasteleijn-Nolst Trenité, onder wiens hoede ik tien jaar geleden met een werkervaringsplaats ben begonnen bij het toen nog zo geheten Instituut voor Epilepsiebestrijding en die mij door de jaren heen heeft blijven weten te steunen bij het uitvoeren van diverse wetenschappelijke onderzoeken. Ik kan dan ook wel zeggen dat dankzij jou inzet en steun ik dit heb kunnen bereiken. 
Mijn naaste collega's in Heemstede bedank ik voor de goede werksfeer en de gezelligheid. Enkele collega's wil ik in het bijzonder bedanken. Ik dank Nienke Wingelaar en Thelma Dijkhuizen voor hun medewerking bij het verzamelen van de onderzoeksgegevens. Nadine Engelberts, met wie ik in de beginjaren als collega-fellow veel gemeenschappelijks had, ondanks onze grote persoonlijke verschillen. Ook ik heb veel van jou geleerd. Patricia Bakvis, die gedurende de laatste fase van mijn promoveren de afdeling kwam verrijken. Met jou heb ik in korte tijd een vriendschappelijke band opgebouwd. Ik mag wel zeggen dat we gewaagd aan elkaar zijn, ook ten aanzien van onze sportieve inspanningen in de vorm van een potje tafeltennis tijdens de lunchpauzes.

Inge Vreeswijk, onze korte samenwerking heb ik als zeer bijzonder ervaren. In relatief zeer korte tijd heb jij mijn gedachten en gevoelens voor een ontwerp van de omslag op perfecte wijze uitgebeeld. Het is een heel bijzondere en mooie omslag geworden die voor mij een gevoelsmatige weerspiegeling is van het onderwerp van dit proefschrift. Ik vond dit een heel boeiend maar ook heel spannend onderdeel van de laatste fase van mijn promoveren.

Lieve pa en ma, ik ben trots op jullie en ik weet dat jullie ook trots op mij zijn. Dit is dan ook de reden om dit proefschrift aan jullie op te dragen.

Mijn schoonouders, familie en vrienden wil ik bedanken voor de belangstelling die zij toonden voor de vorderingen van mijn proefschrift.

Lieve oma. Helaas heb ik na een kort ziekbed afscheid van je moeten nemen, maar ik weet dat je heel trots op me bent.

Lieve Rogier, aan jou ben ik de meeste dank verschuldigd, voor je steun en liefde, en niet op de laatste plaats je geduld dat je al die tijd met me hebt gehad. Jij hebt het proefschrift door de jaren heen van dichtbij zien groeien. Ik ben dan ook heel blij dat je ook tijdens mijn promotie als paranimf mij terzijde wilt staan. 


\section{Curriculum Vitae}

Miranda Swinkels was born on June 27, 1969 in Geldrop, The Netherlands. In 1987, she completed secondary school (VWO) at the Strabrecht College in Geldrop. Subsequently, she did one year Law study at Maastricht University. In 1988 she started to study Psychology, the first year at Tilburg University, and the last four years at the Vrije Universiteit in Amsterdam. In 1993 she graduated in the discipline of Psychonomics (specialization neuropsychology). The following two years she worked as research assistant at the Vrije Universiteit Amsterdam, on a project on attention disorders in children, and as a behavioral scientist at the Netherlands Institute for Brain Research in Amsterdam on a project on the influence of the prefrontal cortex in spatial learning.

In 1995 she started her career at the Epilepsy Institute of the Netherlands, SEIN in Heemstede. Initially she worked as scientific researcher on several projects, such as stress and epilepsy, and the influence of anti-epileptic medication on driving abilities. In 1998, she was also employed for six months for the Netherlands Institute of Mental Health and Addiction, the Trimbos-instituut in Utrecht, at the department of Mental Health.

From 2000 to 2006 she worked, in cooperation with the division of Clinical and Health Psychology of Leiden University and the department of Psychiatry of the Vrije Universiteit Amsterdam, on the dissertation on psychiatric comorbidity in epilepsy. Besides her research activities, she is also active as psychologist for the clinical departments of SEIN.

After this dissertation, she will continue her work for the clinic and the research activities on the subject of psychiatric disorders in epilepsy. 